Edição de Julho 2010, vol. 95 (1), Supl. 1, págs. 1-51

O nome do autor Altamiro Reis da Costa foi omitido involuntariamente do conjunto de participantes do Grupo 7, coordenado por Celso Amodeo, das VI Diretrizes Brasileiras de Hipertensão, publicadas como suplemento da edição de julho dos Arquivos Brasileiros de Cardiologia [Arq Bras Cardiol 2010; 95(1 supl.1): 1-51]. 


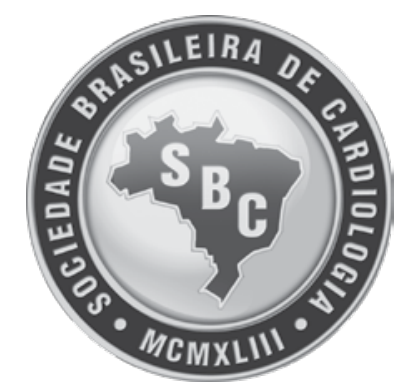

\section{Diretrizes Brasileiras de Hipertensão}

\section{Coordenador de Normatizações e Diretrizes da SBC}

Jadelson Pinheiro de Andrade

Coordenador Geral

Fernando Nobre

\section{Participantes da Reunião Plenária}

Agostinho Tavares (SP), Andréa A. Brandão (RJ), Antonio Felipe Sanjuliani (RJ), Armando da Rocha Nogueira

(RJ), Carlos Alberto Machado (SP), Carlos E. Poli-de-Figueiredo (RS), Carlos Eduardo Negrão (SP), Celso Amodeo (SP), Cibele I. Saad Rodrigues (SP), Dante Marcelo Artigas Giorgi (SP), Décio Mion Júnior (SP), Denizar Vianna (RJ), Fernanda Consolim-Colombo (SP), Fernando Antonio Almeida (SP), Fernando Nobre (SP), Frida Liane Plavnik (SP), Gilson Feitosa (BA), Heno Lopes (SP), Hilton Chaves (PE), José Luiz Santello (SP), José Márcio Ribeiro (MG), Kátia Coelho Ortega (SP), Luiz Aparecido Bortolotto (SP), Marco A. Mota Gomes (AL), Marcus Vinícius B. Malachias (MG), Maria Eliane Campos Magalhães (RJ), Maria Tereza Zanella (SP), Mario Fritsch Neves (RJ), Maurício Wajngarten (SP), Osvaldo Kohlmann Jr. (SP), Osvaldo Passarelli (SP), Paulo César Veiga Jardim (GO), Roberto Jorge da Silva Franco (SP), Rogério A. Mulinari (PR), Rogério Baumgratz de Paula (MG), Sebastião Ferreira Filho (MG), Weimar Kunz Sebba B. de Souza (GO), Wille Oigman (RJ)

Esta diretriz deverá ser citada como: Sociedade Brasileira de Cardiologia / Sociedade Brasileira de Hipertensão / Sociedade Brasileira de Nefrologia. VI Diretrizes Brasileiras de Hipertensão. Arq Bras Cardiol 2010; 95(1 supl.1): 1-51 


\title{
Grupo 1 - Conceituação, Epidemiologia e Prevenção Primária
}

$$
\text { Coordenadora: Andréa A. Brandão (RJ) Secretária: Maria Eliane Campos Magalhães (RJ) }
$$

Adriana Ávila (SP), Agostinho Tavares (SP), Carlos Alberto Machado (SP), érika Maria Gonçalves Campana (RJ), Ines Lessa (BA), José Eduardo Krieger (SP), Luiz Cesar Scala (MT), Mario Fritsch Neves (RJ), Rita de Cássia Gengo e Silva (SP), Rosa Sampaio (DF) - Ministério da Saúde, Sandra Fuchs (RS)

\section{Grupo 2 - Diagnóstico e Classificação}

Coordenadora: Cibele I. Saad Rodrigues (SP) Secretária: Kátia Coelho Ortega (SP)

Angela Maria Geraldo Pierin (SP), Audes Magalhães Feitosa (PE), César Pontes (CE), Dante Marcelo Artigas Giorgi (SP), Décio Mion Júnior (SP), Emilton de Lima (PR), Hilton Chaves (PE), Josiane Lima Gusmão (SP), Leda Lotaif (SP), Lilian Soares da Costa (RJ), Marcio Kalil (MG), Maria Eliete Pinheiro (AL), Natalino Salgado Filho (MA), Tufik José Magalhães Geleilete (SP)

\section{Grupo 3 - Avaliação Clínica e Laboratorial e Estratificação de Risco}

\author{
Coordenadora: Fernanda Consolim-Colombo (SP) \\ Secretário: Luiz Aparecido Bortolotto (SP)
}

Alexandre Alessi (PR), Ayrton Pires Brandão (RJ), Eduardo Cantoni Rosa (SP), Eliuden Galvão de Lima (ES), José Carlos Aidar Ayoub (SP), José Luiz Santello (SP), José

Márcio Ribeiro (MG), Luiz Carlos Bodanese (RS), Paulo Roberto B. Toscano (PA), Raul Dias dos Santos (SP), Roberto Jorge da Silva Franco (SP), Wille Oigman (RJ)

\section{Grupo 4 - Decisão Terapêutica e Metas}

\section{Grupo 5 - Tratamento Não-Medicamentoso e Abordagem Multiprofissional}

\section{Grupo 6 - Tratamento Medicamentos}

Coordenador: Osvaldo Kohlmann Jr. (SP)

Secretário: Miguel Gus (RS)

Artur Beltrame Ribeiro (SP), Denizar Vianna (RJ), Eduardo B. Coelho (SP), Eduardo Barbosa (RS), Fernando Antonio Almeida (SP), Gilson Feitosa (BA), Heitor Moreno (SP),

Jorge llha Guimarães (RS) - SBC, Jorge Pinto Ribeiro (RS), José Antonio Franchini Ramirez (SP), José Fernando Vilela Martins (SP), Robson Augusto S. dos Santos (MG)

\section{Grupo 7 - Hipertensão Arterial Sistêmica Secundária}

Coordenador: Celso Amodeo (SP) Secretário: Armando da Rocha Nogueira (RJ)

Adelaide A. Pereira (SP), Antonio Carlos Cordeiro Jr. (SP), Armando Nogueira (RJ), Eduardo Pimenta (SP - Austrália), Flávio Antonio Borelli (SP), José Gastão Rocha Carvalho (PR), Luciano Ferreira Drager (SP), Pedro Jabur (SP), Rogério A. Mulinari (PR)

\section{Grupo 8 - Hipertensão em Situações Especiais}

\section{Grupo 9 - Hipertensão e Condições Clínicas Associadas}

\author{
Coordenador: Sebastião Ferreira Filho (MG) \\ Secretário: Rogério Baumgratz de Paula (MG)
}

Álvaro Avezum (SP), Gabriel R. de Freitas (SP) - ABN, Emílio Francischetti (RJ), Marcelo Batista (SP), Maria Helena Catelli Carvalho (SP),

Maria Tereza Zanella (SP), Marília de Brito Gomes (RJ) - SBD, Maurício Wajngarten (SP), Nilson Roberto de Melo (SP) - FEBRASGO, Otávio Rizzi Coelho (SP), Ricardo M. da Rocha Meirelles (SP) - SBEM, Roberto Miranda (SP), Rosangela Milagres (MG) 


\section{APRESENTAÇÃO}

As Diretrizes Brasileiras de Hipertensão Arterial agora publicadas resultam da necessidade de uma atualização de sua última versão de 2006, imposta pelo grande número de novas informações geradas e disponibilizadas nesse período de tempo.

Para a produção dessas VI Diretrizes Brasileiras de Hipertensão - DBH VI, foram convocados a participar mais de 100 profissionais afeitos a essa área específica do conhecimento representando as Sociedades Brasileiras de Cardiologia, Hipertensão e Nefrologia, além de outras 10 relacionadas direta ou indiretamente ao assunto.

Estabelecido um cronograma de trabalho, em uma primeira fase, via Web, foram convidados a opinar sobre temas que agora compõem esse documento, divididos em nove grupos com uma coordenação geral e um coordenador por grupo.

Passada essa fase, após dois meses de árduo trabalho, uma reunião plenária, com mais de 40 participantes e com um dia todo de trabalho, reviu todos os textos produzidos e atualizados. Todos os cuidados foram tomados para que refletissem, com o maior rigor, o estado atual do conhecimento em hipertensão arterial.

Os nove grupos de trabalho que foram previamente estabelecidos e tiveram a liderança de expressivos representantes das principais sociedades envolvidas chegaram ao final com um texto abrangente e atual.

Temos conviç̧ão de que o melhor trabalho foi realizado no formato que ora apresentamos.

A sua publicação, nesse momento, nas principais revistas médicas do Brasil diretamente afeitas ao tema Hipertensão Arterial, coroa o trabalho ao tempo em que ele é tornado público.

Esperamos com isso que todo o envolvimento e trabalho dos que participaram para a produção das VI Diretrizes Brasileiras de Hipertensão - DBH VI sejam, nesse instante, coroados pelos benefícios a serem auferidos por seus leitores.

\section{Fernando Nobre}

Coordenador Geral, em nome de todos os participantes das VI Diretrizes Brasileiras de Hipertensão - DBH VI 


\section{Declaração obrigatória de conflito de interesses}

Nos últimos três anos, o autor/colaborador da diretriz:

\begin{tabular}{|c|c|c|c|c|c|c|c|}
\hline Nome do médico & $\begin{array}{l}\text { Participou de } \\
\text { estudos clínicos } \\
\text { elou experimentais } \\
\text { subvencionados } \\
\text { pela indústria } \\
\text { farmacêutica ou } \\
\text { de equipamentos } \\
\text { relacionados à } \\
\text { diretriz em questão }\end{array}$ & $\begin{array}{l}\text { Foi palestrante } \\
\text { em eventos } \\
\text { ou atividades } \\
\text { patrocinadas } \\
\text { pela indústria } \\
\text { relacionados } \\
\text { à diretriz em } \\
\text { questão }\end{array}$ & $\begin{array}{l}\text { Foi (é) membro } \\
\text { do conselho } \\
\text { consultivo } \\
\text { ou diretivo } \\
\text { da indústria } \\
\text { farmacêutica ou } \\
\text { de equipamentos }\end{array}$ & $\begin{array}{l}\text { Participou } \\
\text { de comitês } \\
\text { normativos } \\
\text { de estudos } \\
\text { científicos } \\
\text { patrocinados } \\
\text { pela indústria }\end{array}$ & $\begin{array}{l}\text { Recebeu } \\
\text { auxílio } \\
\text { pessoal ou } \\
\text { institucional } \\
\text { da indústria }\end{array}$ & $\begin{array}{c}\text { Elaborou } \\
\text { textos } \\
\text { científicos em } \\
\text { periódicos } \\
\text { patrocinados } \\
\text { pela indústria }\end{array}$ & $\begin{array}{l}\text { Tem } \\
\text { ações da } \\
\text { indústria }\end{array}$ \\
\hline Adelaide A. Pereira (SP) & não & não & não & não & não & não & não \\
\hline Agostinho Tavares (SP) & não & não & não & não & não & não & não \\
\hline Alexandre Alessi (PR) & não & não & não & não & sim & $\operatorname{sim}$ & não \\
\hline Altamiro Reis da Costa (RS) & não & não & não & não & não & não & não \\
\hline Álvaro Avezum (SP) & sim & não & não & $\operatorname{sim}$ & não & $\operatorname{sim}$ & não \\
\hline Ana Maria Lotemberg (SP) & não & não & não & não & não & não & não \\
\hline Andréa A. Brandão (RJ) & $\operatorname{sim}$ & $\operatorname{sim}$ & sim & não & não & $\operatorname{sim}$ & não \\
\hline Angela Maria Geraldo Pierin (SP) & não & não & não & não & não & não & não \\
\hline Antonio Felipe Sanjuliani (RJ) & não & não & não & não & não & não & não \\
\hline Antônio Felipe Simão (SC) & $\operatorname{sim}$ & $\operatorname{sim}$ & $\operatorname{sim}$ & $\operatorname{sim}$ & $\operatorname{sim}$ & $\operatorname{sim}$ & $\operatorname{sim}$ \\
\hline Antonio Marmo Lucon (SP) & não & não & não & não & não & não & não \\
\hline Armando da Rocha Nogueira (RJ) & não & não & não & não & $\operatorname{sim}$ & não & não \\
\hline Armênio Costa Guimarães (BA) & não & não & não & não & não & não & não \\
\hline Artur Beltrame Ribeiro (SP) & não & $\operatorname{sim}$ & não & $\operatorname{sim}$ & $\operatorname{sim}$ & não & não \\
\hline Audes Magalhães Feitosa (PE) & $\operatorname{sim}$ & $\operatorname{sim}$ & não & não & não & não & não \\
\hline Ayrton Pires Brandão (RJ) & não & não & não & não & não & não & não \\
\hline Carlos Alberto Machado (SP) & não & não & não & não & não & $\operatorname{sim}$ & não \\
\hline Carlos E. Poli-de-Figueiredo (RS) & não & não & não & $\operatorname{sim}$ & sim & não & não \\
\hline Carlos Eduardo Negrão (SP) & $\operatorname{sim}$ & não & não & não & não & não & não \\
\hline Carlos Scherr (RJ) & não & não & não & não & não & $\operatorname{sim}$ & não \\
\hline Celso Amodeo (SP) & sim & $\operatorname{sim}$ & $\operatorname{sim}$ & não & $\operatorname{sim}$ & $\operatorname{sim}$ & não \\
\hline César Pontes (CE) & não & não & não & não & não & não & não \\
\hline Cibele I. Saad Rodrigues (SP) & não & não & não & não & $\operatorname{sim}$ & não & não \\
\hline Claudia Lucia de Moraes Forjaz (SP) & não & não & não & não & não & não & não \\
\hline Dante Marcelo Artigas Giorgi (SP) & não & não & não & não & $\operatorname{sim}$ & $\operatorname{sim}$ & não \\
\hline Décio Mion Júnior (SP) & $\operatorname{sim}$ & $\operatorname{sim}$ & $\operatorname{sim}$ & $\operatorname{sim}$ & $\operatorname{sim}$ & $\operatorname{sim}$ & não \\
\hline Denizar Vianna (RJ) & não & não & não & não & $\operatorname{sim}$ & $\operatorname{sim}$ & não \\
\hline Edgard Pessoa de Mello Jr. (PE) & não & $\operatorname{sim}$ & sim & não & não & não & não \\
\hline Eduardo B. Coelho (SP) & $\operatorname{sim}$ & não & não & não & não & não & não \\
\hline Eduardo Barbosa (RS) & não & não & não & não & não & não & não \\
\hline Eduardo Cantoni Rosa (SP) & não & não & não & não & não & não & não \\
\hline Eduardo Moacyr Krieger (SP) & não & não & não & não & não & não & não \\
\hline Eduardo Pimenta (SP-Austrália) & não & não & não & não & $\operatorname{sim}$ & $\operatorname{sim}$ & não \\
\hline Eliuden Galvão de Lima (ES) & não & não & não & não & não & não & não \\
\hline Elizabete Viana de Freitas (RJ) & não & não & não & não & não & não & não \\
\hline Emílio Francischetti (RJ) & sim & $\operatorname{sim}$ & sim & não & não & não & não \\
\hline Emilton de Lima (PR) & não & $\operatorname{sim}$ & não & não & $\operatorname{sim}$ & não & não \\
\hline Érika Maria Gonçalves Campana (RJ) & $\operatorname{sim}$ & $\operatorname{sim}$ & não & não & não & $\operatorname{sim}$ & não \\
\hline Fernanda Consolim-Colombo (SP) & não & $\operatorname{sim}$ & não & $\operatorname{sim}$ & não & $\operatorname{sim}$ & não \\
\hline Fernando Antonio Almeida (SP) & não & sim & não & não & não & não & não \\
\hline Fernando Nobre (SP) & $\operatorname{sim}$ & $\operatorname{sim}$ & $\operatorname{sim}$ & não & não & $\operatorname{sim}$ & não \\
\hline Flávio Antonio Borelli (SP) & não & não & não & não & não & não & não \\
\hline Frida Liane Plavnik (SP) & não & não & não & não & não & $\operatorname{sim}$ & não \\
\hline Gabriel R. de Freitas (SP) - ABN & sim & não & não & não & $\operatorname{sim}$ & $\operatorname{sim}$ & não \\
\hline Gilson Feitosa (BA) & $\operatorname{sim}$ & $\operatorname{sim}$ & não & não & não & $\operatorname{sim}$ & não \\
\hline Giovânio Vieira da Silva (SP) & não & não & não & não & não & não & não \\
\hline Heitor Moreno (SP) & não & não & sim & não & não & $\operatorname{sim}$ & não \\
\hline Heno Lopes (SP) & não & não & não & não & sim & $\operatorname{sim}$ & não \\
\hline Hilton Chaves (PE) & $\operatorname{sim}$ & $\operatorname{sim}$ & não & não & não & $\operatorname{sim}$ & não \\
\hline Ivan Luiz Cordovil de Oliveira (RJ) & não & não & não & não & não & não & não \\
\hline
\end{tabular}




\begin{tabular}{|c|c|c|c|c|c|c|c|}
\hline João Carlos Rocha (SP) & $\operatorname{sim}$ & $\operatorname{sim}$ & não & não & não & não & não \\
\hline Jorge llha Guimarães (RS) - SBC & não & $\operatorname{sim}$ & não & não & não & não & não \\
\hline Jorge Pinto Ribeiro (RS) & $\operatorname{sim}$ & $\operatorname{sim}$ & $\operatorname{sim}$ & não & $\operatorname{sim}$ & $\operatorname{sim}$ & não \\
\hline José Carlos Aidar Ayoub (SP) & não & não & não & não & não & $\operatorname{sim}$ & não \\
\hline José Ernesto dos Santos (SP) & não & não & não & não & não & não & não \\
\hline José Fernando Vilela Martins (SP) & $\operatorname{sim}$ & $\operatorname{sim}$ & não & não & $\operatorname{sim}$ & não & não \\
\hline José Gastão Rocha Carvalho (PR) & não & não & não & não & não & não & não \\
\hline José Márcio Ribeiro (MG) & não & $\operatorname{sim}$ & não & não & $\operatorname{sim}$ & $\operatorname{sim}$ & não \\
\hline José Xavier de Mello Filho (MA) & não & $\operatorname{sim}$ & não & não & não & não & não \\
\hline Josiane Lima Gusmão (SP) & não & não & não & não & não & sim & não \\
\hline Kátia Coelho Ortega (SP) & $\operatorname{sim}$ & não & não & não & não & $\operatorname{sim}$ & não \\
\hline Leda Lotaif (SP) & não & $\operatorname{sim}$ & não & não & não & não & não \\
\hline Lilian Soares da Costa (RJ) & não & não & não & não & não & não & não \\
\hline Lucélia C. Magalhães (BA) & não & não & não & não & não & não & não \\
\hline Luciana Ferreira Ângelo & não & não & não & não & não & não & não \\
\hline Luiz Aparecido Bortolotto (SP) & $\operatorname{sim}$ & não & não & não & não & $\operatorname{sim}$ & não \\
\hline Luiz Carlos Bodanese (RS) & não & não & não & não & não & não & não \\
\hline Luiz Cesar Scala (MT) & não & não & não & não & $\operatorname{sim}$ & $\operatorname{sim}$ & não \\
\hline Marcelo Batista (SP) & não & não & não & não & não & não & não \\
\hline Marcelo Lima Gusmão (SP) & não & não & não & não & $\operatorname{sim}$ & $\operatorname{sim}$ & não \\
\hline Marcio Kalil (MG) & $\operatorname{sim}$ & $\operatorname{sim}$ & não & não & $\operatorname{sim}$ & não & não \\
\hline Marco A. Mota Gomes (AL) & $\operatorname{sim}$ & sim & $\operatorname{sim}$ & $\operatorname{sim}$ & $\operatorname{sim}$ & sim & não \\
\hline Marcus Vinícius Bolívar Malachias (MG) & não & $\operatorname{sim}$ & não & não & não & $\operatorname{sim}$ & não \\
\hline Maria Eliane Campos Magalhães (RJ) & $\operatorname{sim}$ & $\operatorname{sim}$ & não & $\operatorname{sim}$ & $\operatorname{sim}$ & $\operatorname{sim}$ & não \\
\hline Maria Eliete Pinheiro (AL) & não & sim & não & não & não & não & não \\
\hline Maria Fátima de Azevedo (RN) & não & não & não & não & $\operatorname{sim}$ & não & não \\
\hline Maria Helena Catelli Carvalho (SP) & não & não & não & não & não & não & não \\
\hline Maria Tereza Zanella (SP) & $\operatorname{sim}$ & $\operatorname{sim}$ & não & não & não & sim & não \\
\hline Marilda Lipp (SP) & não & não & não & não & não & não & não \\
\hline Marilia de Brito Gomes (RJ) - SBD & não & não & não & não & $\operatorname{sim}$ & não & não \\
\hline Mario Fritsch Neves (RJ) & não & não & não & não & não & não & não \\
\hline Maurício Wajngarten (SP) & não & sim & não & não & não & não & não \\
\hline Nárcia Elisa B. Kohlmann (SP) & não & não & não & não & não & não & não \\
\hline Nelson Sass (SP) & não & não & não & não & não & não & não \\
\hline Osvaldo Kohlmann Jr. (SP) & $\operatorname{sim}$ & $\operatorname{sim}$ & $\operatorname{sim}$ & $\operatorname{sim}$ & não & $\operatorname{sim}$ & não \\
\hline Oswaldo Passarelli (SP) & não & $\operatorname{sim}$ & não & não & $\operatorname{sim}$ & $\operatorname{sim}$ & não \\
\hline Otávio Rizzi Coelho (SP) & $\operatorname{sim}$ & sim & $\operatorname{sim}$ & não & $\operatorname{sim}$ & sim & não \\
\hline Paulo César Veiga Jardim (GO) & sim & $\operatorname{sim}$ & $\operatorname{sim}$ & não & não & não & não \\
\hline Paulo Roberto B. Toscano (PA) & não & não & não & não & não & não & não \\
\hline Pedro Jabur (SP) & não & não & não & não & não & não & não \\
\hline Rafael Leite Luna (RJ) & não & não & não & não & não & não & não \\
\hline Rita de Cássia Gengo e Silva (SP) & não & não & não & não & não & não & não \\
\hline Roberto Jorge da Silva Franco (SP) & não & não & não & não & não & não & não \\
\hline Roberto Miranda (SP) & $\operatorname{sim}$ & $\operatorname{sim}$ & não & $\operatorname{sim}$ & $\operatorname{sim}$ & $\operatorname{sim}$ & $\operatorname{sim}$ \\
\hline Robson Augusto S. dos Santos (MG) & não & não & não & não & não & não & não \\
\hline Rogério A. Mulinari (PR) & não & não & não & não & não & não & não \\
\hline Rogério Baumgratz de Paula (MG) & não & não & não & não & não & não & não \\
\hline Romero Bezerra (DF) & não & não & não & não & não & não & não \\
\hline $\begin{array}{l}\text { Rosa Sampaio (DF) - Ministério da } \\
\text { Saúde }\end{array}$ & não & não & não & não & não & não & não \\
\hline Rui Póvoa (SP) & não & não & não & não & não & não & não \\
\hline Sandra Fuchs (RS) & não & não & não & não & não & não & não \\
\hline Sarkis Joud Bayeh - SOBRAMFA & não & não & não & não & não & não & não \\
\hline Sebastião Ferreira Filho (MG) & não & não & não & não & $\operatorname{sim}$ & não & não \\
\hline Sérgio Baiochi (GO) & não & não & não & não & $\operatorname{sim}$ & não & não \\
\hline Thales Carvalho (SC) & não & não & não & não & não & não & não \\
\hline Tufik José Magalhães Geleilete (SP) & não & não & não & não & não & não & não \\
\hline Vera Koch (SP) & não & não & não & não & não & não & não \\
\hline Virginia Genelhu Fagundes (RJ) & $\operatorname{sim}$ & não & não & não & não & não & não \\
\hline $\begin{array}{l}\text { Weimar Kunz Sebba B. de Souza } \\
\text { (GO) }\end{array}$ & $\operatorname{sim}$ & $\operatorname{sim}$ & não & não & $\operatorname{sim}$ & $\operatorname{sim}$ & não \\
\hline Wille Oigman (RJ) & $\operatorname{sim}$ & $\operatorname{sim}$ & $\operatorname{sim}$ & não & não & $\operatorname{sim}$ & não \\
\hline
\end{tabular}




\section{Diretrizes}

\section{Capítulo 1 - Conceituação, epidemiologia e prevenção primária}

\section{1 - Conceituação}

A hipertensão arterial sistêmica (HAS) é uma condição clínica multifatorial caracterizada por níveis elevados e sustentados de pressão arterial (PA). Associa-se frequentemente a alterações funcionais e/ou estruturais dos órgãos-alvo (coração, encéfalo, rins e vasos sanguíneos) e a alterações metabólicas, com consequente aumento do risco de eventos cardiovasculares fatais e não-fatais ${ }^{1-4}$.

\section{2 - Impacto médico e social da hipertensão arterial sistêmica}

\subsection{1 - Hipertensão arterial sistêmica e as doenças} cardiovasculares no Brasil e no mundo

A HAS tem alta prevalência e baixas taxas de controle, é considerada um dos principais fatores de risco (FR) modificáveis e um dos mais importantes problemas de saúde pública. A mortalidade por doença cardiovascular (DCV) aumenta progressivamente com a elevação da PA a partir de 115/75 $\mathrm{mmHg}$ de forma linear, contínua e independente ${ }^{1}$. Em 2001, cerca de 7,6 milhões de mortes no mundo foram atribuídas à elevação da PA (54\% por acidente vascular encefálico AVE e $47 \%$ por doença isquêmica do coração - DIC ${ }^{4}$, sendo a maioria em países de baixo e médio desenvolvimento econômico e mais da metade em indivíduos entre 45 e 69 anos. Em nosso país, as DCV têm sido a principal causa de morte. Em 2007 ocorreram 308.466 óbitos por doenças do aparelho circulatório² . (figura 1). Entre 1990 a 2006, observouse uma tendência lenta e constante de redução das taxas de mortalidade cardiovascular (figura 2).

As DCV são ainda responsáveis por alta frequência de internações, ocasionando custos médicos e socioeconômicos elevados $^{1,3}$. Como exemplo, em 2007 foram registradas
1.157.509 internações por DCV no SUS. Em relação aos custos, em novembro de 2009, houve 91.970 internações por DCV, resultando em um custo de $\mathrm{R} \$ 165.461 .644,33$ (DATASUS) 5 . A doença renal terminal, outra condição frequente na HAS, ocasionou a inclusão de 94.282 indivíduos em programa de diálise no SUS, registrando-se 9.486 óbitos em $2007^{5}$.

\subsection{2 - Prevalência da hipertensão arterial sistêmica}

Inquéritos populacionais em cidades brasileiras nos últimos 20 anos apontaram uma prevalência de HAS acima de $30 \%$ 6,7. Considerando-se valores de PA $\geq 140 / 90 \mathrm{mmHg}$, 22 estudos encontraram prevalências entre 22,3\% e 43,9\%, (média de $32,5 \%)$, com mais de $50 \%$ entre 60 e 69 anos e $75 \%$ acima de 70 anos $^{6,7}$.

Entre os gêneros, a prevalência foi de $35,8 \%$ nos homens e de $30 \%$ em mulheres, semelhante à de outros países ${ }^{8}$. Revisão sistemática quantitativa de 2003 a 2008, de 44 estudos em 35 países, revelou uma prevalência global de $37,8 \%$ em homens e $32,1 \%$ em mulheres ${ }^{8}$.

\subsection{3 - Conhecimento, tratamento e controle}

Estudos clínicos demonstraram que a detecção, o tratamento e o controle da HAS são fundamentais para a redução dos eventos cardiovasculares ${ }^{1}$. No Brasil, 14 estudos populacionais realizados nos últimos quinze anos com 14.783 indivíduos (PA $<140 / 90 \mathrm{mmHg}$ ) revelaram baixos níveis de controle da PA $(19,6 \%)^{7,9}$. Estima-se que essas taxas devem estar superestimadas, devido, principalmente, à heterogeneidade dos trabalhos realizados. A comparação das frequências, respectivamente, de conhecimento, tratamento e controle nos estudos brasileiros ${ }^{7,9}$ com as obtidas em 44 estudos de 35 países $^{8}$, revelou taxas semelhantes em relação ao conhecimento (52,3\% vs. 59,1\%), mas significativamente superiores no Brasil em relação ao tratamento e controle (34,9\% e 13,7\% vs. 67,3\% e 26,1\%) em especial em municípios do interior com ampla cobertura do Programa de Saúde da

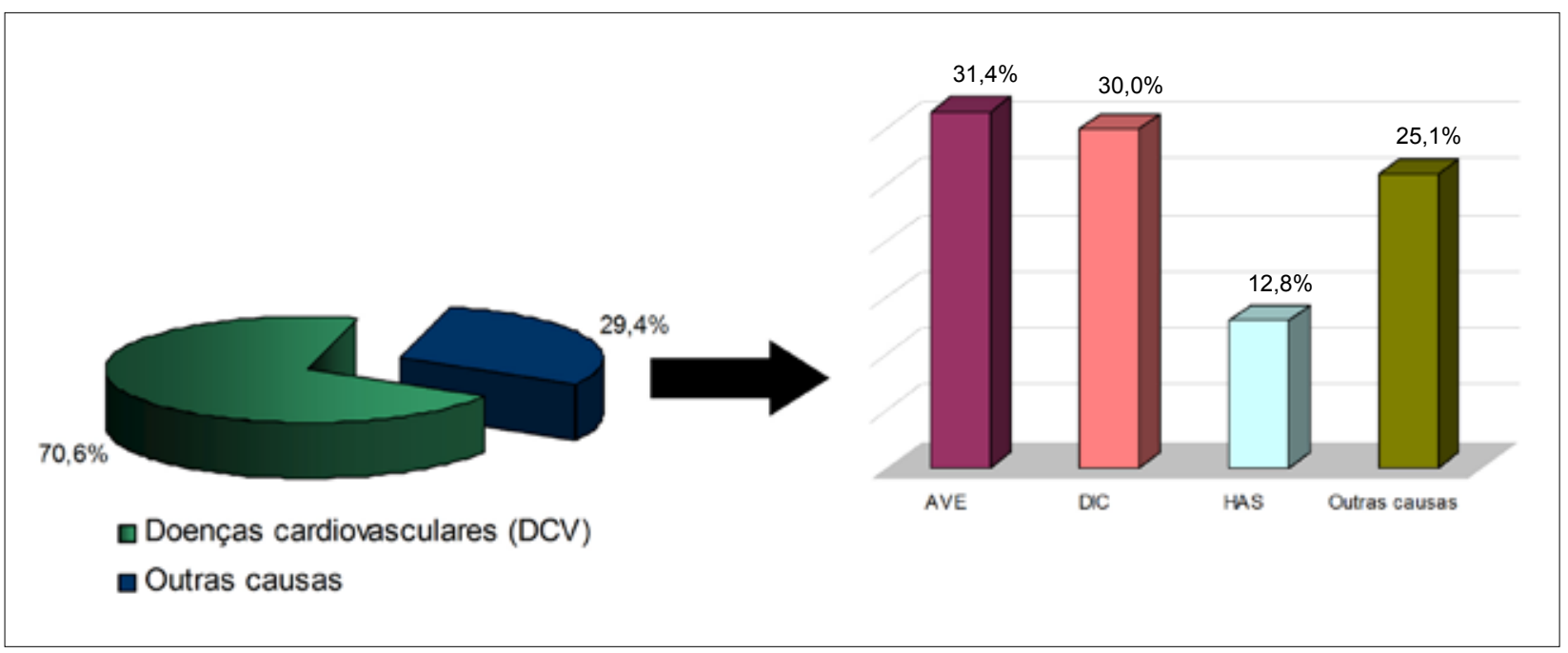

Fig. 1 - Taxas de mortalidade por DCV e suas diferentes causas no Brasil, em 2007. AVE - Acidente Vascular Encefálico; DIC - Doença Isquêmica do Coração; HAS Hipertensão Arterial Sistêmica. 


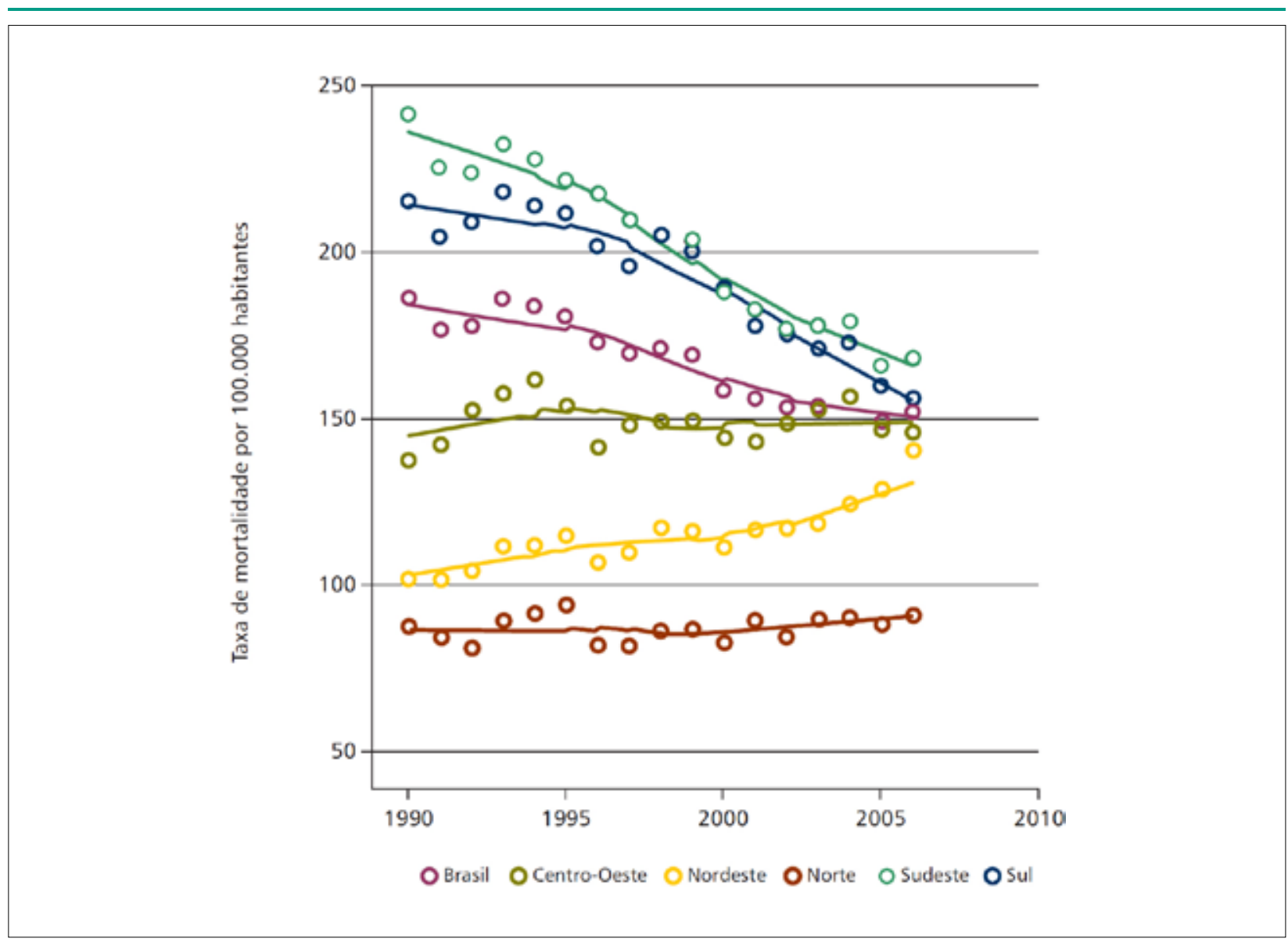

Fig. 2 - Taxas ajustadas de mortalidade por doenças do aparelho circulatório nas regiões brasileiras, de 1990 a 2006. Fonte: Dasis/SVS/Ministério da Saúde

Família $(\mathrm{PSF})^{7}$, mostrando que os esforços concentrados dos profissionais de saúde, das sociedade científicas e das agências governamentais são fundamentais para se atingir metas aceitáveis de tratamento e controle da HAS.

\section{3 - Fatores de risco para HAS}

\subsection{1 - Idade}

Existe relação direta e linear da PA com a idade ${ }^{1}$, sendo a prevalência de HAS superior a $60 \%$ na faixa etária acima de 65 anos $^{6}$. Entre metalúrgicos do RJ e de SP a prevalência de HAS foi de $24,7 \%$ e a idade acima de 40 anos foi a variável que determinou maior risco para esta condição ${ }^{10}$.

\subsection{2 - Gênero e etnia}

A prevalência global de HAS entre homens e mulheres é semelhante, embora seja mais elevada nos homens até os 50 anos, invertendo-se a partir da $5^{a}$ década ${ }^{6,10,11}$. Em relação à cor, a HAS é duas vezes mais prevalente em indivíduos de cor não-branca. Estudos brasileiros com abordagem simultânea de gênero e cor demonstraram predomínio de mulheres negras com excesso de HAS de até $130 \%$ em relação às brancas ${ }^{11}$. Não se conhece, com exatidão, o impacto da miscigenação sobre a HAS no Brasil.

\subsection{3 - Excesso de peso e obesidade}

O excesso de peso se associa com maior prevalência de HAS desde idades jovens ${ }^{12}$. Na vida adulta, mesmo entre indivíduos fisicamente ativos, incremento de $2,4 \mathrm{~kg} / \mathrm{m}^{2}$ no índice de massa corporal (IMC) acarreta maior risco de desenvolver hipertensão. A obesidade central também se associa com $\mathrm{PA}^{13}$.

\subsection{4 - Ingestão de sal}

Ingestão excessiva de sódio tem sido correlacionada com elevação da $\mathrm{PA}^{1}$. A população brasileira apresenta um padrão alimentar rico em sal, açúcar e gorduras. Em contrapartida, em populações com dieta pobre em sal, como os índios brasileiros Yanomami, não foram encontrados casos de HAS' Por outro lado, o efeito hipotensor da restrição de sódio tem sido demonstrado ${ }^{14-18}$.

\subsection{5 - Ingestão de álcool}

A ingestão de álcool por períodos prolongados de tempo pode aumentar a $\mathrm{PA}^{1,10}$ e a mortalidade cardiovascular em geral. Em populações brasileiras o consumo excessivo de etanol se associa com a ocorrência de HAS de forma independente das características demográficas ${ }^{1,19,20}$. 


\section{Diretrizes}

\subsection{6 - Sedentarismo}

Atividade física reduz a incidência de HAS, mesmo em indivíduos pré-hipertensos, bem como a mortalidade ${ }^{1,21}$ e o risco de DCV.

\subsection{7 - Fatores socioeconômicos}

A influência do nível socioeconômico na ocorrência da HAS é complexa e difícil de ser estabelecida ${ }^{22}$. No Brasil a HAS foi mais prevalente entre indivíduos com menor escolaridade ${ }^{6}$.

\subsection{8 - Genética}

A contribuição de fatores genéticos para a gênese da HAS está bem estabelecida na população ${ }^{23}$. Porém, não existem, até o momento, variantes genéticas que, possam ser utilizadas para predizer o risco individual de se desenvolver $\mathrm{HAS}^{23}$.

\subsection{9 - Outros fatores de risco cardiovascular}

Os fatores de risco cardiovascular frequentemente se apresentam de forma agregada, a predisposição genética e os fatores ambientais tendem a contribuir para essa combinação em famílias com estilo de vida pouco saudável ${ }^{1,6}$.

\section{4 - Prevenção primária}

\subsection{1 - Medidas não-medicamentosas}

Mudanças no estilo de vida são entusiasticamente recomendadas na prevenção primária da HAS, notadamente nos indivíduos com PA limítrofe. Mudanças de estilo de vida reduzem a PA bem como a mortalidade cardiovascular ${ }^{24-26}$.
Hábitos saudáveis de vida devem ser adotados desde a infância e adolescência, respeitando-se as características regionais, culturais, sociais e econômicas dos indivíduos. As principais recomendações não-medicamentosas para prevenção primária da HAS são: alimentação saudável, consumo controlado de sódio e álcool, ingestão de potássio,combate ao sedentarismo e ao tabagismo.

\subsection{2 - Medidas medicamentosas}

Estudos foram realizados com o objetivo de avaliar a eficácia e a segurança de medicamentos na prevenção da HAS. Nos estudos TROPHY ${ }^{27}$ e PHARAO ${ }^{28}$ a estratégia medicamentosa foi bem tolerada e preveniu o desenvolvimento de HAS em populações jovens de alto risco. Para o manejo de indivíduos com comportamento limítrofe da PA recomenda-se considerar o tratamento medicamentoso apenas em condições de risco cardiovascular global alto ou muito alto. Até o presente, nenhum estudo já realizado tem poder suficiente para indicar um tratamento medicamentoso para indivíduos com PA limítrofe sem evidências de doença cardiovascular ${ }^{1,29}$.

\subsection{3 - Estratégias para implementação de medidas de prevenção}

A implementação de medidas de prevenção na HAS representa um grande desafio para os profissionais e gestores da área de saúde. No Brasil, cerca de $75 \%$ da assistência à saúde da população é feita pela rede pública do Sistema Único de Saúde - SUS, enquanto o Sistema de Saúde Complementar assiste cerca de 46,5 milhões $^{30}$. A prevenção primária e a detecção precoce são as formas mais efetivas de evitar as doenças e devem ser metas prioritárias dos profissionais de saúde.

\section{Referências}

1. Sociedade Brasileira de Cardiologia. V Diretrizes Brasileiras de Hipertensão. Arq Bras Cardiol 2006 Fev: 1-48.

2. Malta DC, Moura L, Souza FM, Rocha FM, Fernandes FM. Doenças crônicas não-transmissíveis: mortalidade e fatores de risco no Brasil, 1990 a 2006 in Saúde Brasil 2008. Ministério da Saúde, Brasília. 2009. Pág 337-362.

3. Documento do Banco Mundial. Enfrentando o desafio das doenças nãotransmissíveis no Brasil. Relatório No 32576-BR. 15 de novembro de 2005.

4. Williams B. The year in hypertension. JACC 2010; 55(1): 66-73.

5. Consulta realizada nos dias 13, 14, 22, 23 e 24 de Janeiro de 2009 http:// w3.datasus.gov.br/datasus/index.php?area $=0203$.

6. Cesarino CB, Cipullo JP, Martin JFV, Ciorlia LA, Godoy MRP, Cordeiro JA, Rodrigues IC. Prevalência e fatores sociodemográficos em hipertensos de São José do Rio Preto. Arq Bras Card 2008; 91(1): 31-35.

7. Rosário TM, Scala LCNS, França GVA, Pereira MRG, Jardim PCBV. Prevalência, controle e tratamento da hipertensão arterial sistêmica em Nobres, MT. Arq Bras Card 2009; 93(6): 672-678.

8. Pereira M, Lunet N, Azevedo A, Barros H. Differences in prevalence, awareness, treatment and control of hypertension between developing and developed countries. J Hypertension 2009; 27(5): 963-975.

9. Jardim PCV, Peixoto MR, Monego E, Moreira H, Vitorino PVO, Souza WSBS Scala LCN. Hipertensão arterial e alguns fatores de risco em uma capita brasileira. Arq Bras Card 2007; 88(4): 452-457.

10. Martinez MC, Latorre MRDO. Fatores de Risco para Hipertensão Arterial e Diabete Melito em Trabalhadores de Empresa Metalúrgica e Siderúrgica. Arq Bras Cardiol 2006; 87: 471-479.

11. Lessa I. Epidemiologia da insuficiência cardíaca e da hipertensão arterial sistêmica no Brasil. Rev Bras de Hipertens 2001; 8: 383-392.

12. Brandão AA, Pozzan R, Freitas EV, Pozzan R, Magalhães MEC, Brandão AP. Blood pressure and overweight in adolescence and their association with insulin resistance and metabolic syndrome. J Hypertens 2004; 22 (Suppl 1): 111S.

13. World Health Organization. Obesity. Preventing and managing the global epidemic. WHO/NUT/NCD 98.1. Genebra, jun 1997.

14. Appel LJ, Moore TJ, Obarzanek E, Vollmer WM, Svetkey LP, Sacks FM, et al. A clinical trial of the effects of dietary patterns on blood pressure. Dash Collaborative Research Group. N Eng J Med 1997; 336(16): 117-124.

15. Sachs FM, Svetkey LP, Vollmer WM, Appel LJ, Bray GA, Harsha D, et al. Effects on blood pressure of reduced dietary sodium and the Dietary Approaches to Stop Hypertension (DASH) diet. N Engl J Med 2001; 344 (1): 3-10.

16. Intersalt Cooperative Research Group. INTERSALT: An international study of electrolyte excretion and blood pressure. Results of 24 hour urinary sodium and potassion excretion. BMJ 1988; 297: 319. 
17. Strazzullo P, D'Elia L, Ngianga-Bakwin K, Cappuccio FP. Salt intake, stroke, and cardiovascular disease: meta-analysis of prospective studies. BMJ 2009; 339: b4567doi:10.1136/bmj.b4567.

18. FJ \& MacGregor GA. A comprehensive review on salt and health and current experience of worldwide salt reduction programmes. J Human Hypertens 2009; 23: 363-384.

19. Martinez MC, Latorre MRDO. Fatores de Risco para Hipertensão Arterial e Diabete Melito em Trabalhadores de Empresa Metalúrgica e Siderúrgica. Arq Bras Cardiol 2006; 87: 471-479.

20. Scherr C, Ribeiro JP. Gênero, Idade, Nível Social e Fatores de Risco Cardiovascular: Considerações Sobre a Realidade Brasileira. Arq Bras Cardiol 2009; 93(3): e54-e56.

21. Pescatello LS, Franklin BA, Fagard R, Farquhar WB, Kelley GA, Ray CA. American College of Sports Medicine position stand. Exercise and hypertension. Med Sci Sports Exerc 2004; 36: 533-553.

22. Conen D, Glynn RJ, Ridker PM, Buring JE, Albert MA. Socioeconomic status, blood pressure progression, and incident hypertension in a prospective cohort of female health professionals. Eur Heart J 2009; 30: 1378-1384.

23. de Oliveira CM, Pereira AC, de Andrade M, Soler JM, Krieger JE. Heritability of cardiovascular risk factors in a Brazilian population: Baependi Heart Study BMC Medical Genetics 2008, 9: 32.

24. Lewington S, Clarke R, Qizilbash N, Peto R, Collins R, for the Prospective Studies Collaboration. Age-specific relevance of usual blood pressure to vascular mortality: a meta-analysis of individual data for one million adults in 61 prospective studies. Lancet 2002; 360: 1903-1913.

25. Viegas CAA, Araújo AJ, Menezes AMB, Dórea AJP, Torres BS. Diretrizes para cessação do tabagismo. J Bras Pneumol 2004; 30 (Supl2): S1-S76.

26. Rainforth MV, Schneider RH, Nidich SI, Gaylord-King C, Salerno JW Anderson JW. Stress reduction programs in patients with elevated blood pressure: a systematic review and meta-analysis. Curr Hypertens Rep 2007; 9: 520-528.

27. Williams SA, Michelson EL, Cain VA, Yang M, Nesbitt SD, Egan BM et al TROPHY Study Investigators. An evaluation of the effects of an angiotensin receptor blocker on health-related quality of life in patients with high-normal blood pressure (prehypertension) in the Trial of Preventing Hypertension (TROPHY). J Clin Hypertens 2008 Jun; 10(6): 436-442.

28. Lüders S, Schrader J, Berger J e col. PHARAO Study Group. The PHARAO study: prevention of hypertension with the angiotensin-converting enzyme inhibitor ramipril in patients with high-normal blood pressure: a prospective, randomized, controlled prevention trial of the German Hypertension League. J Hypertens 2008 Jul; 26(7): 1487-1496.

29. Neves MF, Oigman W. Pré-hipertensão: uma visão contra o tratamento medicamentoso. Rev Bras Hipertens 2009; 16(2): 112-115.

30. Caderno de Informação da Saúde Suplementar. Beneficiários, operadoras e planos. Ministério da Saúde. Agência Nacional de Saúde Suplementar, Dez 2009.

\section{Capítulo 2 - Diagnóstico e classificação}

\section{1 - Medida da pressão arterial}

A HAS é diagnosticada pela detecção de níveis elevados e sustentados de PA pela medida casual. A medida da PA deve ser realizada em toda avaliação por médicos de qualquer especialidade e demais profissionais da saúde.

\subsection{1 - Medida da pressão arterial}

Os procedimentos de medida da pressão são simples e de fácil realização, contudo, nem sempre são realizados de forma adequada ${ }^{1,2}$. Condutas que podem evitar erros são, por exemplo, o preparo apropriado do paciente, uso de técnica padronizada e equipamento calibrado ${ }^{3-5}$

Os procedimentos que devem ser seguidos para a medida correta da pressão arterial são descritos na tabela 1 .

\subsection{2 - Equipamentos para medida da pressão arterial}

A medida da PA pode ser realizada pelo método indireto com técnica auscultatória com uso de esfigmomanômetro de coluna de mercúrio ou aneroide devidamente calibrados, ou com técnica oscilométrica pelos aparelhos semiautomáticos digitais de braço validados estando também calibrados. Os aparelhos aneroides não são os de primeira escolha, pois descalibram-se mais facilmente ${ }^{6,7}$. Atualmente, entretanto, está havendo uma forte tendência para a substituição dos aparelhos de coluna de mercúrio por equipamentos semiautomáticos ou aneroides em razão do risco de toxicidade

e contaminação ambiental pelo mercúrio, de acordo com a norma regulamentadora NR 15 (125.001-9 / I4) do Ministério do Trabalho, encontrada no site http://www.mte.gov. br/legislacao/normas_regulamentadoras/nr_15_anexo13.pdf. A escolha do aparelho semiautomático deve ser criteriosa, sendo recomendados somente aqueles validados ${ }^{8}$. Os aparelhos de medida no punho e no dedo não são recomendados para a prática clínica embora já existam aparelhos de punho validados ${ }^{9}$

Para a escolha do aparelho semiautomático recomendase consultar os sites http://www.dableducational.org/ sphygmomanometers/devices 2 sbpm.html e http://www. bhsoc.org/bp_monitors/automatic.stm. Todos os aparelhos devem ser validados por protocolos estabelecidos na literatura pela AAMI (Association for the Advancement of Medical Instrumentation) e BHS (British Hypertension Society) e devem, também, ser verificados uma vez por ano, de preferência nas dependências dos órgãos da Rede Brasileira de Metrologia Legal e Qualidade - RBMLQ (IPEMs - Institutos de Pesos e Medidas Estaduais) ou em local designado pelo Inmetro (http:// www.inmetro.gov.br/consumidor/produtos/esfigmo2.asp) e, se necessário, calibrados.

\subsection{3 - Medida da PA em crianças, idosos e gestantes}

\subsubsection{1 - Crianças}

A medida da PA em crianças é recomendada em toda avaliação clínica ${ }^{12}$ após os três anos de idade, pelo menos anualmente, como parte do seu atendimento pediátrico primário, devendo respeitar as padronizações estabelecidas para os adultos (tabela 1) (D). 


\section{Diretrizes}

\section{Tabela 1 - Procedimentos recomendados para a medida da pressão} arterial (D)

\begin{tabular}{l}
\hline Preparo do paciente: \\
\hline 1. Explicar o procedimento ao paciente e deixá-lo em repouso por pelo \\
menos 5 minutos em ambiente calmo. Deve ser instruído a não conversar \\
durante a medida. Possíveis dúvidas devem ser esclarecidas antes ou após o \\
procedimento. \\
\hline 2. Certificar-se de que o paciente NÃO: \\
- está com a bexiga cheia \\
- praticou exercícios físicos há pelo menos 60 minutos \\
- ingeriu bebidas alcoólicas, café ou alimentos \\
- fumou nos 30 minutos anteriores.
\end{tabular}

\section{Posicionamento do paciente:}

Deve estar na posição sentada, pernas descruzadas, pés apoiados no chão, dorso recostado na cadeira e relaxado. 0 braço deve estar na altura do coração (nível do ponto médio do esterno ou 40 espaço intercostal), livre de roupas, apoiado, com a palma da mão voltada para cima e o cotovelo ligeiramente fletido.

\begin{tabular}{l}
\hline Para a medida propriamente: \\
\hline 1. Obter a circunferência aproximadamente no meio do braço. Após a medida \\
selecionar o manguito de tamanho adequado ao braç*. \\
\hline 2. Colocar o manguito, sem deixar folgas, 2 a $3 \mathrm{~cm}$ acima da fossa cubital. \\
\hline 3. Centralizar o meio da parte compressiva do manguito sobre a artéria \\
braquial.
\end{tabular}

4. Estimar o nível da pressão sistólica pela palpação do pulso radial. 0 seu reaparecimento corresponderá à PA sistólica.

5. Palpar a artéria braquial na fossa cubital e colocar a campânula ou o diafragma do estetoscópio sem compressão excessiva.

6. Inflar rapidamente até ultrapassar 20 a $30 \mathrm{mmHg}$ o nível estimado da pressão sistólica, obtido pela palpação.

7. Proceder à deflação lentamente (velocidade de $2 \mathrm{mmHg}$ por segundo).

8. Determinar a pressão sistólica pela ausculta do primeiro som (fase I de Korotkoff), que é em geral fraco seguido de batidas regulares, e, após, aumentar ligeiramente a velocidade de deflação.

9. Determinar a pressão diastólica no desaparecimento dos sons (fase $V$ de Korotkoff).

10. Auscultar cerca de 20 a $30 \mathrm{mmHg}$ abaixo do último som para confirmar seu desaparecimento e depois proceder à deflação rápida e completa.

11. Se os batimentos persistirem até o nível zero, determinar a pressão diastólica no abafamento dos sons (fase IV de Korotkoff) e anotar valores da sistólica/diastólica/zero.

12. Sugere-se esperar em torno de um minuto para nova medida, embora esse aspecto seja controverso ${ }^{10,11}$.

13. Informar os valores de pressões arteriais obtidos para o paciente.

14. Anotar os valores exatos sem "arredondamentos" e o braço em que a pressão arterial foi medida.

* A tabela 2 indica o manguito apropriado em conformidade com as dimensões do braço do examinado.

A interpretação dos valores de pressão arterial obtidos em crianças e adolescentes deve levar em conta a idade, o sexo e a altura. Para avaliação dos valores de pressão arterial de acordo com essas variáveis, consultar tabela disponível em www.sbh.org.br, no texto das Diretrizes Brasileiras de Hipertensão V.

Hipertensão arterial nessa população é definida como pressão igual ou maior ao percentil 95 de distribuição da
Tabela 2 - Dimensões da bolsa de borracha para diferentes circunferências de braço em crianças e adultos (D)

\begin{tabular}{lccc}
\hline \multirow{2}{*}{$\begin{array}{l}\text { Denominação do } \\
\text { manguito }\end{array}$} & $\begin{array}{c}\text { Circunferência } \\
\text { do braço }(\mathbf{c m})\end{array}$ & \multicolumn{2}{c}{ Bolsa de borracha (cm) } \\
\cline { 3 - 4 } & $\leq 10$ & Largura & Comprimento \\
\hline Recém-nascido & $11-15$ & 6 & 8 \\
\hline Criança & $16-22$ & 9 & 12 \\
\hline Infantil & $20-26$ & 10 & 18 \\
\hline Adulto Pequeno & $27-34$ & 12 & 17 \\
\hline Adulto & $35-45$ & 16 & 23 \\
\hline Adulto grande & & & 32 \\
\hline
\end{tabular}

pressão arterial. Crianças também apresentam hipertensão de consultório e efeito do avental branco, mas o papel da MAPA é limitado nessa população especial, sobretudo pela falta de critérios de normalidade ${ }^{13}$.

A classificação da pressão arterial em crianças e adolescentes deve seguir o que está estabelecido na tabela 3.

\subsubsection{2 - Idosos}

Alterações próprias do envelhecimento determinam aspectos diferenciais na PA dessa população como, maior frequência de "hiato auscultatório", que consiste no desaparecimento dos sons durante a deflação do manguito, geralmente entre o final da fase I e o início da fase II dos sons de Korotkoff, resultando em valores falsamente baixos para a sistólica ou falsamente altos para a diastólica. A grande variação da pressão arterial nos idosos, ao longo das 24 horas, torna a MAPA útil. A "pseudo-hipertensão", que está associada ao processo aterosclerótico, pode ser detectada pela manobra de Osler, ou seja, quando a artéria radial permanece ainda palpável, após a insuflação do manguito pelo menos 30 $\mathrm{mmHg}$ acima do desaparecimento do pulso radial ${ }^{14}$. A maior ocorrência de efeito do avental branco, hipotensão ortostática e pós-prandial e, finalmente, a presença de arritmias, como a fibrilação atrial, podem dificultar a medida da PA nesses indivíduos ${ }^{15}(\mathrm{D})$.

\subsubsection{3 - Obesos}

Manguitos mais longos e largos são necessários em pacientes obesos, para não haver superestimação da pressão

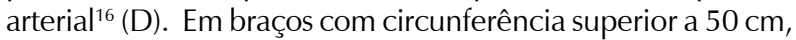
onde não há manguito disponível, pode-se fazer a medida no antebraço e o pulso auscultado deve ser o radial ${ }^{16}$ (D). Há, entretanto, restrições quanto a essa prática, recomendando-se que sejam usados manguitos apropriados. Especial dificuldade ocorre em braços largos e curtos, em forma de cone, onde esses manguitos maiores não se adaptam (D).

\subsubsection{4 - Gestantes}

A pressão arterial deve ser obtida com os mesmos equipamentos e com a mesma técnica recomendada para adultos, entretanto a PA também pode ser medida no braço 
Tabela 3 - Classificação da pressão arterial para crianças e adolescentes (modificado do The Fourth Report on the Diagnosis, Evaluation and Treatment of High Blood Pressure in Children and Adolescents)

\begin{tabular}{|c|c|c|}
\hline Classificação & 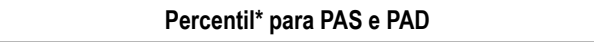 & Frequência de medida da pressão arterial \\
\hline Normal & $\mathrm{PA}<$ percentil 90 & Reavaliar na próxima consulta médica agendada \\
\hline Limítrofe & $\begin{array}{c}\text { PA entre percentis } 90 \text { a } 95 \text { ou se PA exceder } 120 / 80 \mathrm{mmHg} \\
\text { sempre < percentil } 90 \text { até < percentil } 95\end{array}$ & Reavaliar em 6 meses \\
\hline Hipertensão estágio 1 & Percentil 95 a 99 mais $5 \mathrm{mmHg}$ & $\begin{array}{c}\text { Paciente assintomático: reavaliar em } 1 \text { a } 2 \text { semanas; } \\
\text { se hipertensão confirmada encaminhar para avaliação } \\
\text { diagnóstica }\end{array}$ \\
\hline Hipertensão estágio 2 & $\mathrm{PA}>$ percentil 99 mais $5 \mathrm{mmHg}$ & Encaminhar para avaliação diagnóstica \\
\hline Hipertensão do avental branco & $\begin{array}{c}\text { PA > percentil } 95 \text { em ambulatório ou consultório e PA normal } \\
\text { em ambientes } \\
\text { não-relacionados à prática clínica }\end{array}$ & \\
\hline
\end{tabular}

* Para idade, sexo e percentil de estatura.

esquerdo na posição de decúbito lateral esquerdo em repouso, e esta não deve diferir da posição sentada. O 5 ruído de Korotkoff deve ser considerado como a pressão diastólica ${ }^{17}$ (D).

\section{2 - Recomendações para diagnóstico e seguimento}

\subsection{1 - Medida da pressão arterial no consultório}

Na primeira avaliação, as medidas devem ser obtidas em ambos os braços e, em caso de diferença, deve-se utilizar como referência sempre o braço com o maior valor para as medidas subsequentes (D). O indivíduo deverá ser investigado para doenças arteriais se apresentar diferenças de pressão entre os membros superiores maiores de 20/10 mmHg para as pressões sistólica/diastólica respectivamente ${ }^{18}(\mathrm{D})$.

Em cada consulta deverão ser realizadas pelo menos três medidas, sugere-se o intervalo de um minuto entre elas, embora esse aspecto seja controverso ${ }^{10,11}$. A média das duas últimas deve ser considerada a PA real (D). Caso as pressões sistólicas e/ou diastólicas obtidas apresentem diferença maior que $4 \mathrm{mmHg}$, deverão ser realizadas novas medidas até que se obtenham medidas com diferença inferior (D).

A posição recomendada para a medida da pressão arterial é a sentada. As medidas nas posições ortostática e supina devem ser feitas pelo menos na primeira avaliação em todos os indivíduos e em todas as avaliações em idosos, diabéticos, portadores de disautonomias, alcoolistas e/ou em uso de medicação anti-hipertensiva(D).

Novas orientações consideram a utilização da MAPA e da MRPA ferramenta importante na investigação de pacientes com suspeita de hipertensão. Recomenda-se, sempre que possível, a medida da PA fora do consultório para esclarecimento do diagnóstico, identificação da hipertensão do avental branco (HAB) e da hipertensão mascarada (HM) (D) (figura 1 e tabela 4$)^{19}$.

\subsection{2 - Automedida da pressão arterial (AMPA)}

A AMPA foi definida pela World Hypertension League $(1988)^{20}$ como a realizada por pacientes ou familiares, não-profissionais de saúde, fora do consultório, geralmente
Tabela 4 - Recomendações para o seguimento: prazos máximos para reavaliação*

\begin{tabular}{ccc}
\hline \multicolumn{2}{c}{ Pressão arterial inicial $(\mathbf{m m H g})^{* *}$} & Seguimento \\
\cline { 1 - 2 } Sistólica & Diastólica & $\begin{array}{c}\text { Reavaliar em 1 ano } \\
\text { Estimular mudanças de estilo de vida }\end{array}$ \\
\hline 130 & $<85$ & $\begin{array}{c}\text { Reavaliar em 6 meses } \\
\text { Ins* }\end{array}$ \\
$130-139$ & $85-89$ & $\begin{array}{c}\text { Instir em mudanças do estilo de } \\
\text { vida }\end{array}$ \\
\hline $140-159$ & $90-99$ & $\begin{array}{c}\text { Confirmar em 2 meses } \\
\text { Considerar MAPA/MRA }\end{array}$ \\
\hline $160-179$ & $100-109$ & $\begin{array}{c}\text { Confirmar em 1 mês } \\
\text { Considerar MAPA/MRPA }\end{array}$ \\
\hline$\geq 180$ & $\geq 110$ & $\begin{array}{c}\text { Intervenção medicamentosa imediata } \\
\text { ou reavaliar em 1 semana }\end{array}$ \\
\hline
\end{tabular}

* Modificar o esquema de seguimento de acordo com a condição clínica do paciente. ** Se as pressões sistólicas ou diastólicas forem de estágios diferentes, o seguimento recomendado deve ser definido pelo maior nivel de pressão. *** Considerar intervenção de acordo com a situação clínica do paciente (fatores de risco maiores, doenças associadas e lesão em órgãos-alvo).

no domicílio, representando uma importante fonte de informação adicional.

A principal vantagem da AMPA é a possibilidade de obter uma estimativa mais real dessa variável, tendo em vista que os valores são obtidos no ambiente onde os pacientes passam a maior parte do dia ${ }^{21}$.

Na suspeita de HAB ou HM, sugerida pelas medidas da AMPA, recomenda-se a realização de MAPA ou MRPA, para confirmar ou excluir o diagnóstico (D).

Os aparelhos semiautomáticos de braço, validados, com capacidade de armazenar dados em sua memória, são os dispositivos mais recomendados para a AMPA pela sua facilidade de manejo e confiabilidade (D) ${ }^{22}$. Aparelhos de coluna de mercúrio e aneroide apresentam inconvenientes, dificultando o seu manejo por pessoas usualmente nãocapacitadas, no domicílio ${ }^{21}$.

A padronização de um procedimento para AMPA é fundamental para que pacientes e familiares possam 


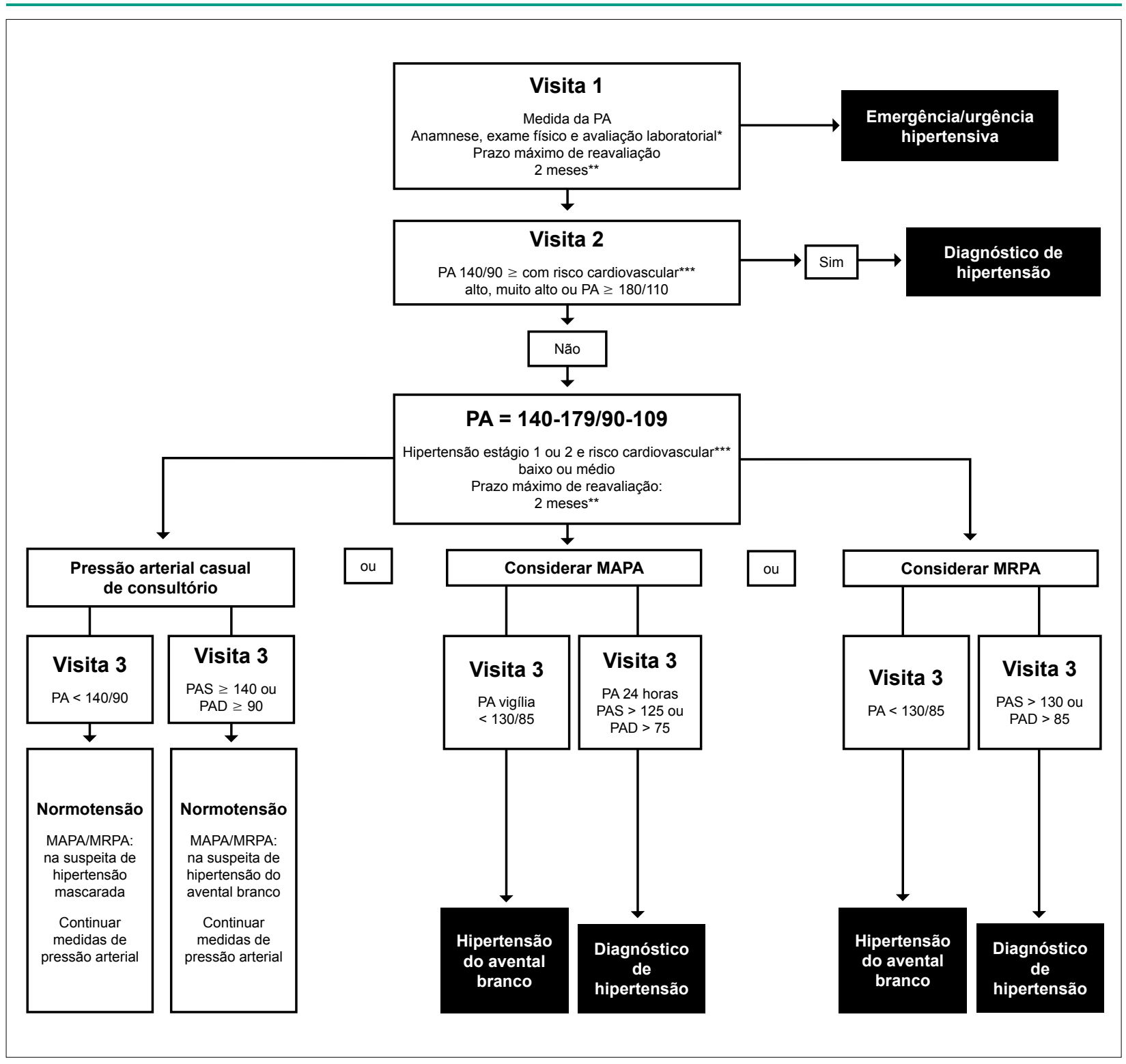

Fig. 1 - Fluxograma para o diagnóstico da hipertensão arterial (modificado de sugestão do Canadian Hypertension Education Program). *Avaliação laboratorial recomendada no capítulo 3. ${ }^{* *}$ Vide tabela 4 (seguimento). ${ }^{* *}$ Estratificação de risco cardiovascular recomendado no capítulo 3. PA - pressão arterial; PAD - pressão arterial diastólica; PAS - pressão arterial sistólica; MAPA - monitorização ambulatorial da pressão arterial; MRPA - monitorização residencial da pressão arterial.

ser orientados durante a consulta no ambulatório ${ }^{23}$. As recomendações para medida domiciliar devem ser as mesmas adotadas ${ }^{24}$.

Valores superiores a 130/85 mmHg, pela AMPA, devem ser considerados alterados $(\mathrm{D})^{25}$.

\subsection{3 - Monitorização residencial da pressão arterial (MRPA)}

A MRPA é o registro da PA, que pode ser realizado obtendo-se três medidas pela manhã, antes do desjejum e da tomada de medicamento, e três à noite, antes do jantar, durante cinco $\operatorname{dias}^{26}$, ou duas medidas em cada sessão, durante sete dias ${ }^{27}$, realizada pelo paciente ou outra pessoa capacitada, durante a vigília, no domicílio ou no trabalho, com equipamentos validados. Não há, nesse momento, protocolos universalmente aceitos para a MRPA. Sua maior utilização pode superar muitas limitações da tradicional medida da PA no consultório, sendo mais barata e de mais fácil execução que a MAPA, embora com limitações, como, por exemplo, a não-avaliação da PA durante o período de sono. É desejável que a MRPA torne-se um componente de rotina da medida da PA para a maioria dos pacientes com hipertensão conhecida ou suspeita, contribuindo para o diagnóstico ${ }^{28}$ e o seguimento da HAS. A MRPA não deve ser confundida com a AMPA (D) ${ }^{29}$. Há vantagens e desvantagens com o seu uso, do mesmo modo que com na $\mathrm{AMPA}^{29-31}$. Apesar de não haver um consenso na literatura em relação a critérios de normalidade, são consideradas anormais medidas de $\mathrm{PA}>130 / 85 \mathrm{mmHg}(\mathrm{B})^{25,32-34}$. 
Tabela 5 - Valores de pressão arterial no consultório, MAPA, AMPA e MRPA que caracterizam efeito do avental branco, hipertensão do avental branco e hipertensão mascarada

\begin{tabular}{|c|c|c|c|c|}
\hline & Consultório & MAPA vigíliaa & AMPA & MRPA \\
\hline $\begin{array}{l}\text { Normotensão ou hipertensão } \\
\text { controlada }\end{array}$ & $<140 / 90$ & $\leq 130 / 85$ & $\leq 130 / 85$ & $\leq 130 / 85$ \\
\hline Hipertensão & $\geq 140 / 90$ & $>130 / 85$ & $>130 / 85$ & $>130 / 85$ \\
\hline Hipertensão do avental branco & $\geq 140 / 90$ & $<130 / 85$ & $<130 / 85$ & $<130 / 85$ \\
\hline Hipertensão mascarada & $<140 / 90$ & $>130 / 85$ & $>130 / 85$ & $>130 / 85$ \\
\hline
\end{tabular}

2.2.4 - Monitorização ambulatorial da pressão arterial de 24 horas (MAPA)

A MAPA é o método que permite o registro indireto e intermitente da pressão arterial durante 24 horas ou mais, enquanto o paciente realiza suas atividades habituais durante os períodos de vigília e sono.

Uma das suas características mais específicas é a possibilidade de identificar as alterações do ciclo circadiano da PA, sobretudo as alterações durante o sono, que têm implicações prognósticas consideráveis ${ }^{35}$.

Tem-se demonstrado que este método é superior à medida de consultório em predizer eventos clínicos, tais como infarto do miocárdio, acidente vascular encefálico, insuficiência renal e retinopatia $(B)^{36}$. São consideradas anormais as médias de PA de 24 horas $>125 \times 75 \mathrm{mmHg}$, vigília $>130 \times 85 \mathrm{mmHg}$ e sono $>110 / 70 \mathrm{mmHg}(\mathrm{B})^{37}$.

\section{3 - Classificação}

\section{Comportamento da pressão arterial}

Os limites de pressão arterial considerados normais são arbitrários. Os valores que classificam os indivíduos acima de 18 anos estão na tabela 6 .

\subsection{1 - Efeito do avental branco}

O efeito do avental branco (EAB) é a diferença de pressão

Tabela 6 - Classificação da pressão arterial de acordo com a medida casual no consultório (> 18 anos)

\begin{tabular}{lcc}
\hline Classificação & $\begin{array}{c}\text { Pressão sistólica } \\
(\mathbf{m m H g})\end{array}$ & $\begin{array}{c}\text { Pressão diastólica } \\
(\mathrm{mmHg})\end{array}$ \\
\hline Ótima & $<120$ & $<80$ \\
\hline Normal & $<130$ & $<85$ \\
\hline Limítrofe* & $130-139$ & $85-89$ \\
\hline Hipertensão estágio 1 & $140-159$ & $90-99$ \\
\hline Hipertensão estágio 2 & $160-179$ & $100-109$ \\
\hline Hipertensão estágio 3 & $\geq 180$ & $<90$ \\
\hline Hipertensão sistólica isolada & $\geq 140$ & \\
\hline $\begin{array}{l}\text { Quando as pressões sistólica e diastólica situam-se em categorias diferentes, } \\
\text { a maior deve ser utilizada para classificação da pressão arterial. }\end{array}$ \\
\hline * Pressão normal-alta ou pré-hipertensão são termos que se equivalem na \\
literatura.
\end{tabular}

obtida entre a medida conseguida no consultório e fora dele, desde que essa diferença seja igual ou superior a $20 \mathrm{mmHg}$ na pressão sistólica e/ou de $10 \mathrm{mmHg}$ na pressão diastólica (C).

O EAB poderá ser verificado considerando-se a PA fora do consultório em comparação com a AMPA, MRPA ou medidas de vigília pela $\mathrm{MAPA}^{38-42}(\mathrm{~B})$.

A prevalência do $E A B$ na população adulta varia entre $18 \%$ a $60 \%{ }^{43}$ (C). Tem componente familiar, sendo mais frequente em brancos, mulheres, idosos, pacientes com sobrepeso e obesos, e mais comum em normotensos que em hipertensos ${ }^{44}(\mathrm{C})$ e em pacientes hipertensos não-tratados que nos tratados ${ }^{45}(\mathrm{C})$.

\subsection{2 - Hipertensão}

A linha demarcatória que define HAS considera valores de PA sistólica $\geq 140 \mathrm{mmHg}$ e/ou de PA diastólica $\geq 90 \mathrm{mmHg}$ em medidas de consultório. O diagnóstico deverá ser sempre validado por medidas repetidas, em condições ideais, em, pelo menos, três ocasiões ${ }^{46-48}(\mathrm{D})$.

A figura 2 mostra as diferentes possibilidades de classificação do comportamento da PA quanto ao diagnóstico, segundo as novas formas de definição.

\subsection{3 - Normotensão verdadeira}

Considera-se normotensão verdadeira se as medidas de consultório são consideradas normais, desde que atendidas todas as condições determinadas nessas diretrizes. Adicionalmente, deve-se considerar médias de pressão na AMPA ou MRPA ou, ainda, no período de vigília pela MAPA $<130 \times 85 \mathrm{mmHg}^{25}$.

A classificação de normotensão verdadeira pode ser observada na tabela $5^{25,37,49}$.

\subsection{4 - Hipertensão sistólica isolada}

Hipertensão sistólica isolada é definida como comportamento anormal da PA sistólica com PA diastólica normal.

A hipertensão sistólica isolada e a pressão de pulso são fatores de risco importantes para doença cardiovascular em pacientes de meia-idade e idosos ${ }^{50}$.

\subsection{5 - Hipertensão do avental branco}

Define-se HAB quando o paciente apresenta medidas de PA persistentemente elevadas $(\geq 140 / 90 \mathrm{mmHg}$ ) no consultório 


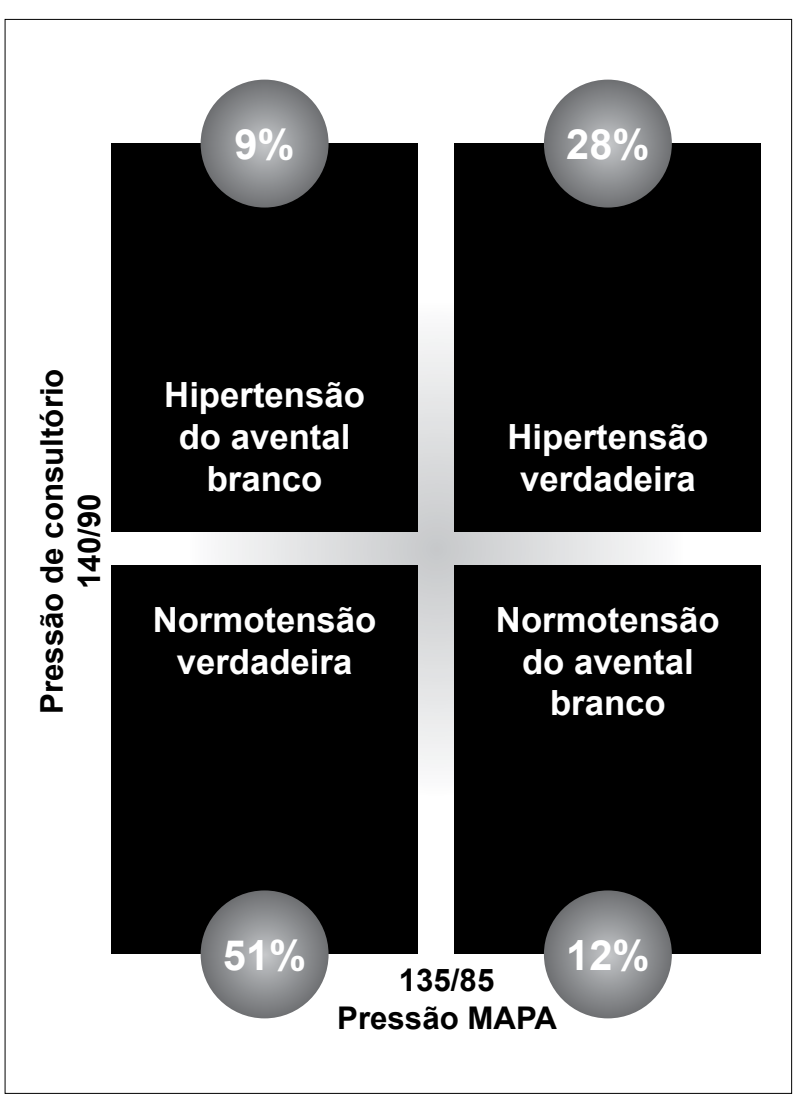

Fig. 2 - Possibilidades de diagnóstico, de acordo com as medidas de pressão arterial casual e MAPA na vigília ou MRPA. Destaque-se que os valores de referência nesse estudo, diferentemente dos considerados nas $D B H \mathrm{VI}$, conferem porcentagens de prevalência a cada uma das formas de comportamento de acordo com os valores nele considerados. e médias de PA consideradas normais seja na residência, pela AMPA ou MRPA, ou pela MAPA ${ }^{25,37}$. Evidências disponíveis apontam para pior prognóstico cardiovascular para a HAB em relação aos pacientes normotensos ${ }^{51}$. Até $70 \%$ dos pacientes com esse comportamento de PA terão HAS pela MAPA e/ou MRPA em um período de dez anos ${ }^{52,53}$.

\subsection{6 - Hipertensão mascarada}

É definida como a situação clínica caracterizada por valores normais de PA no consultório $(<140 / 90 \mathrm{mmHg})$, porém com PA elevada pela MAPA durante o período de vigília ou na MRPA.

Em diversos estudos, a prevalência de HM variou de $8 \%$ a 48\% ${ }^{54-56}$. Esta condição deve ser pesquisada em indivíduos com PA normal ou limítrofe e mesmo nos hipertensos controlados, mas com sinais de lesões em órgãos-alvo, histórico familiar positivo para HAS, risco cardiovascular alto, e medida casual fora do consultório anormal ${ }^{26,27}$ (D).

Os pacientes portadores de HM devem ser identificados e acompanhados, pois apresentam risco de desenvolver lesões de órgãos-alvo de forma semelhante a pacientes hipertensos ${ }^{57}(\mathrm{~A})$.

\section{Referências}

1. Rabello CC, Pierin AM, Mion D Jr. Healthcare professionals' knowledge of blood pressure measurement. Rev Esc Enferm USP 2004; 38(2): 127-134.

2. Veiga EV, Nogueira MS, Cárnio EC, Marques S, Lavrador MA, de Moraes SA, et al. Assessment of the techniques of blood pressure measurement by health professionals. Arq Bras Cardiol 2003; 80(1): 89-93, 83-8.

3. Ogihara T, Kikuchi K, Matsuoka H, Fujita T, Higaki J, Horiuchi M, et al on behalf of The Japanese Society of Hypertension Committee. The Japanese Society of Hypertension Guidelines for the Management of Hypertension (JSH 2009). Hypertension Research 2009; 32, 11-23.

4. Perloff D, Grim C, Flack J, Frohlich ED, Hill M, McDonald M, et al. Human blood pressure determination by sphygmomanometry. Circulation 1993; 88: 2460-2470.

5. Petrie JC, O'Brien ET, Littler WA, de Swiet M. Recommendations on blood pressure measurement. Br Med J 1986; 293: 611-615.

6. Coleman AJ, Steel SD, Ashworth M, Vowler SL, Shennan A. Accuracy of the pressure scale of sphygmomanometers in clinical use within primary care. Blood Press Monit 2005; 10(4): 181-188.

7. de Greeff A, Lorde I, Wilton A, Seed P, Coleman AJ, Shennan AH. Calibration accuracy of hospital-based non-invasive blood pressure measuring devices. J Hum Hypertens 2010; 24(1): 58-63.

8. O'Brien E, Pickering T, Asmar R, Myers M, Parati G, Staessen J, et al. Working Group on Blood Pressure Monitoring of the European Society of Hypertension

International Protocol for validation of blood pressure measuring devices in adults. Blood Press Monit 2002; 7: 3-17.

9. Parati G, Asmar R, Stergiou GS. Self blood pressure monitoring at home by wrist devices: a reliable approach? J Hypertens 2002; 20: 573-578.

10. Koehler NR, Figueiredo CEP, Ribeiro ACM. Serial blood pressure measurements. Braz J Med Biol Res 2002; 35(5): 555-559.

11. Kohler NR, Figueiredo CEP, Ribeiro CCM. Time interval between pairs of arterial blood pressure measurements - Does it matter? Am J Hypertens 2004; 17: 194-196.

12. The fourth report on the diagnosis, evaluation, and treatment of high blood pressure in children and adolescents. National High Blood Pressure Education Program Working Group on High Blood Pressure in Children and Adolescents. Pediatrics 2004; 114: 555-576.

13. Wuhl E, Witte K, Soergel M, Mehls O, Schaefer F, Kirschstein M, et al. German Working Group on Pediatric Hypertension. Distribution of 24-h ambulatory blood pressure in children: normalized reference values and role of body dimensions. J Hypertens 2002; 20: 1995-2007. [erratum in: J Hypertens 2003; $21: 2205-2206]$.

14. Messerli FH, Ventura HO, Amodeo C. Osler's maneuver and pseudohypertension. N Engl J Med 1985; 312: 1548-1551.

15. Sgambatti MS, Pierin A, Mion Jr D. A medida da pressão arterial no idoso. Rev Bras Hipertens 2000; 7: 65-70. 
16. Pickering TG, Hall JE, Lawrence JÁ, Falkner BE, Graves J, Hill MN. Recommendation for blood pressure measurement in humans and experimental animals. Part 1: Blood pressure measurement in humans. A statement for professionals from the subcommittee of professional and public education of the American Heart Association Council on High Blood Pressure Research. Circulation 2005; 45: 142-161.

17. Junqueira SM. Medida da pressão arterial na gestante. Rev Bras Hipertens 2000; 7: 59-64.

18. European Society of Hypertension Wor-king Group on Blood Pressure Monitoring. Practice guidelines of the European Society of Hypertension for clinic, ambulatory and self blood pressure measurement. J Hypertens 2005; 23: 697-701

19. Tobe S, Lebel M, Hemmelgarn B, Hill M, Mahon J, Khan N, et al. Evidence-Based Recommendations Task Force 2008 for the 2009 Canadian Hypertension Education Program Recommendations for the Management of Hypertension. http://hypertension.ca/chep/wp-content/ uploads/2009/04/09-complete-recs.pdf.

20. World Hypertension League. Self-measurement of blood pressure. Bulletin of the World Health Organization (WHO). 1988; 66(2): 155-159.

21. Alessi A. Automedida da pressão arterial - Opinião do agonista. Rev Bras Hipertens 2008; 15(4): 196-198.

22. Coca A, Bertomeu V, Dalfó A, Esmatjes E, Guillén F, Guerrero L, et al. Automedida de la presión arterial. Documento de Consenso Español 2007. Nefrología 2007; 27(2): 139-153.

23. Plá AB, Baqué AD, Sardina MD, Cabello MIE, Becerra IF, Díaz RM, etal. Grupo de Trabajo en HTA semFYC. Automedida de la presión arterial (AMPA) en atención primaria (II). Aten Primaria 2003; 31(9): 606-612.

24. V Diretrizes Brasileiras de Hipertensão Arterial. Arq Bras Cardiol 2007; 89(3): e24-e78.

25. Mancia G, Sega R, Bravi C, De Vito G, Valagussa F, Cesana G, et al. Ambulatory blood pressure normality: results from the PAMELA study. J Hypertens 1995 Dec; 13(12 Pt 1): 1377-1390.

26. Alessi A, Brandão AA, Pierin A, et al. IV Diretriz para uso da monitorização ambulatorial da pressão arterial / II Diretriz para o uso da monitorização residencial da pressão arterial. Arq Bras Cardiol 2005; 85 (supl. II): 5-18.

27. Parati G, Stergiou GS, Asmar R, et al. European Society of Hypertension guidelines for blood pressure monitoring at home: a summary report of the Second International Consensus Conference on Home Blood Pressure Monitoring. J Hypertens 2008, 26: 1505-1526.

28. Pickering TG, Houston Miller N, Ogedegbe G, Krakoff LR, Artinian NT, Goff D. Call to action on use and reimbursement for home blood pressure monitoring: a joint scientific statement from the American Heart Association, American Society of Hypertension, and Preventive Cardiovascular Nurses Association. Hypertension 2008; 52: 10-29.

29. Bobrie G, Chatellier G, Genes N, Clerson P, Vaur L, Vaisse B, et al. Cardiovascular prognosis of "masked hypertension" detected by blood pressure self-measurement in elderly treated hypertensive patients. JAMA $2004 ; 291: 1342-1349$

30. Sega R, Facchetti R, Bombelli M, Cesana G, Corrao G, Grassi G, et al. Prognostic value of ambulatory and home blood pressures compared with office blood pressure in the general population: follow-up results from the Pressioni Arteriose Monitorate e Loro Associazioni (PAMELA) study. Circulation 2005; 111: 1777-1783.

31. Fagard RH, Van Den Broeke C, De Cort P. Prognostic significance of blood pressure measured in the office, at home and during ambulatory monitoring in older patients in general practice. J Hum Hypertens 2005; 19: 801-807.

32. Ohkubo T, Imai Y, Tsuji I, Nagai K, Kato J, Kikuchi N, et al. Home blood pressure measurement has a stronger predictive power for mortality than does screening blood pressure measurement: a population-based observation in Ohasama, Japan. J Hypertens 1998; 16: 971-975.

33. Thijs L, Staessen JA, Celis H, de Gaudemaris R, Imai Y, Julius S, et al. Reference values for self-recorded blood pressure. A meta-analysis of summary data. Arch Intern Med 1998; 158: 481-488.

34. Mansoor GA, White WB. Self-measured home blood pressure in predicting ambulatory hypertension. Am J Hypertens 2004; 17 (pt 1): 1017-1022.
35. Ohkubo T, Imai Y, Tsuji I, Nagai K, Watanabe N, Minami N. Relation between nocturnal decline in blood pressure and mortality. The Ohasama study. Am J Hypertens 1997; 10: 1201-1207.

36. Sega R, Trocino G, Lanzarotti A, Carugo S, Cesana G, Schiavina R, et al. Alterations in cardiac structures in patients with isolated officce ambulatory or home hypertension. Data from the PAMELA study. Circulation 2001; 104: 1385-1392.

37. Kikuya M, Hansen TW, Thijs L, Björklund-Bodegård K, Kuznetsova T, Ohkubo $\mathrm{T}$, et al. On Behalf of the International Database on Ambulatory blood pressure monitoring in relation to Cardiovascular Outcomes (IDACO) Investigators Diagnostic Thresholds for Ambulatory Blood Pressure Monitoring Based on 10-Year Cardiovascular Risk. Circulation 2007; 115: 2145-2152.

38. Guedis AG, Sousa BDB, Marques CF, Piedra DPS, Braga JCMS, et al Hipertensão do avental branco e sua importância de diagnóstico. Rev Bras Hipertens 2008; 15(1): 46-50.

39. Mancia G. White coat effect. Innocuous or adverse phenomenon? Eur Heart J 2000; 21: 1647-1648

40. Pereira T, Maldonado J. Distensibilidade arterial e hipertensão do avental branco: estudo comparativo. Rev Bras Hipertens 2006; 13(4): 249-255.

41. Félix-Redondo FJ, Fernández-Bergés D, Espinosa-Gaciaa J, Pozuelos-Estrada J, Molina-Martines LM, Pérez-Castán JF, et al. Level of blood pressure control in hypertensive population when measurements are performed outside the clinical setting. Cardiol J 2009; 16(1): 57-67.

42. Bochud M, Bovet P, Vollenweider P, Maillard M, Paccaud F, Wandeler G, et al. Association between white-coat effect and blunted dipping of nocturnal blood pressure. Am J Hypertens 2009 Oct; 22(10): 1054-1061.

43. MacDonald MB, Laing GP, Wilson MP, Wilson TW. Prevalence and predictors of white-coat response in patients with treated hypertension. CMAJ 1999; 161(3): 265-269.

44. Segre CA, Ueno RK, Warde KRJ, Accorsi TAD, Miname MH, Chi CK, et al. Efeito hipertensão e normotensão do jaleco branco na liga de hipertensão do hospital das clínicas, FMUSP. Prevalência, características clínicas e demográficas. Arq Bras Cardiol 2003; 80(2): 117-121.

45. Stergiou GS, Efstathiou SP, Argyraki CK, Roussias LG, Mountokalakia TD. White coat effect in treated versus untreated hypertensive individuals: a case-control study using ambulatory and home blood pressure monitoring. Am J Hypertens 2004; 17: 124-128.

46. NICE clinical guideline 34 - hypertension. Management of hypertension in adults in primary care. http://www.nice.org.uk/nicemedia/pdf/ CG034NICEguideline.pdf

47. Mancia G, De Backer G, Dominiczak A, Cifkova R, Fagard R, Germano G, et al. 2007 ESH-ESC Practice Guidelines for the Management of Arterial Hypertension. J Hypertens 2007; 25: 1751-1762.

48. Figueiredo D, Azevedo A, Pereira M, de Barros H. Definition of hypertension: the impact of number of visits for blood pressure measurement. Rev Port Cardiol. 2009 Jul-Aug; 28(7-8): 775-783.

49. The seventh report of the Joint National Committee on Prevention, Detection, Evaluation, and Treatment of High Blood Pressure. The JNC 7 Report. JAMA 2003; 289(19): 2560-2572.

50. Gus M. Ensaios clínicos em hipertensão sistólica isolada. Rev Bras Hipertens 2009; 16(1): 26-28.

51. Mancia G, Facchetti R, Bombelli M, Grassi G, Sega R. Long-term risk of mortality associated with selective and combined elevation in office, home, and ambulatory blood pressure. Hypertension 2006; 47(5): 846-853.

52. Bidlingmeyer I, Burnier M, Bidlingmeyer M, Waeber B, Brunner HR. Isolated office hypertension: a prehypertensive state? J Hypertens 1996; 14(3): 327-332.

53. Mancia G, Bombelli M, Facchetti R, Madotto F, Quarti-Trevano F, Friz HP et al. Long-term risk of sustained hypertension in white-coat or masked hypertension. Hypertension 2009; 54: 226-232.

54. Ungar A, Pepe G, Monami M, Lambertucci L, Torrini M, Baldasseroni S, et al. Isolated ambulatory hypertension is common in outpatients referred to a hypertension centre. J Hum Hypertens 2004 Dec; 18(12): 897-903. 


\section{Diretrizes}

55. Sakaguchi K, Horimatsu T, Kishi M, Takeda A, Ohnishi Y, Koike T, et al. Isolated home hypertension in the morning is associated with target organ damage in patients with type 2 diabetes. J Atheroscler Thromb 2005; 12(4): 225-231.

56. Mallion JM, Clerson P, Bobrie G, Genes N, Vaisse B, Chatellier G. Predictive factors for masked hypertension within a population of controlled hypertensives. J Hypertens 2006 Dec; 24(12): 2365-2370.

57. Bombelli M, Sega R, Facchetti R, Corrao G, Polo Friz H, Vertemati AM, et al. Prevalence and clinical significance of a greater ambulatory versus Office blood pressure ("reverse white coat" condition) in a general population. J Hypertens 2005 Mar; 23(3): 513-520.

\section{Capítulo 3 - Avaliação clínica e laboratorial e estratificação de risco}

\section{1 - Avaliação clínica e laboratorial}

\subsection{1 - Objetivos}

Os principais objetivos da avaliação clínica e laboratorial estão apresentados na tabela 1.

Para atingir tais objetivos é fundamental considerar os aspectos apresentados a seguir, levando-se em conta que o tempo necessário para a avaliação inicial de um paciente com suspeita de hipertensão arterial é de, pelo menos, 30 minutos ${ }^{1}$.

\subsection{2 - Avaliação clínica}

3.1.2.1 - Deve-se obter história clínica completa, com especial atenção aos dados relevantes referentes ao tempo e tratamento prévio de hipertensão, fatores de risco, indícios de hipertensão secundária e de lesões de órgãos-alvo, aspectos socioeconômicos e características do estilo de vida do paciente e ao consumo pregresso ou atual de medicamentos ou drogas que podem interferir em seu tratamento (anti-inflamatórios, anorexígenos, descongestionantes nasais, etc).

Além da medida da PA, a frequência cardíaca deve ser cuidadosamente medida, pois sua elevação está relacionada a maior risco cardiovascular².

Para avaliação de obesidade visceral, recomenda-se a medida da circunferência da cintura (CC) (IIB), dado que a medida da relação cintura-quadril não se mostrou superior à medida isolada da CC na estratificação de risco ${ }^{3}$. Os valores de normalidade da CC adotados nestas diretrizes foram os utilizados no NCEP III $^{4}(88 \mathrm{~cm}$ para mulheres e $102 \mathrm{~cm}$ para homens) e previamente recomendados pela Diretriz

\section{Tabela 1 - Objetivos da avaliação clínica e laboratorial}

\begin{tabular}{l}
\hline Confirmar o diagnóstico de HAS por medida da PA \\
\hline Identificar fatores de risco para doenças cardiovasculares \\
\hline Pesquisar lesões em órgãos-alvo, clínicas ou subclínicas \\
\hline Pesquisar presença de outras doenças associadas \\
\hline Estratificar o risco cardiovascular global \\
\hline Avaliar indícios do diagnóstico de hipertensão arterial secundária
\end{tabular}

Brasileira de Síndrome Metabólica (Ila, C), já que ainda não dispomos de dados nacionais que representem nossa população como um todo ${ }^{5}$.

3.1.2.2 - O exame físico deve ser minucioso, buscando sinais sugestivos de lesões de órgãos-alvo e de hipertensão secundária. O exame de fundo de olho deve ser sempre feito ou solicitado na primeira avaliação, em especial em pacientes com HAS estágio 3, que apresentam diabetes ou lesão em órgãos-alvo ${ }^{6}$ (Classe lla, Nível C).

No exame físico a obstrução do índice tornozelo braquial (ITB) pode ser útil. A tabela 2 traz considerações sobre o ITB.

\subsubsection{A investigação laboratorial básica (tabelas 3 e 4) é indicada para todos os pacientes hipertensos}

A avaliação complementar é orientada para detectar lesões clínicas ou subclínicas com o objetivo de melhor estratificação do risco cardiovascular (tabela 5). Está indicada na presença de elementos indicativos de doença cardiovascular e doenças associadas, em pacientes com dois ou mais fatores de risco, e em pacientes acima de 40 anos de idade com diabetes ${ }^{1}$. (Nível de evidência I, Classe C).

\section{2 - Estratificação de risco}

Para a tomada da decisão terapêutica é necessária a

\section{Tabela 2 - Índice tornozelo braquial (ITB)}

\author{
Indicações ${ }^{8}$ (Classe I, Nível B) \\ - Idade 50-69 e tabagismo ou diabetes \\ - Idade $\geq 70$ anos \\ - Dor na perna com exercício \\ - Alteração de pulsos em membros inferiores \\ - Doença arterial coronária, carotídea ou renal \\ - Risco cardiovascular intermediário
}

Para o cálculo do índice tornozelo braquial

Utilizar os valores de pressão arterial sistólica do braço e tornozelo, sendo considerado o maior valor braquial para cálculo. ITB direito = pressão tornozelo direito/pressão braço direito. ITB esquerdo = pressão tornozelo esquerdo/pressão braço esquerdo ${ }^{8,9}$.

\begin{tabular}{l} 
Interpretação \\
\hline - Normal = acima de 0,90 \\
- Obstrução leve $=0,71-0,90$ \\
- Obstrução moderada $=0,41-0,70$ \\
- Obstrução grave $=0,00-0,408,9$
\end{tabular}


Tabela 3 - Avaliação inicial de rotina para o paciente hipertenso

\begin{tabular}{l}
\hline Análise de urina (Classe I, Nível C) \\
\hline Potássio plasmático (Classe I, Nível C) \\
\hline Creatinina plasmática (Classe I, Nível B) e estimativa do ritmo de filtração \\
glomerular (Classe I, Nível B)10,11 (tabela 4) \\
\hline Glicemia de jejum (Classe I, Nível C) \\
\hline Colesterol total, HDL, triglicérides plasmáticos (Classe I, Nível C)* \\
\hline Ácido úrico plasmático (Classe I, Nível C) \\
\hline Eletrocardiograma convencional (Classe I, Nível B) \\
\hline * O LDL-C é calculado pela fórmula: LDL-C = colesterol total - (HDL-C + \\
triglicérides/5) (quando a dosagem de triglicérides for abaixo de $400 \mathrm{mg} /$ dl).
\end{tabular}

Tabela 4 - Cálculo do clearance de creatinina e ritmo de filtração glomerular e interpretação dos valores para classificação de doença renal crônica de acordo com NKF ${ }^{12}$

Taxa de filtração glomerular estimada (TFGE) pela fórmula de CockcroftGault ${ }^{13:}$ TFGE $(\mathrm{ml} / \mathrm{min})=[140$ - idade] $\times$ peso $(\mathrm{kg}) /$ creatinina plasmática $(\mathrm{mg} /$ dL) $\times 72$ para homens; para mulheres, multiplicar o resultado por 0,85

Ritmo de filtração glomerular pela formula MDRD ${ }^{14}$ no

link www.kidney.org/professionals/kdogi/guidelines_ckd

Interpretação ${ }^{15}$ :

função renal normal: > $90 \mathrm{~m} / / \mathrm{min}$ sem outras alterações no exame de urina; disfunção renal estágio 1: > $90 \mathrm{ml} / \mathrm{min}$ com alterações no exame de urina; disfunção renal estágio 2: 60-90 ml/min; disfunção renal estágio 2: 30-60 ml/ $\mathrm{min}$; disfunção renal estágio 4-5: $<30 \mathrm{ml} / \mathrm{min}$

\section{Tabela 5 - Avaliação complementar para o paciente hipertenso:} exames recomendados e população indicada

\footnotetext{
Radiografia de tórax: recomendada para pacientes com suspeita clínica de insuficiência cardíaca (Classe lla, Nível C) ${ }^{16}$, quando demais exames não estão disponiveis; e para avaliação de acometimento pulmonar e de aorta

Ecocardiograma $^{17,18}$ : hipertensos estágios 1 e 2 sem hipertrofia ventricular esquerda ao ECG, mas com dois ou mais fatores de risco (Classe lla, Nível C); hipertensos com suspeita clínica de insuficiência cardíaca (Classe I, Nível C)

Microalbuminúria ${ }^{19-21}$ : pacientes hipertensos diabéticos (Classe I, Nível A), hipertensos com síndrome metabólica e hipertensos com dois ou mais fatores de risco (Classe I, Nível C)

Ultrassom de carótida ${ }^{22}$ : pacientes com sopro carotídeo, com sinais de doença cerebrovascular, ou com doença aterosclerótica em outros territórios (Classe lla, Nivel B)

Teste ergométrico: suspeita de doença coronariana estável, diabetes ou antecedente familiar para doença coronariana em paciente com pressão arterial controlada (Classe lla, Nível C)

Hemoglobina glicada (Classe lla, Nível B) ${ }^{23}$ : na impossibilidade de realizar hemoglobina glicada sugere-se a realizacão do teste oral de tolerância à glicose em pacientes com glicemia de jejum entre 100 e $125 \mathrm{mg} / \mathrm{dL}$ (Classe Ila, Nivel B)

MAPA, MRPA e medida domiciliar segundo as indicações convencionais para os métodos

Outros exames: velocidade de onda de pulso (se disponivel) ${ }^{24}$ (Classe llb, Nivel C)

Investigação de hipertensão secundária, quando indicada pela história, exame físico ou avaliação laboratorial inicial (capítulo 7)
}

estratificação do risco cardiovascular global (tabela 9) que levará em conta, além dos valores de PA, a presença de fatores de risco adicionais (tabela 6), de lesões em órgãos-alvo (tabela 7) e de doenças cardiovasculares (tabela 8$)^{25-27}$.

Além dos fatores clássicos de risco cardiovascular expostos na tabela 6 , novos fatores de risco cardiovascular vêm sendo identificados, e ainda que não tenham sido incorporados em escores clínicos de estratificação de risco (Framingham ${ }^{29}$, Score $^{30}$ ) têm sido sugeridos como marcadores de risco adicional em diferentes diretrizes: glicemia de jejum (100 a $125 \mathrm{mg} / \mathrm{dL}$ ) e hemoglobina glicada anormal ${ }^{31}$, obesidade abdominal (circunferência da cintura $>102 \mathrm{~cm}$ para homens e $>88 \mathrm{~cm}$ para mulheres), pressão de pulso $>65 \mathrm{mmHg}$ $(\text { em idosos })^{24}$, história de pré-eclampsia na gestação ${ }^{32}$, história familiar de hipertensão arterial (em hipertensos limítrofes) ${ }^{33}$.

\section{Tabela 6 - Fatores de risco cardiovascular adicionais nos pacientes} com HAS

Idade (homem $>55$ e mulheres $>65$ anos)

Tabagismo

Dislipidemias: triglicérides $\geq 150 \mathrm{mg} / \mathrm{dL}$

LDL colesterol > $100 \mathrm{mg} / \mathrm{dL} ; \mathrm{HDL}<40 \mathrm{mg} / \mathrm{dL}$

Diabetes melito

História familiar prematura de doença cardiovascular:

homens $<55$ anos e mulheres $<65$ anos

\section{Tabela 7 - Identificação de lesões subclínicas de órgãos-alvo}

ECG com HVE (Sokolow-Lyon > $35 \mathrm{~mm}$; Cornell > $28 \mathrm{~mm}$ para homens $(\mathrm{H})$; > $20 \mathrm{~mm}$ para mulheres $(\mathrm{M})$

ECO com HVE (índice de massa de VE $>134 \mathrm{~g} / \mathrm{m}^{2}$ em H ou $110 \mathrm{~g} / \mathrm{m}^{2} \mathrm{em} \mathrm{M}$ )

Espessura médio-intimal de carótida $>0,9 \mathrm{~mm}$ ou presença de placa de ateroma

Índice tornozelo braquial $<0,9$

Depuração de creatinina estimada $<60 \mathrm{ml} / \mathrm{min} / 1,72 \mathrm{~m}^{2}$

Baixo ritmo de filtração glomerular ou clearance de creatinina (<60 ml/min)

Microalbuminúria 30 - $300 \mathrm{mg} / 24 \mathrm{~h}$ ou relação albumina/creatinina $>30 \mathrm{mg}$ por $\mathrm{g}$

Velocidade de onda de pulso (se disponível) $>12 \mathrm{~m} / \mathrm{s}$

\section{Tabela 8 - Condições clínicas associadas a hipertensão}

Doença cerebrovascular (AVE, AVEI, AVEH, alteração da função cognitiva)

Doença cardíaca (infarto, angina, revascularização coronária, insuficiência cardíaca)

Doença renal: nefropatia diabética, déficit importante de função (clearance < $60 \mathrm{~m} / \mathrm{min}$ )

Retinopatia avançada: hemorragias ou exsudatos, papiledema

Doença arterial periférica

AVE - acidente vascular encefálico; AVEI - AVE isquêmico; AVEH - AVE hemorrágico. 


\section{Diretrizes}

Tabela 9 - Estratificação do risco cardiovascular global: risco adicional atribuído à classificação de hipertensão arterial de acordo com fatores de risco, lesões de órgãos-alvo e condições clínicas associadas (Classe lla, Nível C)

\begin{tabular}{|c|c|c|c|c|c|c|}
\hline \multirow[b]{2}{*}{$\begin{array}{l}\text { Outros fatores de } \\
\text { risco ou doenças }\end{array}$} & \multicolumn{3}{|c|}{ Normotensão } & \multicolumn{3}{|c|}{ Hipertensão } \\
\hline & $\begin{array}{c}\text { Ótimo } \\
\text { PAS }<120 \\
\text { ou PAD }<80\end{array}$ & $\begin{array}{c}\text { Normal } \\
\text { PAS 120-129 } \\
\text { ou PAD 80-84 }\end{array}$ & $\begin{array}{c}\text { Limítrofe } \\
\text { PAS 130-139 } \\
\text { ou PAD 85-89 }\end{array}$ & $\begin{array}{l}\text { Estágio } 1 \\
\text { PAS 140-159 } \\
\text { PAD 90-99 }\end{array}$ & $\begin{array}{c}\text { Estágio } 2 \\
\text { PAS 160-179 } \\
\text { PAD 100-109 }\end{array}$ & $\begin{array}{l}\text { Estágio } 3 \\
P A S \geq 180 \\
P A D \geq 110\end{array}$ \\
\hline $\begin{array}{l}\text { Nenhum fator de } \\
\text { risco }\end{array}$ & Risco basal & Risco basal & Risco basal & Baixo risco adicional & $\begin{array}{l}\text { Moderado risco } \\
\text { adicional }\end{array}$ & Alto risco adicional \\
\hline $\begin{array}{l}1-2 \text { fatores de } \\
\text { risco }\end{array}$ & Baixo risco adicional & Baixo risco adicional & Baixo risco adicional & $\begin{array}{l}\text { Moderado risco } \\
\text { adicional }\end{array}$ & $\begin{array}{l}\text { Moderado risco } \\
\text { adicional }\end{array}$ & $\begin{array}{l}\text { Risco adicional } \\
\text { muito alto }\end{array}$ \\
\hline $\begin{array}{l}\geq 3 \text { fatores de } \\
\text { risco, LOA ou SM } \\
- \text { DM }\end{array}$ & $\begin{array}{l}\text { Moderado risco } \\
\text { adicional }\end{array}$ & $\begin{array}{l}\text { Moderado risco } \\
\text { adicional }\end{array}$ & Alto risco adicional & Alto risco adicional & Alto risco adicional & $\begin{array}{l}\text { Risco adicional } \\
\text { muito alto }\end{array}$ \\
\hline $\begin{array}{l}\text { Condições clínicas } \\
\text { associadas }\end{array}$ & $\begin{array}{l}\text { Risco adicional } \\
\text { muito alto }\end{array}$ & $\begin{array}{l}\text { Risco adicional } \\
\text { muito alto }\end{array}$ & $\begin{array}{l}\text { Risco adicional } \\
\text { muito alto }\end{array}$ & $\begin{array}{l}\text { Risco adicional } \\
\text { muito alto }\end{array}$ & $\begin{array}{l}\text { Risco adicional } \\
\text { muito alto }\end{array}$ & $\begin{array}{l}\text { Risco adicional } \\
\text { muito alto }\end{array}$ \\
\hline
\end{tabular}

LOA - lesão de órgãos-alvos; SM - síndrome metabólica; DM - diabetes melito.

\section{Referências}

1. Mancia G, De Backer G, Dominiczak A, et al. ESH-ESC Task Force on the Management of Arterial Hypertension. 2007 ESH-ESC Practice Guidelines for the Management of Arterial Hypertension: ESH-ESC Task Force on the Management of Arterial Hypertension. J Hypertens 2007; 25(9): 1751-1762.

2. Benetos A, Rudnichi A, Thomas F, Safar M, Guize L. Influence of heart rate on mortality in a French population: role of age, gender, and blood pressure. Hypertension 1999; 33: 44-52.

3. Pouliot MC, Després JP, Lemieux S, et al. Waist circumference and abdominal sagital diameter: best simple anthropometric indexes of abdominal visceral adipose tissues accumulation and related cardiovascular risk in men and women. Am J Cardiol 1994; 73(7): 460-468.

4. Third Report of the National Cholesterol Education Program (NCEP) Expert Panel on Detection, Evaluation, and Treatment of High Blood Cholesterol in Adults (Adult Treatment Panel III) Final Report. Circulation 2002; 106: 3143-3421.

5. Alberti KG, Eckel RH, Grundy SM, et al. Harmonizing the metabolic syndrome: a joint interim statement of the International Diabetes Federation Task Force on Epidemiology and Prevention; National Heart, Lung, and Blood Institute; American Heart Association; World Heart Federation; International Atherosclerosis Society; and International Association for the Study of Obesity. Circulation 2009; 120(16): 1640-1645.

6. Van den Born BJ, Hulsman CA, Hoekstra JB, Schlingemann RO, van Montfrans GA. Value of routine funduscopy in patients with hypertension: systematic review. BMJ 2005; 331(7508): 73.

7. Obisesan TO, Obisesan A, Martins S, Alamgir L, Bond V, Maxwell C, et al. High blood pressure, hypertension, and high pulse pressure are associated with poorer cognitive function in persons aged 60 and older: the Third National Health and Nutrition Examination Survey. J Am Geriatr Soc 2008; 56(3): 501-509.

8. Beckman JA, Higgins CO, Gerhard-Herman. Automated oscillometric determination of the ankle-brachial index provides accuracy necessary for office practice. Hypertension 2006; 47: 35-38.

9. Ankle Brachial Index Collaboration, Fowkes FG, Murray GD, Butcher I, et al. Ankle brachial combined with Framingham Risk Score to predict cardiovascular events and mortality: a meta-analysis. JAMA 2008; 300(2): 197-208.

10. Sarnak MI, Levey AS, Schoolwerth AC, et al. Kidney disease as a risk factor for development of cardiovascular disease: a statement from the American Heart Association Councils on Kidney in Cardiovascular Disease, High Blood Pressure Research, Clinical Cardiology, and Epidemiology and Prevention. Hypertension 2003; 42(5): 1050-1065.
11. Culleton BF, Larson MG, Wilson PW, Evans JC, Parfrey PS, Levy D. Cardiovascular disease and mortality in a community-based cohort with mild renal insufficiency. Kidney Int 1999; 56: 2214-2219.

12. Levey AS, Coresh J, Balk E, et al. National Kidney Foundation. National Kidney Foundation practice guidelines for chronic kidney disease: evaluation, classification, and stratification. Ann Intern Med 2003 Jul 15; 139(2): 137-147.

13. Cockcroft DW, Gault MH. Prediction of creatinine clearance from serum creatinine. Nephron 1976; 16: 31-41.

14. Levey AS, Coresh J, Greene T, et al. Using standardized serum creatinine values in the Modification of Diet in Renal Disease study equation for estimating glomerular filtration rate. Ann Intern Med 2006; 145: 247-254.

15. Moe S, Drueke T, Cunningham J, et al. Kidney Disease: Improving Global Outcomes (KDIGO). Definition and classification of chronic kidney disease: a position statement from Kidney Disease: Improving Global Outcomes (KDIGO). Kidney Int 2005; 67: 2089-2100.

16. Rayner BL, Goodman H, Opie LH. The Chest Radiograph. A useful investigation in the evaluation of hypertensive patients. Am J Hypertens 2004; 17: $507-510$

17. Martinez MA, Sancho T, Armada E, et al. Prevalence of left ventricular hypertrophy in patients with mild hypertension in primary care: impact of echocardiography on cardiovascular risk stratification. Am J Hypertens 2003; 16: 556-563

18. Koren MJ, Devereux RB, Casale PN, Savage DD, Laragh J. Relation of left ventricular mass and geometry to morbidity and mortality in uncomplicated essential hypertension. Ann Intern Med 1991; 114: 345-352.

19. Hsu CC, Brancati FL, Astor BC, et al. Blood pressure, atherosclerosis, and albuminuria in 10,113 participants in the atherosclerosis risk in communities study. J Hypertens 2009; 27(2): 397-409.

20. Volpe M, Consentino F, Ruilope LM. Is it to measure microalbuminuria in hypertension. J Hypertens 2003; 21: 1213-1220.

21. Gerstein HC, Mann JF, Yi Q, et al. HOPE Study Investigators. Albuminuria and risk of cardiovascular events, death, and heart failure in diabetic and nondiabetic individuals. JAMA 2001; 286: 421-426.

22. Cuspidi C, Ambrosioni E, Mancia G, Pessina AC, Trimarco B, Zanchetti A. Role of echocardiography and carotid ultrasonography in stratifying risk in patients with essential hypertension: the Assessment of Prognostic Risk Observational Survey. J Hypertens 2002; 20: 1307-1314.

23. Selvin E, Steffes MW, Zhu H, Matsushita K, Wagenknecht L, Pankow J, et 
al. Brancati Glycated hemoglobin, diabetes, and cardiovascular risk in nondiabetic adults. N Engl J Med. 2010 Mar 4; 362(9): 800-811.

24. Safar ME, Levy BI, Struijker-Boudier H. Current perspectives on arterial stiffness and pulse pressure in hypertension and cardiovascular diseases. Circulation 2003;107:2864-2869.

25. Vasan RS, Larson MG, Leip EP, et al. Impact of high-normal blood pressure on the risk of cardiovascular disease. N Engl J Med 2001; 345(18): 1291-1297.

26. Kshisagar AV, Carpenter M, Bang H, Wyatt SB, Colindres RE. Blood pressure usually considered normal is associated with an elevated risk of cardiovascular disease. Am J Med 2006; 119: 133-141.

27. Zanchetti A, Hansson L, Dahlof B, et al. Effects of individual risk factors on the incidence of cardiovascular events in the treated hypertensive patients of the Hypertension Optimal Treatment Study. HOT Study Group. J Hypertens 2001; 19: 1149-1159.

28. Mancia G, Laurent S, Agabiti-Rosei E, et al. Reappraisal of European Guidelines on Hypertension Management. A European Society of Hypertension Task Force document. J Hypertens 2009; 27: 2121-2158.

29. D'Agostino RB Sr, Vasan RS, Pencina MJ, et al. General cardiovascular risk profile for use in primary care: the Framingham Heart Study. Circulation 2008 12; 117(6): 743-753.

30. Graham I, Atar D, Borch-Johnsen K, et al. European guidelines on cardiovascular disease prevention in clinical practice: executive summary. Fourth Joint Task Force of the European Society of Cardiology and other Societies on Cardiovascular Disease Prevention in Clinical Practice (constituted by representatives of nine societies and by invited experts). Eur J Cardiovasc Prev Rehabil 2007; 14 (Suppl 2): S1-S113.

31. Standl E, Bartnik M, Van den Berghe G, et al. Task Force on Diabetes and Cardiovascular Diseases of the European Society of Cardiology (ESC); European Association for the Study of Diabetes (EASD). Guidelines on diabetes, pre-diabetes, and cardiovascular diseases: executive summary: The Task Force on Diabetes and Cardiovascular Diseases of the European Society of Cardiology (ESC) and of the European Association for the Study of Diabetes (EASD). Eur Heart J 2007; 28: 88-136.

32. Magnussen EB, Vatten LJ, Smith GD, Romundstad PR. Hypertensive disorders in pregnancy and subsequently measured cardiovascular risk factors. Obstet Gynecol. 2009; 114: 961-970.

33. Gu D, Chen J, Wu X, et al. Prehypertension and risk of cardiovascular disease in Chinese adults. J Hypertens 2009; 27: 721-729.

\section{Capítulo 4 - Decisão terapêutica e metas}

A decisão terapêutica deve ser baseada no risco cardiovascular considerando-se a presença de fatores de risco, lesão em órgão-alvo e/ou doença cardiovascular estabelecida, e não apenas no nível da PA.

\section{1 - Abordagem para níveis de PA entre 130-139/85-89 $\mathrm{mmHg}$}

A justificativa para intervenções em pessoas com esses níveis de PA baseia-se no fato de que metade do ônus atribuível ocorre para pressões sistólicas entre 130 e 150 $\mathrm{mmHg}$, isto é, incluindo o comportamento limítrofe de $\mathrm{PA}^{1}$ (Grau B).

Uma importante consideração a ser feita é que nessa faixa de PA há uma grande parcela de indivíduos com doença cardiovascular e renal estabelecidas, além de boa parte de indivíduos com diabetes, doença renal, múltiplos fatores de risco cardiovascular e síndrome metabólica.

Assim, parece pertinente que esses indivíduos recebam tratamento medicamentoso. Deve-se, entretanto, considerar que foi demonstrado benefício dessa intervenção, em estudo incluindo pacientes de alto risco com doença coronariana ${ }^{2}$ ou em outro que avaliou pacientes com doença encefálica prévia $^{3}$, e finalmente, em indivíduos diabéticos tipo $2^{4}$. Alguns estudos aleatórios e controlados contra placebo sugerem que a instituição de tratamento medicamentoso em pacientes de alto risco reduz os eventos cardiovasculares quando há valores de PA entre 130-139 /85-89 mm Hg $^{5-14}$ (Grau A).

\section{2 - Abordagem em pacientes hipertensos com risco cardiovascular médio, alto e muito alto}

A instituição precoce do tratamento medicamentoso visa à proteção dos órgãos-alvos; redução do impacto causado pela elevação da $\mathrm{PA}$; redução do impacto causado pela presença de fatores de risco associados e na progressão do processo aterosclerótico.

\section{3 - Racional para decisão terapêutica}

Modificações de estilo de vida podem se refletir no retardo do desenvolvimento da HAS em indivíduos com pressão limítrofe. Têm também impacto favorável nos fatores de risco envolvidos no desenvolvimento ou agravo da hipertensão ${ }^{12-15}$ (Grau B).

Assim, devem ser indicadas indiscriminadamente.

O período de tempo recomendado para as medidas de modificação de estilo de vida isoladamente em pacientes hipertensos e naqueles com comportamento limítrofe da pressão arterial, com baixo risco cardiovascular, é de no máximo seis meses.

Caso os pacientes não estejam respondendo a essas medidas após três meses, uma nova avaliação, em seis meses, deve ser feita para confirmar o controle da PA. Se esse benefício não for confirmado, já está indicada a instituição do tratamento medicamentoso em associação.

Em pacientes com riscos médios, altos ou muito altos, independentemente da PA, a abordagem deve ser combinada (não-medicamentosa e medicamentosa) para se atingir a meta preconizada o mais precocemente.

Para a decisão terapêutica, considerar a tabela 1, e para as metas de PA nas diferentes categorias de risco considerar a tabela 2 .

Novos estudos não demostraram haver benefícios com reduções mais intensas da PA como se julgava anteriormente $^{16,17}$ (Grau A). 


\section{Diretrizes}

Tabela 1 - Decisão terapêutica

\begin{tabular}{lc}
\hline Categoria de risco & Considerar \\
\hline Sem risco adicional & Tratamento não-medicamentoso isolado \\
\hline Risco adicional baixo & $\begin{array}{c}\text { Tratamento não-medicamentoso isolado por } \\
\text { até 6 meses. Se não atingir a meta, associar } \\
\text { tratamento medicamentoso }\end{array}$ \\
\hline $\begin{array}{l}\text { Risco adicional médio, alto } \\
\text { e muito alto }\end{array}$ & Tratamento não-medicamentoso + \\
\end{tabular}

Tabela 2 - Metas a serem atingidas em conformidade com as características individuais

\begin{tabular}{|c|c|}
\hline Categoria & Considerar \\
\hline $\begin{array}{l}\text { Hipertensos estágios } 1 \text { e } 2 \text { com risco } \\
\text { cardiovascular baixo e médio }\end{array}$ & $<140 / 90 \mathrm{mmHg}$ \\
\hline $\begin{array}{l}\text { Hipertensos e comportamento limítrofe com } \\
\text { risco cardiovascular alto e muito alto, ou com } 3 \\
\text { ou mais fatores de risco, DM, SM ou LOA }\end{array}$ & \multirow{2}{*}{$130 / 80 \mathrm{mmHg}$} \\
\hline $\begin{array}{l}\text { Hipertensos com insuficiência renal com } \\
\text { proteinúria }>1,0 \mathrm{~g} / \mathrm{l}\end{array}$ & \\
\hline
\end{tabular}

DM - diabetes melito; SM - síndrome metabólica; LOA - lesões em órgãos-alvo.

\section{4 - Justificativa para as metas de pressão a serem} atingidas

\subsection{1 - Hipertensão sistólica isolada (HSI)}

Em pacientes com hipertensão sistólica isolada ( $\mathrm{HSI}$ ), a PA será dependente do risco cardiovascular, isto é, naqueles pacientes sem fator de risco adicional ou com risco cardiovascular baixo ou médio a meta deve ser inferior a 140 $\mathrm{mmHg}$. Já nos pacientes com risco cardiovascular alto ou muito alto, a meta deve ser igual a $130 \mathrm{mmHg}$.

\subsection{2 - Hipertrofia ventricular esquerda}

Tem sido observado que o controle rigoroso da PA sistólica (130 mmHg) em pacientes hipertensos não-diabéticos com pelo menos um fator de risco associado diminuiu a chance de hipertrofia ventricular esquerda, comparando-se com o controle não-rigoroso (PAS $<140 \mathrm{mmHg})^{18}$ (Grau B).

\subsubsection{Síndrome metabólica (SM)}

Embora não existam evidências quanto à indicação do tratamento medicamentoso em pacientes com SM e PA limítrofe, é importante frisar que esta condição está presente em cerca de $30 \%$ dos indivíduos com HAS, sendo considerado um preditor independente de eventos cardiovasculares, mortalidade geral e cardiovascular ${ }^{19-21}$ (Grau A) 22,23 (Grau C).

O objetivo do tratamento é a redução do risco para eventos cardiovasculares, e, portanto, a presença de três ou mais fatores de risco ou lesões em órgãos-alvo já sinaliza $\mathrm{o}$ alto risco para doença cardiovascular ${ }^{21,22}$. Desta forma, pacientes com SM devem ser abordados de acordo com o risco cardiovascular.

\subsection{4 - Diabéticos}

De acordo com as recomendações da American Diabetes Association - ADA de 2009, pacientes diabéticos com PA entre 130 e $139 \mathrm{mmHg}$ e $80-89 \mathrm{mmHg}$ podem ser tratados com modificação de estilo de vida por um tempo máximo de três meses. Se após esse período não houver resposta adequada, o tratamento medicamentoso deve ser iniciado.

Pacientes com PA $\geq 140 / 90 \mathrm{mmHg}$ no momento do diagnóstico ou durante o seguimento devem receber tratamento medicamentoso em conjunto com modificação do estilo de vida ${ }^{24}$ (Grau D). Sugere-se que a meta de PA seja 130/80 $\mathrm{mmHg}$, pois o estudo recentemente publicado não mostrou benefícios com reduções mais rigorosas da $\mathrm{PA}^{16}$.

\subsubsection{Doença arterial periférica (DAP)}

Embora não haja consenso quanto à meta mais adequada em pacientes com DAP, em geral esses pacientes apresentam lesões em outros territórios vasculares, apresentando, portanto, alto risco cardiovascular.

\subsection{6 - Curva J}

De acordo com revisão de Rosendorff e Black ${ }^{25}$ parece adequado evitar reduções importantes da PA diastólica (PAD) ( $<65 \mathrm{mmHg}$ ) ou de forma muito rápida quando essa pressão inicial é muito elevada em pacientes com doença arterial coronariana oclusiva.

Inúmeros estudos documentaram uma relação inversa entre a PAD e a doença coronária. Em muitos deles os efeitos da "curva J" foram registrados em variações fisiológicas da PAD, ou seja abaixo de 70 a $80 \mathrm{mmHg}^{25}$ (Grau A). Para a mesma redução da PAD há pouca evidência do efeito "curva J" sobre outros órgãos-alvo, como cérebro e rim. Há também pouca evidência desse fenômeno envolvendo a PA sistólica ${ }^{26}$.

\section{Referências}

1. Rodgers A, Ezzati M, Vander Hoorn S, Lopez AD, Lin RB, Murray CJ; Comparative Risk Assessment Collaborating Group. Distribution of major health risks: findings from the Global Burden of Disease study. PLoS Med 2004 Oct; 1(1): e27.

2. Heart Outcomes Prevention Evaluation Study Investigators. Effects of an angiotensin converting enzyme inhibitor, ramipril, on cardiovascular events in high risk patients. N Engl J Med 2000; 342: 145-153.

3. PROGRESS Collaborative Group. Randomised trial of a perindopril based blood pressure lowering regimen among 6,105 individuals with previous stroke or transient ischaemic attack. Lancet 2001; 358: 1033-1041.

4. ADVANCE Collaborative Group. Effects of a fixed combination of perindopril and indapamide on macrovascular and microvascular outcomes in patients with type 2 diabetes mellitus (the ADVANCE trial): a randomised controlled trial. Lancet 2007; 370: 829-840. 
5. The European Reduction of Cardiac Events with Perindopril in Stable Coronary Artery Disease Investigators. Efficacy of perindopril in reduction of cardiovascular events among patients with stable coronary artery disease: randomized, double-blind, placebo-controlled multicentre trial (EUROPA). Lancet 2003; 362: 782-788.

6. Hansson L, Zanchetti A, Carruthers SG, Dahlöf B, Elmfeldt D, Julius S, et al. Effects of intensive blood pressure lowering and low-dose aspirin in patients with hypertension: principal results of the Hypertension Optimal Treatment (HOT) randomised trial. HOT Study Group. Lancet 1998; 351: 1755-1762.

7. Bangalore S, Messerli FH, Wun C, Zuckerman AL, DeMicco D, Kostis JB, LaRosa JC, Treating to New Targets Steering Committee and Investigators. J-Curve revisited: an analysis of the Treating to New Targets (TNT) Trial. J Am Coll Cardiol 2009; 53: A217.

8. Weber MA, Julius S, Kjeldsen SE, Brunner HR, Ekman S, Hansson L, et al. Blood pressure dependent and independent effects of antihypertensive treatment on clinical events in the VALUE Trial. Lancet 2004; 363 2049-2051.

9. Mancia G, Messerli F, Bakris G, Zhou Q, Champion A, Pepine CJ. Blood pressure control and improved cardiovascular outcomes in the International Verapamil SR-Trandolapril Study. Hypertension 2007; 50: 299-305.

10. Sleight P, Redon J, Verdecchia P, Mancia G, Gao P, Fagard R, et al. ONTARGET investigators. Prognostic value of blood pressure in patients with high vascular risk in the Ongoing Telmisartan Alone and in combination with Ramipril Global Endpoint Trial study. J Hypertens 2009; 27:1360-1369.

11. Redon J, Sleight P, Mancia G, Gao O, Verdecchia P, Fagard R, et al. Safety and efficacy of aggressive blood pressure lowering among patients with diabetes: subgroup analyses from the ONTARGET trial. J Hypertens 2009; 27 (Suppl 4): S16.

12. Moore LL, Visioni AJ, Qureshi MM, et al. Weight loss in overweight adults and the long-term risk of hypertension: the Framingham study. Arch Intern Med 2005, 165: 1298-1303

13. Halperin RO, Sesso HD, Ma J, et al. Dyslipidemia and the risk of incident hypertension in men. Hypertension 2006, 47: 45-50.

14. Haffner SM, Miettinen H, Gaskill SP, Stern MP. Metabolic precursors of hypertension. The San Antonio Heart Study. Arch Intern Med 1996, 156: 1994-2001.

15. Zhang Y, Lee ET, Devereux RB, Yeh J, Best LG, Fabsitz RR, et al. Prehypertension, diabetes, and cardiovascular disease risk in a population based sample: the Strong Heart Study. Hypertension 2006; 47: 410- 414.

16. The ACCORD Study Group. Effects of intensive blood-pressure control in type 2 Diabetes mellitus. N Engl J Med 2010. DOI:10.1056/NEJMoa1001286.

17. Pepine CJ, Handberg EM, Cooper-DeHoff RM, et al., for the INVEST Investigators. A calcium antagonist vs. a non-calcium antagonist hypertension treatment strategy for patients with coronary artery disease. The International Verapamil-Trandolapril Study (INVEST): a randomized controlled trial. JAMA 2003; 290: 2805-2816.

18. Verdecchia P, Staessen JA, Angeli F, de Simone G, Achilli A, Ganau A, et al On behalf of the Cardio-Sis investigators. Usual versus tight control of systolic blood pressure in non-diabetic patients with hypertension (Cardio-Sis): an open-label randomised trial. Lancet 2009; 374: 525-533.

19. Schillaci G, Pirro M, Vaudo G, Gemelli F, Marchesi S, Porcellati C, et al. Prognostic value of the metabolic syndrome in essential hypertension. J Am Coll Cardiol 2004; 43: 1817-1822.

20. Dekker JM, Girman C, Rhodes T, Nijpels G, Stehouwer CD, Bouter LM, et al Metabolic syndrome and 10-year cardiovascular disease risk in the Hoorn Study. Circulation 2005; 112: 666-673.

21. Mancia G, Bombelli M, Corrao G, Facchetti R, Madotto F, Giannattasio C, etal Metabolic syndrome in the Pressioni Arteriose Monitorate E Loro Associazion (PAMELA) study: daily life blood pressure, cardiac damage, and prognosis. Hypertension 2007; 49: 40-47.

22. Redon J, Cifkova R, Laurent S, Nilsson P, Narkiewicz K, Erdine S, et al. On behalf of the Scientific Council of the European Society of Hypertension. The metabolic syndrome in hypertension: European society of hypertension position statement. J Hypertens 2008, 26: 1891-1900.

23. Grundy SM, Cleeman JI, Daniels SR, Donato KA, Eckel RH, Franklin BA Gordon DJ, et al. Diagnosis and management of the metabolic syndrome. An American Heart Association/National Heart, Lung, and Blood Institute Scientific Statement. Circulation 2005 ,112: 2735-2752.

24. Standards of Medical Care in Diabetes - 2009. Position Statement. Diabetes Care 2009; 32, Suppl 1: S13-S61.

25. Rosendorff C, Black HR. Evidence for a lower target blood pressure for people with heart disease. Curr Opin Cardiol 2009, 24: 318-324.

26. Messerli FH, Panjrath GS. J-Curve between blood pressure and coronary artery disease or essential hypertension: exactly how essential? J Am Coll Cardiol 2009, 54; 1827-1834.

\section{Capítulo 5 - Tratamento não- medicamentoso e abordagem multiprofissional}

Com relação ao tratamento não-medicamentoso, devemos considerar:

\section{1 - Controle de peso}

A relação entre os aumentos de peso e da pressão arterial é quase linear, sendo observada em adultos ${ }^{1}$ e adolescentes ${ }^{2}$. Perdas de peso e da circunferência abdominal correlacionamse com reduções da PA e melhora de alterações metabólicas associadas $^{2,3}$. Assim, as metas antropométricas a serem alcançadas são o índice de massa corporal (IMC) menor que $25 \mathrm{~kg} / \mathrm{m}^{2}$ e a circunferência abdominal $<102 \mathrm{~cm}$ para os homens e $<88$ para as mulheres ${ }^{4}$.
O sucesso do tratamento depende fundamentalmente de mudança comportamental e da adesão a um plano alimentar saudável ${ }^{5}$. Mesmo uma modesta perda do peso corporal está associada a reduções na PA em pessoas com sobrepeso, mas o alcance das metas deve ser perseguido ${ }^{6}$. A utilização de dietas radicais, como as ricas em carboidratos ou em gorduras, deve ser desencorajada, pois não são sustentáveis a longo prazo e resultam invariavelmente em abandono de tratamento $^{7}$. O acompanhamento dos indivíduos após o emagrecimento deve ser estimulado com o objetivo de evitar o reganho de peso $^{8,9}$. Foi demonstrado que manter o IMC abaixo de $25 \mathrm{~kg} / \mathrm{m}^{2}$ preveniu em $40 \%$ o desenvolvimento de HAS em mulheres, em um estudo com seguimento médio de 14 anos $^{10}$.

Controle de peso - grau de recomendação I e nível de evidência A. 


\section{Diretrizes}

A cirurgia bariátrica é considerada o tratamento efetivo para obesidade moderada a grave ${ }^{11}$. Em pacientes com obesidade grave, a cirurgia bariátrica reduz a mortalidade e tem potencial para controlar condições clínicas como HAS e diabetes melito tipo $2^{12,13}$. Assim como no tratamento convencional, é necessário seguimento dos indivíduos a longo prazo no sentido de evitar o reganho de peso ${ }^{14}$.

Cirurgia bariátrica para hipertensos com obesidade grave ou moderada (com distúrbios metabólicos associados): grau de recomendação I e nível de evidência A.

\section{2 - Estilo alimentar (dietas DASH, mediterrânea, vegetariana e outras)}

O padrão dietético DASH (Dietary Approaches to Stop Hypertension), rico em frutas, hortaliças, fibras, minerais e laticínios com baixos teores de gordura, tem importante impacto na redução da $\mathrm{PA}^{15}$. Um alto grau de adesão a esse tipo de dieta reduziu em 14\% o desenvolvimento de hipertensão ${ }^{10}$. Os benefícios sobre a PA têm sido associados ao alto consumo de potássio, magnésio e cálcio nesse padrão nutricional ${ }^{16}$. A dieta DASH potencializa ainda o efeito de orientações nutricionais para emagrecimento, reduzindo também biomarcadores de risco cardiovascular ${ }^{17}$. O quadro 1 demonstra como adotar uma dieta ao estilo DASH.

Dieta DASH - grau de recomendação I e nível de evidência A.

A dieta do Mediterrâneo associa-se também à redução da $\mathrm{PA}^{18}$. O alto consumo de frutas e hortaliças revelou ser inversamente proporcional aos níveis de PA, mesmo com um mais alto percentual de gordura ${ }^{19}$. A substituição do excesso de carboidratos nesta dieta por gordura insaturada induz à mais significativa redução da $\mathrm{PA}^{20,21}$.

Dieta mediterrânea para hipertensos - grau de recomendação Ila; nível de evidência $B$.

Dietas vegetarianas são inversamente associadas com a incidência de doenças cardiovasculares. Isto se explica em razão de fornecerem menor quantidade de nutrientes, como gordura saturada e colesterol ${ }^{22}$. Entretanto, essas dietas são deficientes em micronutrientes como ferro, vitamina B12 e cálcio, sendo necessária a suplementação para atender às recomendações vigentes ${ }^{23}$. As deficiências de micronutrientes, muitas vezes observadas em lacto-vegetarianos, têm sido identificadas como fatores predisponentes à HAS em adultos seguidores desse estilo alimentar ${ }^{24}$. Fato relevante é a observação de que os vegetarianos apresentam, em geral, menor IMC, fato que, independentemente do tipo de dieta, se associa a menor $\mathrm{PA}^{25-27}$.

Dieta vegetariana para hipertensos - grau de recomendação Ila; nível de evidência $B$.

Dietas da moda e programas de emagrecimento comercialmente disponíveis, avaliados comparativamente, demostraram baixa adesão a longo prazo ${ }^{28}$. Apesar de a redução de peso obtida associar-se a redução da $\mathrm{PA}^{29}$, há evidências de que dietas com altos teores de gordura associam-se com maior risco de infarto do miocárdio e mortalidade cardiovascular, não havendo razões para a sua recomendação ${ }^{30,31}$.

Dietas comerciais (da moda) para hipertensos - grau de recomendação III; nível de evidência D.

\section{3 - Redução do consumo de sal}

A relação entre PA e a quantidade de sódio ingerido é heterogênea. Este fenômeno é conhecido como sensibilidade ao sal. Indivíduos normotensos com elevada sensibilidade à ingestão de sal apresentaram incidência cinco vezes maior de HAS, em 15 anos, do que aqueles com baixa sensibilidade ${ }^{32}$. Alguns trabalhos demonstraram que o peso do indivíduo ao nascer tem relação inversa com a sensibilidade ao sal e está diretamente relacionado com o ritmo de filtração glomerular e HAS na idade adulta ${ }^{33}$. Uma dieta contendo cerca de $1 \mathrm{~g}$ de sódio promoveu rápida e importante redução de PA em hipertensos resistentes ${ }^{34}$. Apesar das diferenças individuais de sensibilidade, mesmo modestas reduções na quantidade de sal são, em geral, eficientes em reduzir a $\mathrm{PA}^{35}$. Tais evidências reforçam a necessidade de orientação a hipertensos e "limítrofes" quanto aos benefícios da redução de sódio na dieta. A necessidade nutricional de sódio para os seres humanos é de $500 \mathrm{mg}$ (cerca de 1,2 g de sal), tendo sido definido recentemente, pela Organização Mundial de Saúde, em 5 g de cloreto de sódio ou sal de cozinha (que corresponde a 2 g de sódio) a quantidade considerada máxima saudável para ingestão alimentar diária. O consumo médio do brasileiro corresponde ao dobro do recomendado ${ }^{36}$.

Dieta hipossódica - grau de recomendação Ilb e nível de evidência B.

\section{Quadro 1 - Como recomendar uma dieta ao estilo DASH}

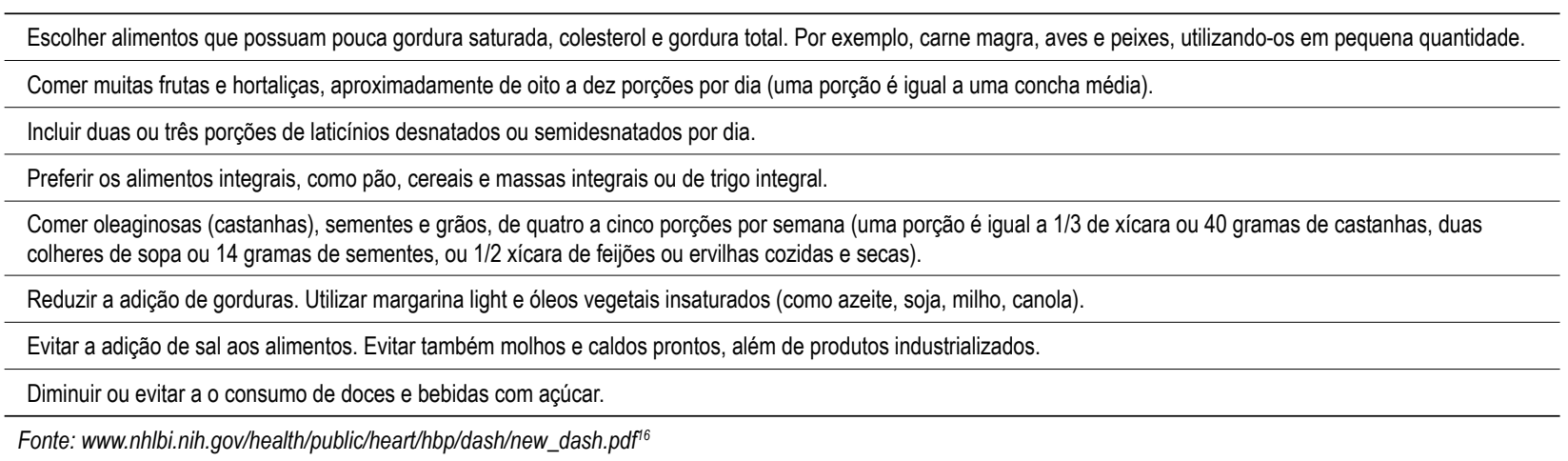




\section{4 - Ácidos graxos insaturados}

Observa-se uma discreta redução da PA com a suplementação de óleo de peixe (ômega 3) em altas doses diárias e predominantemente nos idosos ${ }^{37,38}$. As principais fontes dietéticas de ácidos graxos monoinsaturados (oleico) são óleo de oliva, óleo de canola, azeitona, abacate e oleaginosas (amendoim, castanhas, nozes, amêndoas) ${ }^{39}$. Temse demonstrado que a ingestão de óleo de oliva pode reduzir a PA, principalmente devido ao elevado teor de ácido oléico ${ }^{40}$.

\section{5 - Fibras}

As fibras são classificadas em solúveis e insolúveis. As solúveis são representadas pelo farelo de aveia, pectina (frutas) e pelas gomas (aveia, cevada e leguminosas: feijão, grão de bico, lentilha e ervilha). As fibras insolúveis são representadas pela celulose (trigo), hemicelulose (grãos) e lignina (hortaliças). A recomendação de ingestão de fibra alimentar total para adultos é de 20 a $30 \mathrm{~g} / \mathrm{dia}, 5$ a $10 \mathrm{~g}$ devendo ser solúveis ${ }^{22}$. O betaglucano, presente na aveia, determina discreta diminuição da PA em obesos, efeito nãoobservado em indivíduos com peso normal ${ }^{41}$.

\section{6 - Proteína de soja}

As principais fontes de soja na alimentação são: feijão de soja, queijo de soja (tofu), farinha, leite de soja e o concentrado proteico da soja. O molho de soja (shoyu) industrializado contém elevado teor de sódio, devendo ser evitado. A substituição isocalórica de parte da proteína alimentar por um composto de soja associada a outras medidas nãomedicamentosas promoveu queda da PA em mulheres após a menopausa ${ }^{42}$.

\section{7 - Oleaginosas}

Há controvérsias sobre os efeitos da suplementação das diferentes castanhas em relação à redução da $\mathrm{PA}^{43,44}$. O consumo de oleaginosas pode trazer benefícios à saúde se integradas a um plano alimentar saudáve ${ }^{45}$.

\section{8 - Laticínios}

O consumo de duas ou mais porções diárias de laticínios magros correlacionou-se a menor incidência de HAS. Tais benefícios provavelmente estão associados ao maior aporte de cálcio ${ }^{46,47}$

\section{9 - Alho}

O alho, cujo principal componente ativo é a alicina, tem ação metabólica, podendo atuar na coagulação, aumentando o tempo de sangramento e promovendo discreta redução de pressão ${ }^{48,49}$.

\subsection{0 - Café e chá}

Os polifenóis contidos no café e em alguns tipos de chás têm potenciais propriedades vasoprotetoras ${ }^{50,51}$. Os riscos de elevação da PA causados pela cafeína, em doses habituais, são irrelevantes.

\subsection{1 - Chocolate amargo}

O chocolate amargo (com alto teor de cacau) pode promover discreta redução da PA, devido às altas concentrações de polifenóis ${ }^{52}$.

\subsection{2 - Álcool}

Há associação entre a ingestão de álcool e alterações de PA dependentes da quantidade ingerida. Claramente, uma quantidade maior de etanol eleva a PA e está associada a maiores morbidade e mortalidade cardiovasculares. Por outro lado, as evidências de correlação entre uma pequena ingestão de álcool e a consequente redução da pressão arterial ainda são frágeis e necessitam de comprovações. Em indivíduos hipertensos, a ingestão de álcool, agudamente e dependentemente da dose, reduz a PA, porém ocorre elevação algumas horas após o seu consumo. Tendo em vista a controvérsia em relação à segurança e ao benefício cardiovascular de baixas doses, assim como a ação nefasta do álcool na sociedade, devemos orientar aqueles que têm o hábito de ingerir bebidas alcoólicas a não ultrapassarem $30 \mathrm{~g}$ de etanol ao dia, para homens, de preferência nãohabitualmente; sendo a metade dessa quantidade a tolerada para as mulheres. As quantidades dos mais comuns tipos de bebidas que contêm $30 \mathrm{~g}$ de etanol estão colocadas na tabela 1. Para aqueles que não têm o hábito, não se justifica recomendar que o façam ${ }^{53-55}$.

Redução do consumo de álcool para hipertensos - grau de recomendação Ilb, nível de evidência $B$. Recomendação de consumo de álcool para hipertensos: grau de recomendação III, nível de evidência D.

\subsection{3 - Atividade física}

Ensaios clínicos controlados demonstraram que os exercícios aeróbios (isotônicos), que devem ser complementados pelos resistidos, promovem reduções de PA, estando indicados para a prevenção e o tratamento da HAS $^{56,60}$. Para manter uma boa saúde cardiovascular e qualidade de vida, todo adulto deve realizar, pelo menos cinco vezes por semana, 30 minutos de atividade física moderada de forma contínua ou acumulada, desde que em condições de realizá-la. A frequência cardíaca (FC) de pico deve ser avaliada por teste ergométrico, sempre que possível, e na vigência da medicação cardiovascular de uso constante. Na falta do teste, a intensidade do exercício pode ser controlada objetivamente pela ventilação, sendo a atividade considerada predominantemente aeróbia quando o indivíduo permanecer discretamente ofegante, conseguindo falar frases completas sem interrupções. Embora haja possibilidade de erros com a utilização de fórmulas que consideram a idade, na impossibilidade de utilização da ergometria pode-se usar a fórmula FC máxima $=220$ idade, exceto em indivíduos em uso de betabloqueadores e/ou inibidores de canais de cálcio não-diidropiridínicos.

A recomendação é de que inicialmente os indivíduos realizem atividades leves a moderadas ${ }^{61,62}$. Somente após estarem adaptados, caso julguem confortável e não haja nenhuma contraindicação, é que devem passar às vigorosas ${ }^{63-65}$. 


\section{Diretrizes}

Tabela 1 - Características das principais bebidas alcoólicas e teor de etanol por quantidade definida

\begin{tabular}{lcccc}
\hline Bebida & $\begin{array}{c}\text { \% de etanol } \\
\text { ('GL Gay Lussac) }\end{array}$ & Quantidade de etanol (g) & $\begin{array}{c}\text { Volume para } 30 \mathrm{~g} \\
\text { de etanol }\end{array}$ & Volume aproximado \\
\hline Cerveja & $\begin{array}{c}\sim 6 \% \\
(3-8)\end{array}$ & $6 \mathrm{~g} / 100 \mathrm{ml} \times 0,8^{*}=4,8 \mathrm{~g}$ & $625 \mathrm{ml}$ & $\begin{array}{c}\sim 2 \text { latas }(350 \times 2=700 \mathrm{ml}) \\
\text { ou } 1 \mathrm{garrafa}(650 \mathrm{ml})\end{array}$ \\
\hline Vinho & $\begin{array}{c}\sim 12 \% \\
(5-13)\end{array}$ & $12 \mathrm{~g} / 100 \mathrm{ml} \times 0,8^{*}=9,6 \mathrm{~g}$ & $312,5 \mathrm{ml}$ & $\begin{array}{r}\sim \text { taças de } 150 \mathrm{ml} \text { ou } \\
1 \text { taça de } 300 \mathrm{ml}\end{array}$ \\
\hline Uisque, vodka, aguardente & $\begin{array}{c}\sim 40 \% \\
(30-50)\end{array}$ & $40 \mathrm{~g} / 100 \mathrm{ml} \times 0,8^{*}=32 \mathrm{~g}$ & $93,7 \mathrm{ml}$ & $\begin{array}{c}2 \text { doses de } 50 \mathrm{ml} \text { ou } \\
3 \text { doses de } 30 \mathrm{ml}\end{array}$ \\
\hline
\end{tabular}

*Densidade do etanol.

Tabela 2 - Algumas modificações de estilo de vida e redução aproximada da pressão arterial sistólica*

\begin{tabular}{|c|c|c|}
\hline Modificação & Recomendação & Redução aproximada na PAS** \\
\hline Controle de peso & $\begin{array}{l}\text { Manter o peso corporal na faixa normal } \\
\text { (índice de massa corporal entre } 18,5 \text { a } 24,9 \mathrm{~kg} / \mathrm{m}^{2} \text { ) }\end{array}$ & $\begin{array}{l}5 \text { a } 20 \mathrm{mmHg} \text { para cada } \\
10 \mathrm{~kg} \text { de peso reduzido }\end{array}$ \\
\hline Padrão alimentar & $\begin{array}{l}\text { Consumir dieta rica em frutas e vegetais e alimentos com baixa densidade } \\
\text { calórica e baixo teor de gorduras saturadas e totais. } \\
\text { Adotar dieta DASH }\end{array}$ & 8 a $14 \mathrm{mmHg}$ \\
\hline Redução do consumo de sal & $\begin{array}{l}\text { Reduzir a ingestão de sódio para não mais que } 2 \mathrm{~g} \\
(5 \mathrm{~g} \text { de sal/dia) }=\text { no máximo } 3 \text { colheres de café rasas } \\
\text { de sal }=3 \mathrm{~g}+2 \mathrm{~g} \text { de sal dos próprios alimentos }\end{array}$ & 2 a $8 \mathrm{mmHg}$ \\
\hline $\begin{array}{l}\text { Moderação no consumo de } \\
\text { álcool }\end{array}$ & Limitar o consumo a $30 \mathrm{~g} / \mathrm{dia}$ de etanol para os homens e $15 \mathrm{~g} / \mathrm{dia}$ para mulheres & 2 a $4 \mathrm{mmHg}$ \\
\hline Exercício físico & $\begin{array}{l}\text { Habituar-se à prática regular de atividade física aeróbica, como caminhadas por, pelo } \\
\text { menos, } 30 \text { minutos por dia, } 3 \text { vezes/semana, para prevenção e diariamente para tratamento }\end{array}$ & 4 a $9 \mathrm{mmHg}$ \\
\hline
\end{tabular}

${ }^{*}$ Associar abandono do tabagismo para reduzir o risco cardiovascular. ${ }^{*}$ Pode haver efeito aditivo para algumas das medidas adotadas.

Sugestão da intensidade de exercícios isotônicos segundo a frequência cardíaca:

Atividades leves - Mantém-se com até 70\% da FC máxima ou de pico, recomendando-se a faixa entre $60 \%$ e $70 \%$, quando se objetiva o treinamento efetivo eminentemente aeróbio.

Atividades moderadas - Mantém-se entre $70 \%$ e $80 \%$ da FC máxima ou de pico, sendo considerada a faixa ideal para o treinamento que visa a prevenção e o tratamento da hipertensão arterial.

Atividades vigorosas - Mantém-se acima de $80 \%$ da FC máxima ou de pico, propondo-se a faixa entre $80 \%$ e $90 \%$ quando se objetiva o treinamento com expressivo componente aeróbio, desenvolvido já com considerável participação do metabolismo anaeróbio.

Em relação aos exercícios resistidos, recomenda-se que sejam realizados entre 2 e 3 vezes por semana, por meio de 1 a 3 séries de 8 a 15 repetições, conduzidas até a fadiga moderada (parar quando a velocidade de movimento diminuir).

Recomenda-se a avaliação médica antes do início de um programa de treinamento estruturado e sua interrupção na presença de sintomas. Em hipertensos, a sessão de treinamento não deve ser iniciada se as pressões arteriais sistólica e diastólica estiverem superiores a 160 e/ou 105 $\mathrm{mmHg}$ respectivamente.
Atividade física: grau de recomendação I e nível de evidência A.

\subsection{4 - CPAP e outras formas de tratamento da síndrome da apneia/hipopneia obstrutiva do sono (SAHOS)}

O uso do CPAP (pressão positiva contínua nas vias aéreas) está indicado para a correção dos distúrbios ventilatórios e metabólicos da SAHOS grave. Há indícios de que o uso desse dispositivo pode contribuir para o controle da PA, queda do descenso da pressão durante o sono, melhora da qualidade de vida e redução dos desfechos cardiovasculares ${ }^{66-68}$. Não existem evidências quanto aos efeitos hipotensores de outras formas de tratamento da SAHOS.

CPAP na SAHOS grave - grau de recomendação I e nível de evidência $A$.

\subsection{5 - Controle do estresse psicossocial}

Fatores psicossociais, econômicos, educacionais e o estresse emocional participam do desencadeamento e manutenção da HAS e podem funcionar como barreiras para a adesão ao tratamento e mudança de hábitos ${ }^{69-71}$. Diferentes técnicas de controle do estresse têm sido avaliadas, porém com resultados conflitantes. Meditação ${ }^{72}$, musicoterapia ${ }^{73}$, biofeedback, yoga, entre outras técnicas de controle do estresse, foram capazes de reduzir discretamente a PA de hipertensos ${ }^{74,75}$. 
Técnicas de controle do estresse - grau de recomendação Ila e nível de evidência B.

\subsection{6 - Respiração lenta}

A utilização da técnica de respiração lenta, com dez respirações por minuto por 15 minutos diários, com ou sem o uso de equipamentos, tem mostrado reduções da $\mathrm{PA}^{76-78}$.

Respiração lenta - grau de recomendação lla e nível de evidência B.

\subsection{7 - Cessação do tabagismo}

A cessação do tabagismo constitui medida fundamental e prioritária na prevenção primária e secundária das doenças cardiovasculares e de diversas outras doenças ${ }^{79}$.

Não há, entretanto, evidências de que, para o controle de PA, haja benefícios.

\section{Referências}

1. Willett WC, Dietz WH, Colditz GA. Primary Care: Guidelines for Healthy Weight. N Engl J Med 1999; 341: 427-434.

2. Guimarães ICB, de Almeida A, Santos AS, Barbosa DBV, Guimarães AC Pressão arterial: efeito do índice de massa corporal e da circunferência abdominal em adolescentes. Arq Bras Cardiol 2008; 90(6): 426-432.

3. Stevens VJ, Obarzanek E, Cook NR, Lee IM, Appel LJ, Smith West D, et al. Long-term weight loss and changes in blood pressure: results of the trials of hypertension prevention, phase II. Ann Intern Med 2001; 134: 1-11.

4. I Diretriz Brasileira de Diagnóstico e Tratamento da Síndrome Metabólica. Arq Bras Cardiol 2005: 84, S I:1-2.

5. Greenberg I, Stampfer MJ, Schwarzfuchs D, Shai I; DIRECT Group. Adherence and success in long-term weight loss diets: the dietary intervention randomized controlled trial (DIRECT). Am Coll Nutr 2009; 28(2): 159-168.

6. Hermansen K. Diet, blood pressure and hypertension. Br J Nutr 2000 Mar; 83 (Suppl 1): S113-119.

7. Alhassan S, Kim S, Bersamin A, King AC, Gardner CD. Dietary adherence and weight loss success among overweight women: results from the A TO Z weight loss study. Int J Obes (Lond) 2008; 32(6): 985-991.

8. Wadden TA, Sternberg JA, Letizia KA, Stunkard AJ, Foster GD. Treatment of obesity by very low calorie diet, behavior therapy, and their combination: a five-year perspective. Int J Obes 1989; 13 (Suppl 2): 39-46.

9. Cupples ME, McKnight A. Five year follow up of patients at high cardiovascular risk who took part in randomised controlled trial of health promotion. BMJ 1999; 319: 687-688.

10. Forman JP, Stampfer MJ, Curhan GC. Diet and lifestyle risk factors associated with incident hypertension in women. JAMA 2009; 302(4): 401-411.

11. Picot J, Jones J, ColquittJL, Gospodarevskaya E, Loveman E, Baxter L, et al. The clinical effectiveness and costeffectiveness of bariatric (weight loss) surgery for obesity: a systematic review and economic evaluation. Health Technol Assess 2009 Sep; 13(41).

12. Buchwald H, Avidor Y, Braunwald E, Jensen MD, Pories W, Fahrbach K, et al. Bariatric surgery: systematic review and meta-analysis. JAMA 2004; 292: 1724-1737.

13. Sjostrom L, Lindroos AK, Peltonen $M$, et al. Lifestyle, diabetes, and cardiovascular risk factors 10 years after bariatric surgery. N Engl J Med 2004; 351(26): 2683-2693.

14. Bond DS, Phelan S, Leahey TM, Hill JO, Wing RR. Weight-loss maintenance in successful weight losers: surgical vs. non-surgical methods. Int J Obes (Lond)

\subsection{8 - Equipe multiprofissional}

A equipe multiprofissional pode ser constituída por todos os profissionais que lidam com pacientes hipertensos: médicos, enfermeiros, técnicos e auxiliares de enfermagem, nutricionistas, psicólogos, assistentes sociais, fisioterapeutas, professores de educação física, musicoterapeutas, farmacêuticos, educadores, comunicadores, funcionários administrativos e agentes comunitários de saúde. Como a HAS é uma síndrome clínica multifatorial, contar com a contribuição da equipe multiprofissional de apoio ao hipertenso é conduta desejável, sempre que possível ${ }^{80,81}$.

Abordagem multidisciplinar: grau de recomendação I e nível de evidência A.

Considerando-se as principais intervenções nãomedicamentosas podemos observar, na tabela 2, os benefícios médios estimados na população com as suas aplicações.

2009 Jan; 33(1): 173-180

15. Sacks FM, Svetkey LP, Vollmer WM, Appel LJ, Bray GA, Harsha D, et al. Effects on blood pressure of reduced dietary sodium and the Dietary Approaches to Stop Hypertension (DASH) diet. DASH-Sodium Collaborative. Research Group. N Engl J Med 2001; 344: 3-10.

16. www.nhlbi.nih.gov/health/public/heart/hbp/dash/new_dash.pdf

17. Babyak MA, Hinderliter A, Watkins LL, Craighead L, Lin PH, Caccia C, et al. Effects of the DASH diet alone and in combination with exercise and weight loss on blood pressure and cardiovascular biomarkers in men and women with high blood pressure: the ENCORE study. Arch Intern Med 2010 Jan 25 ; 170(2):126-135.

18. Núñez-Córdoba JM, Valencia-Serrano F, Toledo E, Alonso A, MartínezGonzález MA. The Mediterranean diet and incidence of hypertension: the Seguimiento Universidad de Navarra (SUN) Study. Am J Epidemiol 2009 Feb 1; 169(3): 339-346.

19. Alonso A, de la Fuente C, Martín-Arnau AM, de Irala J, Martínez JA, MartínezGonzález MA. Fruit and vegetable consumption is inversely associated with blood pressure in a Mediterranean population with a high vegetable-fat intake: the Seguimiento Universidad de Navarra (SUN) Study. Br J Nutr 2004; 92(2): 311-319.

20. Carey VJ, Bishop L, Charleston J, Conlin P, Erlinger T, Laranjo N, et al. Rationale and design of the Optimal Macro-Nutrient Intake Heart Trial to Prevent Heart Disease (OMNI-Heart). Clin Trials 2005; 2(6): 529-537.

21. Myers VH, Champagne CM. Nutritional effects on blood pressure. Curr Opin Lipidol 2007 Feb; 18(1): 20-24.

22. Toohey ML, Harris MA, DeWitt W, Foster G, Schmidt WD, Melby CL. Cardiovascular disease risk factors are lower in African- American vegans compared to lacto-ovovegetarians. J Am Coll Nutr 1998; 17: 425-434.

23. Craig WJ, Mangels AR; American Dietetic Association. Position of the American Dietetic Association: vegetarian diets. J Am Diet Assoc 2009; 109(7): 1266-1282.

24. Chiplonkar SA, Agte VV, Tarwadi KV, Paknikar KM, Diwate UP. Micronutrient deficiencies as predisposing factors for hypertension in lacto-vegetarian Indian adults. J Am Coll Nutr 2004; 23(3): 239-247.

25. Appleby PN, Davey GK, Key TJ. Hypertension and blood pressure among meat eaters, fish eaters, vegetarians and vegans in EPIC-Oxford. Public Health Nutr 2002; 5: 645-654.

26. Sacks FM, Kass EH. Low blood pressure in vegetarians: effects of specific foods and nutrients. Am J Clin Nutr 1988; 48 (3 Suppl): 795-800. 


\section{Diretrizes}

27. Melby CL, Toohey ML, Cebrick J. Blood pressure and blood lipids among vegetarian, semivegetarian, and nonvegetarian African Americans. Am J Clin Nutr 1994; 59: 103-109.

28. Dansinger ML, Gleason JA, Griffith JL, Selker HP, Schaefer EJ. Comparison of the Atkins, Ornish, Weight Watchers, and Zone diets for weight loss and heart disease risk reduction: a randomized trial.JAMA 2005 Jan 5; 293(1): 43-53.

29. Phillips SA, Jurva JW, Syed AQ, Syed AQ, Kulinski JP, Pleuss J, et al. Benefit of low-fat over low-carbohydrate diet on endothelial health in obesity. Hypertension. 2008; 51(2): 376-382.

30. Iqbal R, Anand S, Ounpuu S, Islam S, Zhang X, Rangarajan S, et al. INTERHEART Study Investigators. Dietary patterns and the risk of acute myocardial infarction in 52 countries: results of the INTERHEART study. Circulation 2008; 118(19): 1929-1937.

31. Warensjö E, Sundström J, Vessby B, Cederholm T, Risérus UMarkers of dietary fat quality and fatty acid desaturation as predictors of total and cardiovascular mortality: a population-based prospective study. Am J Clin Nutr 2008; 88(1): 203-209.

32. Skrabal F, Herholz H, Neumayr M, Hamberger L, Ledochowsky M, Sporer $\mathrm{H}$, et al. Salt sensitivity in humans is linked to enhanced sympathetic responsiveness and to enhanced proximal tubular reabsorption. Hypertension 1984; 6: 152-158.

33. de Boer MP, ljzerman RG, de Jongh RT, Eringa EC, Stehouwer CD, Smulders YM, et al. Birth Weight Relates to Salt Sensitivity of Blood Pressure in Healthy Adults. Hypertension 2008; 51: 928-932.

34. Pimenta E, Gaddam KK, Oparil S, Aban I, Husain S, Dell'Italia LI, Calhoun DA. Effects of dietary sodium reduction on blood pressure in subjects with resistant hypertension: results from a randomized trial. Hypertension 2009; 54(3): 475-481.

35. Dumler F. Dietary sodium intake and arterial blood pressure. J Ren Nutr 2009; 19(1): 57-60.

36. Nakasato M. Sal e Hipertensão. Rev Bras Hipertens 2004; 11: 95-97.

37. Geleijnsea JM, Giltaya EJ, Grobbeeb DE, Dondersb ART, Koka FJ. Blood pressure response to fish oil supplementation: metaregression analysis of randomized trials. J Hypertens 20: 1493-1499.

38. Morris MC, Sacks F, Rosner B. Does fish oil lower blood pressure? A metaanalysis of controlled trials. Circulation 1993; 88: 523-533.

39. IV Diretriz Brasileira de Dislipidemia e Prevenção da Aterosclerose. Arq Bras Cardiol 2007: 88 (Suppl.1): 1-19.

40. Terés S, Barceló-Coblijn G, Benet M, Alvarez R, Bressani R, Halver JE, et al Proc Natl Acad Sci U S A. Oleic acid content is responsible for the reduction in blood pressure induced by olive oil. Proc Natl Acad Sci U SA. 2008 Sep16; 105(37): 13811-13816

41. Maki KC, Galant R, Samuel P, Tesser J, Witchger MS, Ribaya-Mercado JD, et al. Effects of consuming foods containing oat beta-glucan on blood pressure, carbohydrate metabolism and biomarkers of oxidative stress in men and women with elevated blood pressure. Eur J Clin Nutr 2007; 61(6): 786-795.

42. Welty FK, Lee KS, Lew NS, Zhou JR. Effect of soy nuts on blood pressure and lipid levels in hypertensive, prehypertensive, and normotensive postmenopausal women. Arch Intern Med 2007 May 28; 167(10): 1060-1067.

43. Jenkins DJ, Kendall CW, Faulkner DA, Kemp T, Marchie A, Nguyen TH, et al. Long-term effects of a plant-based dietary portfolio of cholesterol-lowering foods on blood pressure. Eur J Clin Nutr 2008; 62(6): 781-788.

44. Djousse L, Rudich T, Gaziano JM. Nut consumption and risk of hypertension in US male physicians. Clin Nutr 2008; 28: 10-14.

45. Martinez-Lapiscina EH, Pimenta AM, Beunza JJ, Bes-Rastrollo M, Martinez JA, Martinez-Gonzalez MA. Nut consumption and incidence of hypertension: the SUN prospective cohort. Nutr Metab Cardiovasc Dis 2009.

46. Moore LL, Singer MR, Bradlee ML, et al. Intake of fruits, vegetables, and dairy products in early childhood and subsequent blood pressure change. Epidemiology 2005 Jan 16: 4-11

47. Wang L, Manson JE, Buring JE, Lee IM, Sesso HD. Dietary intake of dairy products, calcium, and vitamin D and the risk of hypertension in middle-aged and older women. Hypertension 2008 Apr 51(4): 1073-1079).
48. Ried K, Frank OR, Stocks NP, Fakler P, Sullivan T. Effect of garlic on blood pressure: a systematic review and meta-analysis. BMC Cardiovasc Disord 2008; 8(13): 1-12

49. Ackermann RT, Mulrow CD, Ramirez G, Gardner CD, Morbidoni L, Lawrence VA. Garlic shows promise for improving some cardiovascular risk factors. Arch Intern Med 2001; 161: 813-824.

50. Hu G, Jousilahti P, Nissinen A, Bidel S, Antikainen R, Tuomilehto J. Coffee consumption and the incidence of antihypertensive drug treatment in Finnish men and women. Am J Clin Nutr 2007 Aug; 86(2): 457-464.

51. Yang YC, Lu FH, Wu JS, Wu CH, Chang CJ. The protective effect of habitual tea consumption on hypertension. Arch Intern Med 2004 Jul 26; 164(14): 1534-1540.

52. Desch S, Schmidt J, Kobler D, Sonnabend M, Eitel I, Sereban M. Effect of cocoa products on blood pressure: systematic review and meta-analysis. Am J Hypertens 2010; 23(1): 97-103.

53. O'Keefe JH, Bybee KA, Lavie CJ. Alcohol and cardiovascular health. J Am Coll Cardiol 2007; 50: 1009-1014).

54. Sesso HD, Cook NR, Buring JE, Manson JE, Gaziano JM. Alcohol consumpt: on and the risk of hypertension in women and men. Hypertension 2008; 51 : 1080-1087.

55. Xin X, He J, Frontini G, Ogden LG, Motsamai OI, Whelton PK. Effects of alcohol reduction on blood pressure. A meta-analysis of randomized controlled trials. Hypertension 2001; 38: 1112-1117.

56. Whelton SP, Chin A, Xin X, He J. Effect of aerobic exercise on blood pressure: a meta-analysis of randomized, controlled trials. Ann Intern Med 2002; 136(7): 493-503.

57. Cornelissen VA, Fagard RH. Effect of resistance training on resting blood pressure: a meta-analysis of randomized controlled trials. J Hypertens 2005; 23(2): 251-259.

58. Murphy MH, Nevill AM, Murtagh EM, Holder RL. The effect of walking on fitness, fatness and resting blood pressure: a meta-analysis of randomised, controlled trials. Prev Med 2007; 44(5): 377-385.

59. Fagard RH, Cornelissen VA. Effect of exercise on blood pressure control in hypertensive patients. Eur J Cardiovasc Prev Rehabil 2007; 14(1): 12-17.

60. Fletcher GF, Balady GJ, Amsterdam EA, et al. Exercise standards for testing and training: a statement for healthcare professionals from the American Heart Association. Circulation 2001; 104(14): 1694-1740.

61. II Diretrizes da Sociedade Brasileira de Cardiologia sobre teste ergométrico. Arq Bras Cardiol 2002; 78 (Supl II): 1-18.

62. Caspersen CJ, Powell KE, Christenson GM. Physical activity, exercise, and physical fitness: definitions and distinctions for health-related research. Public Health Rep 1985; 100(2): 126-131.

63. Tanaka H, Monahan KD, Seals DR. Agepredicted maximal heart revisited. J Am Coll Cardiol 2001; 37(1): 153-156.

64. Camarda SR, Tebexreni AS, Páfaro CN, Sasai FB, Tambeiro VL, Juliano Y, et al. Comparison of maximal heart rate using the prediction equations proposed by Karvonen and Tanaka. Arq Bras Cardiol 2008; 91(5): 311-314.

65. Merz CNB, Alberts MJ, Balady GJ, Ballantyne CM, Berra K, Black HR, et al. ACCF/AHA/ACP 2009 Competence and Training Statement: A Curriculum on Prevention of Cardiovascular Disease. A Report of the American College of Cardiology Foundation/American Heart Association/American College of Physicians Task Force on Competence and Training (Writing Committee to Develop a Competence and Training Statement on Prevention of Cardiovascular Disease). Circulation 2009; 120: e100-e126.

66 Sleep Apnea and Cardiovascular Disease. AHA/ACCF Scientific Statement In Collaboration With the National Heart, Lung, and Blood Institute National Center on Sleep. Circulation 2008; 118: 1080-1111.

67. Haentjens P, Meerhaeghe AV, Moscariello A, De Weerdt S, Poppe K, Rupont A, et al. The impact of continuous positive airway pressure on blood pressure in patients with obstructive sleep apnea syndrome. Arch Intern Med 2007; 167: 757-765.

68. Bazzano LA, Khan Z, Reynolds K, He J. Effect of nocturnal nasal continuous positive airway pressure on blood pressure in obstructive sleep apnea. 
Hypertension 2007; 50: 417-423.

69. Dimsdale JE. Psychological stress and cardiovascular disease. J Am Coll Cardiol. 2008; 51: 1237-1246.

70. Figueredo VM. The time has come for physicians to take notice: the impact of psychosocial stressors on the heart. Am J Med 2009; 122: 704-712.

71. Fonseca FCA, Coelho RZ, Malloy-Diniz R, Silva Filho HC. A influência de fatores emocionais sobre a hipertensão arterial. J Bras Psiquiatr 2009, 58(2): 128-134.

72. Anderson JW, Chunxu L, Kryscio RJ. Blood pressure response to transcendental meditation: a meta-analysis. Am J Hypertens 2008; 21: 310-316.

73. Zanini CRO, Jardim PCBV, Salgado CM, Nunes MC, Urzêda FL, Carvalho MVC, et al. Arq Bras Cardiol 2009; 93(5): 534-540).

74. Jacob RG, et al. Ann Behav Med 1991; 13: 5-17, Wassertheil-Smoller S et al., Arch Intern Med 1992; 152: 131-136.

75. Lipp MEN. Controle do estresse e hipertensão arterial sistêmica. Rev Bras Hipertens 2007; 14(2): 89-93.
76. Meles E, Giannattasio C, Failla M, Gentile G, Capra A, Mancia G Nonpharmacologic treatment of hypertension by respiratory exercise in the home setting. Am J Hypertens 2004; 17(4): 370-374.

77. Gianfranco P, Carretta R. Device-guided slow breathing as a nonpharmacological approach to antihypertensive treatment: efficacy, problems and perspectives. J Hypertens. 2007; 25(1): 57-61.

78. Schein MH, Gavish B, Baevsky T, Kaufman M, Levine S, Nessing A, et al. Treating hypertension in type II diabetic patients with device-guided breathing: a randomized controlled trial. J Hum Hypertens 2009; 23(5): 325-331.

79. National Institute of Health State-of-The Science Conference Statement: Tobacco use: Prevention, Cessation, and Control. NIH Conference. Ann Intern Med 2006; 145: 839-844.

80. Glynn LG, Murphy AW, Smith SM, Schroeder K. Interventions used to improve control of blood pressure in patients with hypertension. Cochrane Database Syst Rev 2010;3:CD005182.

81. Carter BL, Rogers M, Daly J, Zheng S, James PA. The potency of team-based care interventions for hypertension: a meta-analysis. Arch Intern Med 2009; 169(19): 1748-1755.

\section{Capítulo 6 - Tratamento medicamentoso}

\section{1 - Objetivos}

O objetivo primordial do tratamento da hipertensão arterial é a redução da morbidade e da mortalidade cardiovasculares $^{1,2}$. Assim, os anti-hipertensivos devem não só reduzir a pressão arterial, mas também os eventos cardiovasculares fatais e não-fatais, e, se possível, a taxa de mortalidade. As evidências provenientes de estudos de desfechos clinicamente relevantes, com duração relativamente curta, de três a quatro anos, demonstram redução de morbidade e mortalidade em estudos com diuréticos ${ }^{3-6}(\mathrm{~A})$, betabloqueadores ${ }^{3,4,7,8}(\mathrm{~A})$, inibidores da enzima conversora da angiotensina (IECA $)^{6,9-13}(\mathrm{~A})$, bloqueadores do receptor $\mathrm{AT}_{1}$ da angiotensina (BRA II) ${ }^{14-20}(\mathrm{~A})$ e com antagonistas dos canais de cálcio (ACC) $)^{6,9,13,21-25}(\mathrm{~A})$, embora a maioria dos estudos utilizem, no final, associação de anti-hipertensivos. Este benefício é observado com a redução da pressão arterial per se, e, com base nos estudos disponíveis até o momento, parece independer da classe de medicamentos utilizados ${ }^{26}$.
Metanálises recentes indicam que este benefício é de menor monta com betabloqueadores, em especial com atenolol, quando em comparação com os demais anti-hipertensivos ${ }^{27-29}$.

\section{2 - Princípios gerais do tratamento medicamentoso}

Os aspectos importantes na escolha do anti-hipertensivo estão na tabela 1. Deve-se explicar, detalhadamente, aos pacientes a ocorrência de possíveis efeitos adversos, a possibilidade de eventuais modificações na terapêutica instituída e o tempo necessário para que o efeito pleno dos medicamentos seja obtido.

\section{3 - Escolha do medicamento}

Qualquer medicamento dos grupos de anti-hipertensivos (tabela 2) comercialmente disponíveis, desde que resguardadas as indicações e contraindicações específicas, pode ser utilizado para o tratamento da hipertensão arterial.

Os anti-hipertensivos comercialmente disponíveis no Brasil, por classes, estão mostrados na tabela 3, enquanto

\section{Tabela 1 - Características importantes do anti-hipertensivo}

\begin{tabular}{lr}
\hline Ser eficaz por via oral & Ser seguro e bem tolerado e com relação de risco/benefício favorável ao paciente \\
\hline $\begin{array}{l}\text { Permitir a administração em menor número possível de tomadas, com } \\
\text { preferência para dose única diária }\end{array}$ & $\begin{array}{l}\text { Ser iniciado com as menores doses efetivas preconizadas para cada situação } \\
\text { clínica, podendo ser aumentadas gradativamente ressalvando-se que, quanto } \\
\text { maior a dose, maiores serão as probabilidades de efeitos adversos }\end{array}$ \\
\hline $\begin{array}{l}\text { Não ser obtido por meio de manipulação, pela inexistência de informações } \\
\text { adequadas de controle de qualidade, bioequivalência e/ou de interação química } \\
\text { dos compostos }\end{array}$ & $\begin{array}{l}\text { Ser considerado em associação para os pacientes com hipertensão em estágios } \\
\text { das vezes, não alcançam a meta de redução da pressão arterial preconizada com } \\
\text { a monoterapia }\end{array}$ \\
\hline $\begin{array}{l}\text { Ser utilizado por um período mínimo de quatro semanas, salvo em situações } \\
\text { especiais, para aumento de dose, substituição da monoterapia ou mudança das } \\
\text { associações em uso }\end{array}$ & $\begin{array}{l}\text { Ter demonstração, em ensaios clínicos, da capacidade de reduzir a morbidade e a } \\
\text { mortalidade cardiovasculares associadas à hipertensão arterial (característica para } \\
\text { preferência de escolha) }\end{array}$ \\
\hline
\end{tabular}




\section{Diretrizes}

Tabela 2 - Classes de anti-hipertensivos disponíveis para uso clínico

\begin{tabular}{l}
\hline Diuréticos \\
\hline Inibidores adrenérgicos \\
Ação central - agonistas alfa-2 centrais \\
Betabloqueadores - bloqueadores beta-adrenérgicos \\
Alfabloqueadores - bloqueadores alfa-1 adrenérgicos \\
\hline Vasodilatadores diretos \\
\hline Bloqueadores dos canais de cálcio \\
\hline Inibidores da enzima conversora da angiotensina \\
\hline Bloqueadores do receptor $\mathrm{AT}_{1}$ da angiotensina II \\
\hline Inibidor direto da renina \\
\hline
\end{tabular}

as principais associações medicamentosas podem ser observadas na tabela 4.

\subsection{1 - Diuréticos}

O mecanismo de ação anti-hipertensiva dos diuréticos se relaciona inicialmente aos seus efeitos diuréticos e natriuréticos, com diminuição do volume extracelular. Posteriormente, após cerca de quatro a seis semanas, o volume circulante praticamente se normaliza e há redução da resistência vascular periférica. São eficazes no tratamento da hipertensão arterial, tendo sido comprovada sua eficácia na redução da morbidade e da mortalidade cardiovasculares $^{3-6}$ (A). Para uso como anti-hipertensivos, são preferidos os diuréticos tiazídicos e similares, em baixas doses. Os diuréticos de alça são reservados para situações de hipertensão associada a insuficiência renal com taxa de filtração glomerular abaixo de $30 \mathrm{ml} / \mathrm{min} / 1,73 \mathrm{~m}^{2}$ (D) e na insuficiência cardíaca com retenção de volume. Em pacientes com aumento do volume extracelular (insuficiências cardíaca e renal), o uso associado de diurético de alça e tiazídico pode ser benéfico tanto para o controle do edema quanto da pressão arterial, ressalvando-se o risco maior de eventos adversos. Os diuréticos poupadores de potássio apresentam pequena eficácia diurética, mas, quando associados aos tiazídicos e aos diuréticos de alça, são úteis na prevenção e no tratamento de hipopotassemia. Seu uso em pacientes com redução da função renal poderá acarretar hiperpotassemia.

Principais reações adversas

Hipopotassemia, por vezes acompanhada de hipomagnesemia, que pode induzir arritmias ventriculares, e hiperuricemia. O emprego de baixas doses diminui o risco de efeitos adversos, sem prejuízo da eficácia anti-hipertensiva, especialmente quando em associação com outros antihipertensivos. Os diuréticos também podem provocar intolerância à glicose, aumentar o risco do aparecimento do diabetes melito, além de promover aumento de triglicérides, efeitos esses, em geral, dependentes da dose.

\subsection{2 - Inibidores adrenérgicos}

\subsubsection{1 - Ação central}

Atuam estimulando os receptores alfa-2 adrenérgicos
Tabela 3 - Anti-hipertensivos comercialmente disponíveis no Brasil

\begin{tabular}{lccc}
\hline \multirow{2}{*}{ Medicamentos } & \multicolumn{2}{c}{ Posologia (mg) } & \multirow{2}{*}{$\begin{array}{c}\text { Número de } \\
\text { tomadas/dia }\end{array}$} \\
\cline { 2 - 3 } Diuréticos & Mínima & Máxima & \\
\hline Tiazídicos & & & \\
\hline Clortalidona & 12,5 & 25 & 1 \\
\hline Hidroclorotiazida & 12,5 & 25 & 1 \\
\hline Indapamida & 2,5 & 5 & 1 \\
\hline Indapamida SR & 1,5 & 5 & 1 \\
\hline Alça & & & \\
\hline Bumetamida & 0,5 & $* *$ & $1-2$ \\
\hline Furosemida & 20 & $* *$ & $1-2$ \\
\hline Piretanida & 6 & 12 & 1 \\
\hline Poupadores de potássio & & & 1 \\
\hline Amilorida* & 2,5 & 10 & $1-2$ \\
\hline Espironolactona & 25 & 100 & 1 \\
\hline Triantereno* & 50 & 100 & \\
\hline Inibidores adrenérgicos & & & \\
\hline
\end{tabular}

Inibidores adrenérgicos

Ação central

\begin{tabular}{lccc} 
Alfametildopa & 500 & 1.500 & $2-3$ \\
\hline Clonidina & 0,2 & 0,6 & $2-3$ \\
\hline Guanabenzo & 4 & 12 & $2-3$ \\
\hline Moxonidina & 0,2 & 0,6 & 1 \\
\hline Rilmenidina & 1 & 2 & 1 \\
\hline Reserpina $^{*}$ & 12,5 & 25 & $1-2$
\end{tabular}

Betabloqueadores

\begin{tabular}{|c|c|c|c|}
\hline Atenolol & 25 & 100 & $1-2$ \\
\hline Bisoprolol & 2,5 & 10 & $1-2$ \\
\hline Carvedilol $^{+}$ & 12,5 & 50 & $1-2$ \\
\hline $\begin{array}{l}\text { Metoprolol e } \\
\text { Metoprolol }(\mathrm{ZOK})^{* * *}\end{array}$ & 50 & 200 & $1-2$ \\
\hline Nadolol & 40 & 120 & 1 \\
\hline Nebivolol $^{++}$ & 5 & 10 & 1 \\
\hline $\begin{array}{l}\text { Propranolol }{ }^{* *} / \\
\text { Propranolol (LA) }\end{array}$ & $40 / 80$ & $240 / 160$ & $2-3 / 1-2$ \\
\hline Pindolol & 10 & 40 & $1-2$ \\
\hline \multicolumn{4}{|l|}{ Alfabloqueadores } \\
\hline Doxazosina & 1 & 16 & 1 \\
\hline Prazosina & 1 & 20 & $2-3$ \\
\hline Prazosina $\mathrm{XL}^{* * *}$ & 4 & 8 & 1 \\
\hline Terazosina & 1 & 20 & $1-2$ \\
\hline \multicolumn{4}{|l|}{ Vasodilatadores diretos } \\
\hline Hidralazina & 50 & 150 & $2-3$ \\
\hline Minoxidil & 2,5 & 80 & $2-3$ \\
\hline \multicolumn{4}{|c|}{ Bloqueadores dos canais de cálcio } \\
\hline \multicolumn{4}{|l|}{ Fenilalquilaminas } \\
\hline Verapamil Retard ${ }^{\star * *}$ & 120 & 480 & $1-2$ \\
\hline
\end{tabular}


Continuação Tabela 3 - Anti-hipertensivos comercialmente disponíveis no Brasil

\begin{tabular}{|c|c|c|c|}
\hline \multirow{2}{*}{ Medicamentos } & \multicolumn{2}{|c|}{ Posologia (mg) } & \multirow{2}{*}{$\begin{array}{l}\text { Número de } \\
\text { tomadas/dia }\end{array}$} \\
\hline & Mínima & Máxima & \\
\hline \multicolumn{4}{|l|}{ Benzotiazepinas } \\
\hline $\begin{array}{l}\text { Diltiazem AP, SR ou } \\
\mathrm{CD}^{\star \star \star}\end{array}$ & 180 & 480 & $1-2$ \\
\hline \multicolumn{4}{|l|}{ Diidropiridinas } \\
\hline Anlodipino & 2,5 & 10 & 1 \\
\hline Felodipino & 5 & 20 & $1-2$ \\
\hline Isradipina & 2,5 & 20 & 2 \\
\hline Lacidipina & 2 & 8 & 1 \\
\hline Lercarnidipino & 10 & 30 & 1 \\
\hline Manidipino & 10 & 20 & 1 \\
\hline Nifedipino Oros ${ }^{* * *}$ & 30 & 60 & 1 \\
\hline Nifedipino Retard ${ }^{\star \star *}$ & 20 & 60 & $2-3$ \\
\hline Nisoldipino & 5 & 40 & $1-2$ \\
\hline Nitrendipino & 10 & 40 & $2-3$ \\
\hline \multicolumn{4}{|l|}{ Inibidores da ECA } \\
\hline Benazepril & 5 & 20 & 1 \\
\hline Captopril & 25 & 150 & $2-3$ \\
\hline Cilazapril & 2,5 & 5 & 1 \\
\hline Delapril & 15 & 30 & $1-2$ \\
\hline Enalapril & 5 & 40 & $1-2$ \\
\hline Fosinopril & 10 & 20 & 1 \\
\hline Lisinopril & 5 & 20 & 1 \\
\hline Perindopril & 4 & 8 & 1 \\
\hline Quinapril & 10 & 20 & 1 \\
\hline Ramipril & 2,5 & 10 & 1 \\
\hline Trandolapril & 2 & 4 & 1 \\
\hline \multicolumn{4}{|c|}{ Bloqueadores do receptor $\mathrm{AT}_{1}$} \\
\hline Candesartana & 8 & 32 & 1 \\
\hline Irbersartana & 150 & 300 & 1 \\
\hline Losartana & 25 & 100 & 1 \\
\hline Olmesartana & 20 & 40 & 1 \\
\hline Telmisartana & 40 & 160 & 1 \\
\hline Valsartana & 80 & 320 & 1 \\
\hline \multicolumn{4}{|l|}{ Inibidor direto da renina } \\
\hline Alisquireno & 150 & 300 & 1 \\
\hline \multicolumn{4}{|c|}{$\begin{array}{l}\text { * Medicamentos comercializados apenas em associações com outros anti- } \\
\text { hipertensivos. }{ }^{* *} \text { Dose máxima variável de acordo com a indicação médica. } \\
\text { *** Retard, } S R \text {, ZOK, Oros, } X L, L A, A P, S R \text { e CD: formas farmacêuticas de } \\
\text { liberação prolongada ou controlada. }+ \text { Alfa-1 e betabloqueador adrenérgico. ++ } \\
\text { Betabloqueador e liberador de óxido nitrico. }\end{array}$} \\
\hline
\end{tabular}

pré-sinápticos no sistema nervoso central, reduzindo o tônus simpático, como fazem a alfametildopa, a clonidina e o guanabenzo e/ou os inibidores dos receptores imidazolidínicos, como moxonidina e a rilmenidina.
Tabela 4 - Combinações fixas de anti-hipertensivos disponíveis no Brasil

\begin{tabular}{|c|c|}
\hline Associações & Posologia (mg) \\
\hline \multicolumn{2}{|l|}{ Diurético + diurético } \\
\hline Clortalidona + amilorida & $25+5$ \\
\hline Espironolactona + hidroclorotiazida & $50+50$ \\
\hline Furosemida + amilorida & $40+10$ \\
\hline Furosemida + espironolactona & $20+100$ \\
\hline Hidroclorotiazida + amilorida & $\begin{array}{c}25+2,5 \\
50+5\end{array}$ \\
\hline Hidroclorotiazida + triantereno & $50+50$ \\
\hline \multicolumn{2}{|c|}{ Inibidor adrenérgico de ação central + diurético } \\
\hline Alfametildopa + hidroclorotiazida & $250+15$ \\
\hline Reserpina + clortalidona & $25+50$ \\
\hline \multicolumn{2}{|l|}{ Betabloqueador + diurético } \\
\hline Atenolol + clortalidona & $\begin{array}{c}25+12,5 \\
50+12,5 \\
100+25\end{array}$ \\
\hline Bisoprolol + hidroclorotiazida & $\begin{array}{c}2,5+6,25 \\
5+6,25 \\
10+6,25\end{array}$ \\
\hline Metoprolol + hidroclorotiazida & $100+12,5$ \\
\hline Metoprolol ZOK ${ }^{* * *}+$ hidroclorotiazida & $95+12,5$ \\
\hline Pindolol + clopamida & $10+5$ \\
\hline Propranolol + hidroclorotiazida & $\begin{array}{c}40+25 \\
80+12,5 \\
80+25\end{array}$ \\
\hline \multicolumn{2}{|l|}{ Inibidor da ECA + diurético } \\
\hline Benazepril + hidroclorotiazida & $\begin{array}{c}5+6,25 \\
10+12,5\end{array}$ \\
\hline Captopril + hidroclorotiazida & $50+25$ \\
\hline Cilazapril + hidroclorotiazida & $5+12,5$ \\
\hline Enalapril + hidroclorotiazida & $\begin{array}{c}10+25 \\
20+12,5 \\
50+25\end{array}$ \\
\hline Fosinopril + hidroclorotiazida & $10+12,5$ \\
\hline Lisinopril + hidroclorotiazida & $\begin{array}{l}10+12,5 \\
20+12,5 \\
\end{array}$ \\
\hline Perindopril + indapamida & $4+1,25$ \\
\hline Ramipril + hidroclorotiazida & $\begin{array}{c}5+12,5 \\
5+25\end{array}$ \\
\hline \multicolumn{2}{|l|}{ Bloqueador do receptor AT1 + Diurético } \\
\hline Candesartana + hidroclorotiazida & $\begin{array}{c}8+12,5 \\
16+12,5\end{array}$ \\
\hline Irbersartana + hidroclorotiazida & $\begin{array}{c}150+12,5 \\
300+12,5 \\
300+25\end{array}$ \\
\hline Losartana + hidroclorotiazida & $\begin{array}{c}50+12,5 \\
50+25 \\
100+25\end{array}$ \\
\hline Olmesartana + hidroclorotiazida & $\begin{array}{c}20+12,5 \\
40+12,5 \\
40+25\end{array}$ \\
\hline Telmisartana + hidroclorotiazida & $\begin{array}{c}40+12,5 \\
80+12,5 \\
80+25\end{array}$ \\
\hline
\end{tabular}




\section{Diretrizes}

\section{Continuação Tabela 4 - Combinações fixas de anti-hipertensivos}

\begin{tabular}{|c|c|}
\hline Associações & Posologia (mg) \\
\hline Valsartana + hidroclorotiazida & $\begin{array}{c}80+12,5 \\
160+12,5 \\
160+25 \\
320+12,5 \\
320+25\end{array}$ \\
\hline \multicolumn{2}{|l|}{ Inibidor direto da renina + diurético } \\
\hline Alisquireno + hidroclorotiazida & $\begin{array}{c}150+12,5 \\
150+25 \\
300+12,5 \\
300+25 \\
\end{array}$ \\
\hline \multicolumn{2}{|c|}{ Bloqueador dos canais de cálcio + betabloqueador } \\
\hline Nifedipino + atenolol & $\begin{array}{l}10+25 \\
20+50\end{array}$ \\
\hline Anlodipino + atenolol & $\begin{array}{l}5+25 \\
5+50\end{array}$ \\
\hline \multicolumn{2}{|c|}{ Bloqueador dos canais de cálcio + inibidor da ECA } \\
\hline Anlodipino + benazepril & $\begin{array}{c}2,5+10 \\
5+10 \\
5+20\end{array}$ \\
\hline Anlodipino + enalapril & $\begin{array}{c}2,5+10 \\
5+10 \\
5+20\end{array}$ \\
\hline Anlodipino + ramipril & $\begin{array}{c}2,5+5 \\
5+5 \\
5+10 \\
10+10 \\
\end{array}$ \\
\hline Manidipino + delapril & $10+30$ \\
\hline \multicolumn{2}{|c|}{ Bloqueador dos canais de cálcio + bloqueador do receptor AT1 } \\
\hline Anlodipino + losartana & $\begin{array}{c}2,5+50 \\
5+50 \\
5+100\end{array}$ \\
\hline Anlodipino + olmesartana & $\begin{array}{c}5+20 \\
5+40 \\
10+40\end{array}$ \\
\hline Anlodipino + valsartana & $\begin{array}{c}5+80 \\
5+160 \\
5+320 \\
10+160 \\
10+320 \\
\end{array}$ \\
\hline \multicolumn{2}{|c|}{ Bloqueador dos canais de cálcio + bloqueador do receptor AT1 + diurétic } \\
\hline Anlodipino + valsartana + hidroclorotiazida & $\begin{array}{c}5+160+12,5 \\
5+160+25 \\
10+160+12,5 \\
10+160+25\end{array}$ \\
\hline
\end{tabular}

Seu efeito hipotensor como monoterapia é, em geral, discreto (B). Entretanto, podem ser úteis em associação com medicamentos de outros grupos, particularmente quando há evidência de hiperatividade simpática.

A experiência favorável em relação à segurança do binômio materno-fetal recomenda a alfametildopa como agente de escolha para tratamento da hipertensão das grávidas.

Não interferem com a resistência periférica à insulina ou com o perfil lipídico.

Principais reações adversas

São, em geral, decorrentes da ação central, como sonolência, sedação, boca seca, fadiga, hipotensão postural e disfunção sexual. A frequência é um pouco menor com os inibidores de receptores imidazolidínicos.

A alfametildopa pode provocar, ainda, embora com pequena frequência, galactorreia, anemia hemolítica e lesão hepática, sendo contraindicada se há insuficiência hepática.

No caso da clonidina, destaca-se a hipertensão de rebote, quando da suspensão brusca da medicação, e a ocorrência mais acentuada de boca seca.

\subsubsection{2 - Betabloqueadores}

Seu mecanismo anti-hipertensivo envolve diminuição inicial do débito cardíaco, redução da secreção de renina, readaptação dos barorreceptores e diminuição das catecolaminas nas sinapses nervosas. Betabloqueadores de geração mais recente (terceira geração) como o carvedilol e o nebivolol, diferentemente dos betabloqueadores de primeira e segunda gerações também proporcionam vasodilatação, que no caso do carvedilol decorre em grande parte do efeito de bloqueio concomitante do receptor alfa-1 adrenérgico ${ }^{30,31}$ e no caso do nebivolol de aumento da síntese e liberação endotelial de óxido nítrico ${ }^{30,32}$.

São eficazes no tratamento da hipertensão arterial. A redução da morbidade e da mortalidade cardiovasculares é bem documentada em grupos de pacientes com idade inferior a $60 \operatorname{anos}^{3,4,7,8}$ (A). Estudos e metanálises recentes ${ }^{27-29}$ não têm apontado redução de desfechos relevantes, principalmente acidente vascular encefálico, em pacientes com idade superior a 60 anos, situação em que o uso dessa classe de medicamentos seria reservada para situações especiais, como nos portadores de coronariopatia, com disfunção sistólica, arritmias cardíacas ou infarto do miocárdio prévio ${ }^{33}$ (A). Estudos de desfecho com carvedilol, metoprolol, bisoprolol e, recentemente, com nebivolol têm demonstrado que estes fármacos são úteis na redução de mortalidade e morbidade cardiovasculares de pacientes com insuficiência cardíaca, hipertensos ou não, independentemente da faixa etária ${ }^{34-37}$. O propranolol se mostra também útil em pacientes com tremor essencial, síndromes hipercinéticas, cefaleia de origem vascular e naqueles com hipertensão portal.

\section{Principais reações adversas}

Broncoespasmo, bradicardia, distúrbios da condução atrioventricular, vasoconstrição periférica, insônia, pesadelos, depressão psíquica, astenia e disfunção sexual.

Betabloqueadores de primeira e segunda geração podem acarretar também intolerância à glicose, induzir ao aparecimento de novos casos de diabetes, hipertrigliceridemia com elevação do LDL-colesterol e redução da fração HDL-colesterol. O impacto sobre o metabolismo da glicose é potencializado quando os betabloqueadores são utilizados em combinação com diuréticos. O efeito sobre o metabolismo lipídico parece estar relacionado à dose e à seletividade, sendo de pequena monta com o uso de baixas doses de betabloqueadores cardiosseletivos.

Diferentemente, betabloqueadores de terceira geração, como o carvedilol e o nebivolol, têm impacto neutro ou até podem melhorar o metabolismo da glicose e lipídico, 
possivelmente em decorrência do efeito de vasodilatação com diminuição da resistência à insulina e melhora da captação de glicose pelos tecidos periféricos ${ }^{38}$. Estudos com o nebivolol também têm apontado para uma menor interferência na função sexual ${ }^{39}$, possivelmente em decorrência do efeito sobre a síntese de óxido nítrico endotelial.

A suspensão brusca dos betabloqueadores pode provocar hiperatividade simpática, com hipertensão de rebote e/ ou manifestações de isquemia miocárdica, sobretudo em hipertensos com pressão arterial prévia muito elevada. Devem ser utilizados com cautela em pacientes com doença vascular de extremidade.

Os betabloqueadores de primeira e segunda geração são formalmente contraindicados a pacientes com asma brônquica, DPOC e bloqueio atrioventricular de segundo e terceiro graus.

\subsubsection{3 - Alfabloqueadores}

Apresentam efeito hipotensor discreto a longo prazo como monoterapia, devendo, portanto, ser associados com outros anti-hipertensivos. Podem induzir ao aparecimento de tolerância, o que exige o uso de doses gradativamente crescentes. Têm a vantagem de propiciar melhora discreta no metabolismo lipídico e glicídico e nos sintomas de pacientes com hipertrofia prostática benigna.

Principais reações adversas

Hipotensão postural, mais evidente com a primeira dose, sobretudo se a dose inicial for alta, palpitações e, eventualmente, astenia. No estudo ALLHAT, a comparação entre o alfabloqueador doxazosina e a clortalidona indicou a maior ocorrência de insuficiência cardíaca congestiva no grupo tratado com a doxazosina. A partir dessas conclusões estabeleceu-se a ideia de que o alfabloqueador testado nesse estudo não deve ser medicamento de primeira escolha para o tratamento da hipertensão ${ }^{40}(\mathrm{~A})$.

\subsection{3 - Vasodilatadores diretos}

Atuam sobre a musculatura da parede vascular, promovendo relaxamento muscular com consequente vasodilatação e redução da resistência vascular periférica. São utilizados em associação com diuréticos e/ou betabloqueadores. Hidralazina e minoxidil são dois dos principais representantes desse grupo.

Principais reações adversas

Pela vasodilatação arterial direta, promovem retenção hídrica e taquicardia reflexa, o que contraindica seu uso como monoterapia.

\subsection{4 - Antagonistas dos canais de cálcio}

A ação anti-hipertensiva decorre da redução da resistência vascular periférica por diminuição da concentração de cálcio nas células musculares lisas vasculares. Apesar do mecanismo final comum, esse grupo é dividido em três subgrupos, com características químicas e farmacológicas diferentes: fenilalquilaminas, benzotiazepinas e diidropiridinas.

São anti-hipertensivos eficazes e reduzem a morbidade e mortalidade cardiovasculares ${ }^{6,9,13,21-25}$ (A). Deve-se dar preferência aos bloqueadores dos canais de cálcio de longa duração de ação intrínseca ou por formulação galênica que permita uma liberação controlada. Estudo de desfecho reafirmou a eficácia, tolerabilidade e segurança do uso dessa classe de medicamentos no tratamento da hipertensão arterial de pacientes com doença coronariana ${ }^{41}$. Não são recomendados agentes de curta duração.

\section{Principais reações adversas}

Cefaleia, tontura, rubor facial - mais frequente com diidropiridínicos de curta ação - e edema de extremidades, sobretudo maleolar. Esses efeitos adversos são, em geral, dose-dependentes. Mais raramente, podem induzir a hipertrofia gengival. Os diidropiridínicos de ação curta provocam importante estimulação simpática reflexa, sabidamente deletéria para o sistema cardiovascular. Verapamil e diltiazem podem provocar depressão miocárdica e bloqueio atrioventricular. Obstipação intestinal é observada, particularmente, com verapamil.

\subsection{5 - Inibidores da enzima conversora da angiotensina}

Agem fundamentalmente pela inibição da enzima conversora da angiotensina (ECA), bloqueando a transformação da angiotensina I em II no sangue e nos tecidos, embora outros fatores possam estar envolvidos nesse mecanismo de ação.

São eficazes no tratamento da HAS, reduzindo a morbidade e a mortalidade cardiovasculares nos hipertensos ${ }^{6,7,10,13,42}(\mathrm{~A})$, pacientes com insuficiência cardíaca ${ }^{43-45}(\mathrm{~A})$, com infarto agudo do miocárdio, em especial quando apresentam baixa fração de ejeção ${ }^{11,45-47}(\mathrm{~A})$, de alto risco para doença aterosclerótica $^{11}(A)$, sendo também úteis na prevenção secundária do acidente vascular encefálico ${ }^{12}(\mathrm{~A})$. Quando administrados a longo prazo, os IECAs retardam o declínio da função renal em pacientes com nefropatia diabética ou de outras etiologias ${ }^{48-50}(\mathrm{~A})$.

Principais reações adversas

Tosse seca, alteração do paladar e, mais raramente, reações de hipersensibilidade com erupção cutânea e edema angioneurótico.

Em indivíduos com insuficiência renal crônica, podem eventualmente agravar a hiperpotassemia. Em pacientes com hipertensão renovascular bilateral ou unilateral associada a rim único, podem promover redução da filtração glomerular com aumento dos níveis séricos de ureia e creatinina.

Seu uso em pacientes com função renal reduzida pode causar aumento de até $30 \%$ da creatininemia, mas a longo prazo, prepondera seu efeito nefroprotetor ${ }^{51}$.

Seu uso é contraindicado na gravidez pelo risco de complicações fetais. Desta forma, seu emprego deve ser cauteloso e frequentemente monitorado em adolescentes e mulheres em idade fértil.

\subsection{6 - Bloqueadores dos receptores $\mathrm{AT}_{1}$ da angiotensina II}

Bloqueadores dos receptores $\mathrm{AT}_{1}$ da angiotensina II (BRA II) antagonizam a ação da angiotensina II por meio do bloqueio específico de seus receptores $\mathrm{AT}_{1}$. São eficazes no tratamento 
da hipertensão. No tratamento da hipertensão arterial, especialmente em populações de alto risco cardiovascular ou com comorbidades proporcionam redução da morbidade e mortalidade cardiovascular ${ }^{14-20}$ (A). Estudos também comprovam seu efeito benéfico em insuficiência cardíaca congestiva $^{52-54}$ (A) e são úteis na prevenção do acidente vascular cerebral ${ }^{14,15,55,56}$ (A). São nefroprotetores no paciente com diabetes melito tipo 2 com nefropatia estabelecida ${ }^{57-59}$ (A) e incipiente ${ }^{60}(\mathrm{~A})$. Metanálise recente aponta equivalência entre BRA II e IECA na redução de eventos coronarianos ${ }^{61}$ e superioridade dos BRA II na proteção cerebrovascular ${ }^{61}$, contrapondo-se a metanálises anteriores que indicavam redução de eventos coronarianos apenas com os inibidores da $\mathrm{ECA}^{62,63}$. O tratamento com BRA II, assim como o uso de IECA, vem sendo associado a uma menor incidência de novos casos de diabetes melito tipo $2^{14,16,18,64,65}$ (A).

Principais reações adversas

Os bloqueadores do receptor $\mathrm{AT}_{1}$ apresentam bom perfil de tolerabilidade.

Foram relatadas tontura e, raramente, reação de hipersensibilidade cutânea ("rash"). As precauções para seu uso são semelhantes às descritas para os IECA.

\subsection{7 - Inibidores diretos da renina}

Alisquireno, único representante da classe atualmente disponível para uso clínico, promove uma inibição direta da ação da renina com consequente diminuição da formação de

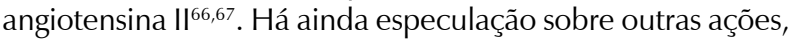
como redução da atividade plasmática de renina ${ }^{67}$, bloqueio de um receptor celular próprio de renina/pró-renina ${ }^{67-69}$ e diminuição da síntese intracelular de angiotensina $\|^{70,71}$.

Estudos de eficácia anti-hipertensiva comprovam sua capacidade, em monoterapia, de redução da pressão arterial de intensidade semelhante aos demais anti-hipertensivos ${ }^{72-74}$. Estudos clínicos de curta duração indicam efeito benéfico na redução de morbidade cardiovascular e renal, hipertrofia de ventrículo esquerdo e proteinúria ${ }^{75-77}$. São aguardados os resultados de estudos de desfecho com avaliação do impacto deste medicamento na mortalidade e morbidade cardiovascular e renal.

\section{Principais reações adversas}

Apresentam boa tolerabilidade.

"Rash" cutâneo, diarreia (especialmente com doses elevadas, acima de $300 \mathrm{mg} / \mathrm{dia}$ ), aumento de CPK e tosse são os eventos mais frequentes, porém em geral com incidência inferior a $1 \%$. Seu uso é contraindicado na gravidez.

\section{4 - Esquemas terapêuticos}

\subsection{1 - Monoterapia}

A monoterapia pode ser a estratégia anti-hipertensiva inicial para pacientes com hipertensão arterial estágio 1, e com risco cardiovascular baixo a moderado.

O tratamento deve ser individualizado e a escolha inicial do medicamento como monoterapia deve-se basear nos seguintes aspectos:

- capacidade de o agente escolhido reduzir morbidade e mortalidade cardiovasculares;

- perfil de segurança do medicamento;

- mecanismo fisiopatogênico predominante no paciente a ser tratado;

- características individuais;

- doenças associadas;

- condições socioeconômicas.

Com base nestes critérios, as classes de anti-hipertensivos atualmente consideradas preferenciais para o controle da pressão arterial em monoterapia inicial são:

- diuréticos ${ }^{3-6}(\mathrm{~A})$;

- betabloqueadores ${ }^{3,4,7,8}$ (A) (com as ressalvas já apontadas na seção 6.3);

- bloqueadores dos canais de cálcio ${ }^{6,9,13,21-25}(\mathrm{~A})$;

- inibidores da $\mathrm{ECA}^{6,8-13}(\mathrm{~A})$;

- bloqueadores do receptor $\mathrm{AT}_{1}{ }^{14-20}(\mathrm{~A})$.

Alisquireno pode ser considerado uma opção para o tratamento inicial em monoterapia dos pacientes com hipertensão estágio 1, com risco cardiovascular baixo a moderado ${ }^{72-74}$, ressalvando-se que até o presente momento não estão disponíveis estudos que demonstrem redução de mortalidade cardiovascular com o seu uso.

A posologia deve ser ajustada até que se consiga redução da pressão arterial pelo menos a um nível inferior a 140/90 $\mathrm{mmHg}^{1,2,78}$ (A). Se o objetivo terapêutico não for conseguido com a monoterapia inicial, três condutas são possíveis:

- se o resultado for parcial ou nulo, mas sem reação adversa, recomenda-se aumentar a dose do medicamento em uso ou associar anti-hipertensivo de outro grupo terapêutico;

- quando não se obtiver efeito terapêutico na dose máxima preconizada, ou se surgirem eventos adversos não toleráveis, recomenda-se a substituição do antihipertensivo inicialmente utilizado;

- se, ainda assim, a resposta for inadequada, deve-se associar dois ou mais medicamentos (figura 1).

\subsubsection{Terapêutica anti-hipertensiva combinada}

Com base em evidências de vários estudos mostrando que em cerca de 2/3 dos casos a monoterapia não foi suficiente para atingir as reduções de pressão previstas, e diante da demonstração de que valores da pressão arterial mais baixos (130/80 mmHg) podem ser benéficos para pacientes com características peculiares:

- de alto e muito alto risco cardiovascular ${ }^{14,16,78,79}(\mathrm{~A})$;

- diabéticos ${ }^{15,79-81}(\mathrm{~A})$;

- com doença renal crônica ${ }^{57-59,82}$, mesmo que em fase incipiente $^{60}(\mathrm{~A})$;

- em prevenção primária ${ }^{79,83}(B)$ e secundária ${ }^{12,56}(A)$ de acidente vascular encefálico, há clara tendência atual para a introdução mais precoce de terapêutica combinada de anti-hipertensivos, como primeira medida medicamentosa, sobretudo nos pacientes com hipertensão em estágios 2 e 3 e para aqueles 
com hipertensão arterial estágio 1, mas com risco cardiovascular alto e muito alto.

As associações de anti-hipertensivos (tabela 5) devem seguir a lógica de não combinar medicamentos com mecanismos de ação similares, com exceção da combinação de diuréticos tiazídicos e de alça com poupadores de potássio. Tais associações de anti-hipertensivos podem ser feitas por meio de medicamentos em separado ou por associações em doses fixas.

A eficácia anti-hipertensiva destas diferentes associações parece ser semelhante, embora sejam escassos os estudos que avaliaram de forma comparativa direta o tratamento com cada uma destas combinações.

Recentemente um estudo de desfechos relevantes avaliou de forma comparativa, em pacientes de alto risco cardiovascular, o impacto do tratamento com a combinação fixa de um IECA com um diurético e com um bloqueador dos canais de cálcio (BCC), tendo sido demonstrado que para o mesmo grau de redução de controle da pressão arterial a combinação do IECA com o BCC foi mais eficaz em reduzir a morbidade e mortalidade cardiovasculares ${ }^{84}$ e a progressão da doença renal ${ }^{85}$

O emprego da combinação de betabloqueadores e diuréticos deve ser cauteloso em pacientes com, ou altamente predispostos a apresentar, distúrbios metabólicos, especialmente glicídicos.

O uso da combinação de inibidor da ECA e bloqueador do receptor $\mathrm{AT}_{1}$ da angiotensina II em pacientes hipertensos, além de não adicionar benefício cardiovascular em comparação com os medicamentos usados em separado, aumentou o risco de eventos adversos ${ }^{20}$, não estando, portanto indicado o seu uso. Exceção se faz em relação àqueles com insuficiência cardíaca classes 3 e 4 da NYHA ${ }^{52,53}$ ou com proteinúria ${ }^{86,87}$ e, mesmo assim, devem ser usados com cautela.
Algumas associações destacadas na tabela 4 também estão disponíveis no mercado em doses fixas. Seu emprego, desde que criterioso, pode ser útil por simplificar o esquema posológico, reduzindo o número de comprimidos administrados e, assim, estimulando a adesão ao tratamento.

Se o objetivo terapêutico não for conseguido com a combinação inicial, três condutas são possíveis:

- se o resultado for parcial ou nulo, mas sem reação adversa, recomenda-se aumentar a dose da combinação em uso ou associar um terceiro anti-hipertensivo de outra classe;

- quando não se obtiver efeito terapêutico na dose máxima preconizada, ou se surgirem eventos adversos não-toleráveis, recomenda-se a substituição da combinação;

- se ainda assim a resposta for inadequada, deve-se associar outros anti-hipertensivos (figura 1).

\section{Tabela 5 - Associações reconhecidas como eficazes}

\begin{tabular}{l}
\hline Diuréticos com outros diuréticos de diferentes mecanismos de ação \\
\hline Diuréticos com simpatolíticos de ação central \\
\hline Diuréticos com betabloqueadores \\
\hline Diuréticos com inibidores da ECA \\
\hline Diuréticos com bloqueadores do receptor $\mathrm{AT}_{1}$ da angiotensina II \\
\hline Diuréticos com inibidor direto da renina \\
\hline Diuréticos com bloqueadores dos canais de cálcio \\
\hline Bloqueadores dos canais de cálcio com betabloqueadores \\
\hline Bloqueadores dos canais de cálcio com inibidores da ECA \\
\hline Bloqueadores dos canais de cálcio com bloqueadores do receptor $\mathrm{AT}_{1}$ \\
\hline Bloqueadores dos canais de cálcio com inibidor da renina \\
\hline
\end{tabular}

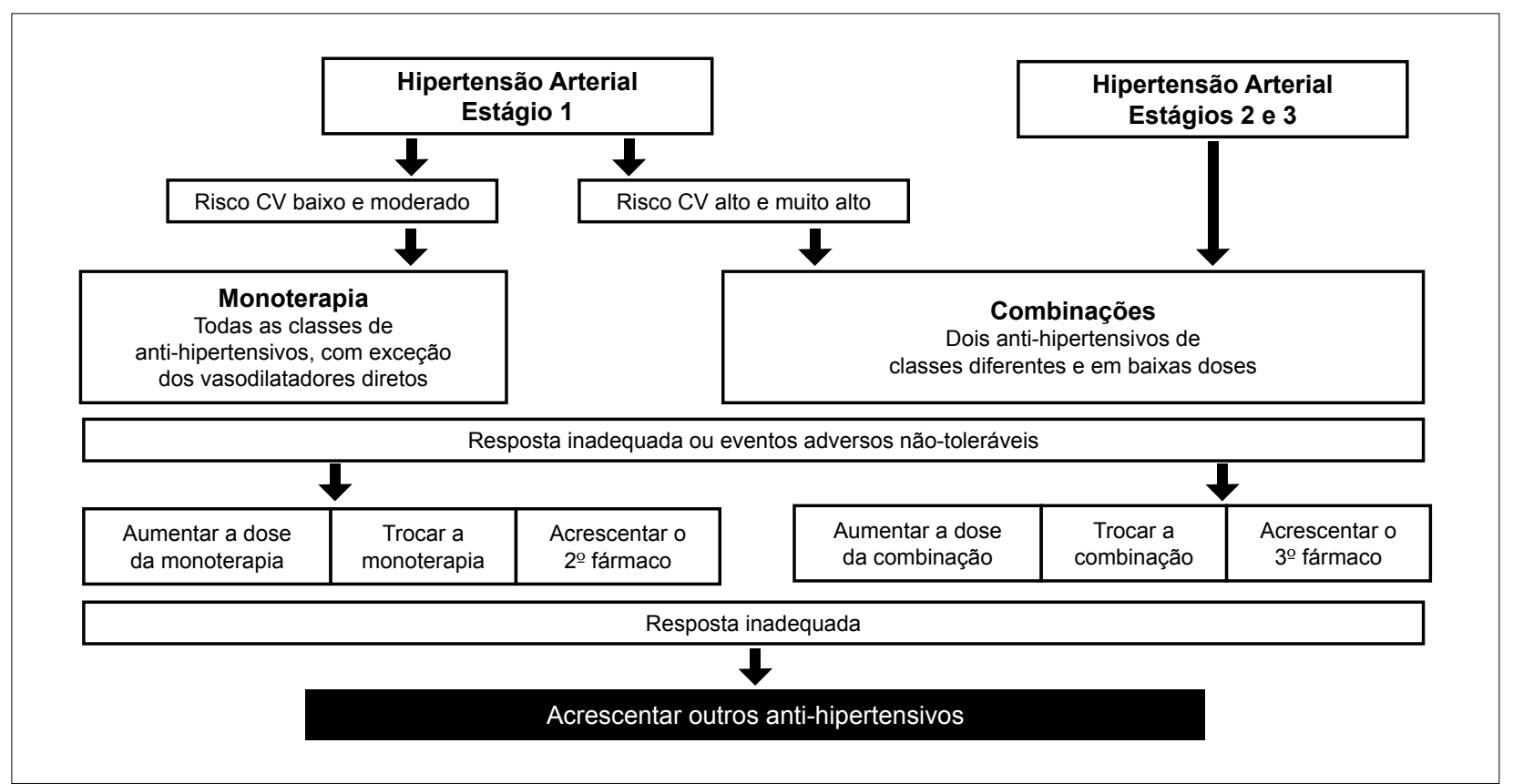

Fig. 1 - Fluxograma para o tratamento da hipertensão arterial. 


\section{Diretrizes}

\section{Tabela 6 - Anti-hipertensivos: interações medicamentosas}

\begin{tabular}{|c|c|c|}
\hline Anti-hipertensivo & Medicamentos & Efeitos \\
\hline \multicolumn{3}{|l|}{ Diuréticos } \\
\hline \multirow{4}{*}{ Tiazídicos e de alça } & Digitálicos & Intoxicação digitálica por hipopotassemia \\
\hline & Anti-inflamatórios esteroides e não-esteroides & Antagonismo do efeito diurético \\
\hline & Hipoglicemiantes orais & Efeito diminuído pelos tiazídicos \\
\hline & Lítio & Aumento dos níveis séricos do lítio \\
\hline Poupadores de potássio & Suplementos de potássio e inibidores da ECA & Hipercalemia \\
\hline \multicolumn{3}{|l|}{ Inibidores adrenérgicos } \\
\hline Ação central & Antidepressivos tricíclicos & Redução do efeito anti-hipertensivo \\
\hline \multirow{9}{*}{ Betabloqueadores } & Insulina e hipoglicemiantes orais & $\begin{array}{l}\text { Redução dos sinais de hipoglicemia e bloqueio da mobilização } \\
\text { de glicose }\end{array}$ \\
\hline & Amiodarona quinidina & Bradicardia \\
\hline & Cimetidina & Redução da depuração hepática de propranolol e metoprolol \\
\hline & Cocaína & Potencialização do efeito da cocaína \\
\hline & Vasoconstritores nasais & Facilitação do aumento da pressão pelos vasoconstritores nasais \\
\hline & Diltiazem, verapamil & Bradicardia, depressão sinusal e atrioventricular \\
\hline & Dipiridamol & Bradicardia \\
\hline & Anti-inflamatórios esteroides e não-esteroides & Antagonismo do efeito hipotensor \\
\hline & $\begin{array}{l}\text { Diltiazem, verapamil, betabloqueadores e medicamentos de ação } \\
\text { central }\end{array}$ & Hipotensão \\
\hline \multicolumn{3}{|l|}{ Inibidores da ECA } \\
\hline & Suplementos e diuréticos poupadores de potássio & Hipercalemia \\
\hline & Ciclosporina & Aumento dos níveis de ciclosporina \\
\hline & Anti-inflamatórios esteroides e não-esteroides & Antagonismo do efeito hipotensor \\
\hline & Lítio & Diminuição da depuração do lítio \\
\hline & Antiácidos & Redução da biodisponibilidade do captopril \\
\hline & Hipoglicemiantes da classe dos inibidores da enzima DPP4 & Aumento do risco de angioedema associado ao uso de IECA \\
\hline \multicolumn{3}{|c|}{ Bloqueadores dos canais de cálcio } \\
\hline & Digoxina & Verapamil e diltiazem aumentam os níveis de digoxina \\
\hline & Bloqueadores de $\mathrm{H} 2$ & Aumento dos níveis dos bloqueadores dos canais de cálcio \\
\hline & Ciclosporina & $\begin{array}{l}\text { Aumento do nível de ciclosporina, com exceção de anlodipino e } \\
\text { felodipino }\end{array}$ \\
\hline & Teofilina, prazosina & Níveis aumentados com verapamil \\
\hline & Moxonidina & Hipotensão \\
\hline \multicolumn{3}{|c|}{ Bloqueadores do receptor $\mathrm{AT}_{1}$} \\
\hline & Moxonidina & Hipotensão com losartana \\
\hline & Suplementos e diuréticos poupadores de potássio & Hipercalemia \\
\hline \multicolumn{3}{|l|}{ Inibidor direto da renina } \\
\hline & Ciclosporina e cetoconazol & Aumento da concentração plasmática de alisquireno \\
\hline & Furosemida & $\begin{array}{l}\text { Redução da biodisponibilidade da furosemida - redução do efeito } \\
\text { natriurético }\end{array}$ \\
\hline & Suplementos e diuréticos poupadores de potássio & Hipercalemia \\
\hline
\end{tabular}


Quando já estão sendo usados pelo menos dois medicamentos, o uso de um diurético é fundamental.

Pacientes aderentes ao tratamento e não-responsivos à tríplice terapia otimizada que inclua um diurético caracterizam a situação clínica de hipertensão resistente. Nesta situação clínica deverá ser avaliada a presença de fatores que dificultam o controle da pressão arterial, tais como ingestão excessiva de sal, álcool, obesidade, uso de fármacos com potencial de elevar a pressão arterial, síndrome de apneia obstrutiva do sono e formas secundárias de hipertensão arterial, procedendo à correção destes fatores. Se ausentes ou se a pressão arterial persistir elevada mesmo após a correção dos fatores de agravamento do quadro hipertensivo, a adição de espironolactona e de simpatolíticos centrais e betabloqueadores ao esquema terapêutico tem-se mostrado útil ${ }^{88}$. Reserva-se para pacientes que não responderam adequadamente à estratégia proposta a adição de vasodilatadores diretos, como hidralazina e minoxidil, que devem ser usados em combinação com diuréticos e betabloqueadores.

\subsection{3 - Outras considerações a respeito da terapêutica anti-hipertensiva}

Com relação ao tratamento anti-hipertensivo deve-se também considerar:

- o esquema anti-hipertensivo deve manter a qualidade de vida do paciente, de modo a estimular a adesão às recomendações prescritas;

- existem evidências de que para hipertensos com a pressão arterial controlada a prescrição de ácido acetilsalicílico em baixas doses $(75 \mathrm{mg})$ diminui a ocorrência de complicações cardiovasculares, desde que não haja contraindicação para o seu uso e que os benefícios superem os eventuais riscos da sua administração ${ }^{79,89}(\mathrm{~A})$;

- dada a necessidade de tratamento crônico da hipertensão arterial, o Sistema Único de Saúde deve garantir o fornecimento contínuo de, pelo menos, um representante de cada uma das cinco principais classes de anti-hipertensivos comumente usados.

\section{5 - Interações medicamentosas}

É importante conhecer as principais interações de antihipertensivos e medicamentos de uso contínuo que podem ser prescritos para o paciente hipertenso (tabela 6).

\section{6 - Adesão ao tratamento}

A adesão ao tratamento é definida como o grau de coincidência entre a prescrição e o comportamento do paciente. Vários são os determinantes para a não-adesão ao tratamento ${ }^{90-92}$ (tabela 7).

Os percentuais de controle de pressão arterial são muito baixos, apesar das evidências de que o tratamento antihipertensivo é eficaz em diminuir a morbidade e mortalidade cardiovascular, devido à baixa adesão ao tratamento. Estudos isolados apontam controle de $20 \%$ a $40 \% \%^{93,94}$. A taxa de abandono, grau mais elevado de falta de adesão, é crescente
Tabela 7 - Principais determinantes da não-adesão ao tratamento anti-hipertensivo

Falta de conhecimento por parte do paciente sobre a doença ou de motivação para tratar uma doença assintomática e crônica

Baixo nível socioeconômico, aspectos culturais e crenças erradas adquiridas em experiências com a doença no contexto familiar, e baixa auto-estima

Relacionamento inadequado com a equipe de saúde

Tempo de atendimento prolongado, dificuldade na marcação de consultas, falta de contato com os faltosos e com aqueles que deixam o serviço

Custo elevado dos medicamentos e ocorrência de efeitos indesejáveis

Interferência na qualidade de vida após início do tratamento

conforme o tempo decorrido após o início da terapêutica. A tabela 8 indica sugestões para melhorar a adesão às prescrições para os hipertensos.

A relação médico/paciente deve ser a base de sustentação para o sucesso do tratamento anti-hipertensivo. A participação de vários profissionais da área da saúde, com uma abordagem multidisciplinar, pode facilitar a adesão ao tratamento antihipertensivo e consequentemente aumentar o controle da hipertensão arterial (Tabela 8$)^{95}$.

\section{7 - Complicações}

\section{Hipertensivas agudas}

Pressão arterial muito elevada, acompanhada de sintomas, caracteriza uma complicação hipertensiva aguda e requer avaliação clínica adequada, incluindo exame físico detalhado, fundoscopia e exames complementares, solicitados para avaliação das lesões em órgãos-alvo.

\subsection{1 - Urgências hipertensivas}

A elevação crítica da pressão arterial, em geral pressão arterial diastólica $\geq 120 \mathrm{mmHg}$, porém com estabilidade clínica, sem comprometimento de órgãos-alvo, caracteriza o que se convencionou definir como urgência hipertensiva $(\mathrm{UH})$.

Pacientes que cursam com UH estão expostos a maior risco futuro de eventos cardiovasculares comparados com hipertensos que não a apresentam, fato que evidencia o seu impacto no risco cardiovascular de indivíduos hipertensos e enfatiza a necessidade de controle adequado

Tabela 8 - Principais sugestões para a melhor adesão ao tratamento anti-hipertensivo

Educação em saúde com especial enfoque sobre conceitos de hipertensão e suas características

Orientações sobre os benefícios dos tratamentos, incluindo mudanças de estilo de vida

Informações detalhadas e compreensíveis aos pacientes sobre os eventuais efeitos adversos dos medicamentos prescritos e necessidades de ajustes posológicos com o passar do tempo

Cuidados e atenções particularizadas em conformidade com as necessidades

Atendimento médico facilitado sobretudo no que se refere ao agendamento de consultas 


\section{Diretrizes}

da pressão arterial cronicamente ${ }^{96}$. A pressão arterial, nesses casos, deverá ser tratada com medicamentos por via oral buscando-se redução da pressão arterial em até 24 horas (D).

Embora a administração sublingual de nifedipino de ação rápida seja amplamente utilizada para esse fim, foram descritos efeitos adversos graves com essa conduta. A dificuldade de controlar o ritmo e o grau de redução da pressão arterial, sobretudo quando intensa, pode ocasionar acidentes vasculares encefálicos e coronarianos. O risco de importante estimulação simpática secundária e a existência de alternativas eficazes e mais bem toleradas tornam o uso de nifedipino de curta duração (cápsulas) não recomendável nessa situação. O uso desse medicamento, sobretudo de forma abusiva, foi analisado em parecer técnico do Conselho Regional de Medicina do Estado de São Paulo (http://www. cremesp.org.br) - clicar em pareceres (parecer CREMESP 45922 de 2003).

\subsection{2 - Emergências hipertensivas}

É condição em que há elevação crítica da pressão arterial com quadro clínico grave, progressiva lesão de órgãos-alvo e risco de morte, exigindo imediata redução da pressão arterial com agentes aplicados por via parenteral (D) (tabela 9).

Há elevação abrupta da pressão arterial ocasionando, em território cerebral, perda da autorregulação do fluxo sanguíneo e evidências de lesão vascular, com quadro clínico de encefalopatia hipertensiva, lesões hemorrágicas dos vasos da retina e papiledema. Habitualmente, apresentam-se com pressão arterial muito elevada em pacientes com hipertensão crônica ou menos elevada em pacientes com doença aguda, como em eclâmpsia, glomerulonefrite aguda, e em uso de drogas ilícitas, como cocaína. Podem estar associadas a acidente vascular encefálico, edema agudo dos pulmões, síndromes isquêmicas miocárdicas agudas e dissecção aguda da aorta. Nesses casos, há risco iminente à vida ou de lesão orgânica grave.

Depois de obtida a redução imediata da pressão arterial, deve-se iniciar a terapia anti-hipertensiva de manutenção e interromper a medicação parenteral. A hidralazina é contraindicada nos casos de síndromes isquêmicas miocárdicas agudas e de dissecção aguda de aorta por induzir ativação simpática, com taquicardia e aumento da pressão de pulso. Em tais situações, indica-se o uso de betabloqueadores e de nitroglicerina ou nitroprussiato de sódio (C).

\section{Tabela 9 - Medicamentos usados por via parenteral para o tratamento das emergências hipertensivas}

\begin{tabular}{|c|c|c|c|c|c|}
\hline Medicamentos & Dose & Início & Duração & $\begin{array}{l}\text { Efeitos adversos e } \\
\text { precauções }\end{array}$ & Indicações \\
\hline $\begin{array}{l}\text { Nitroprussiato de sódio } \\
\text { (vasodilatador arterial e } \\
\text { venoso) }\end{array}$ & $0,25-10 \mathrm{mg} / \mathrm{kg} / \mathrm{min} \mathrm{EV}$ & Imediato & $1-2 \min$ & $\begin{array}{l}\text { Náuseas, vômitos, } \\
\text { intoxicação por cianeto. } \\
\text { Cuidado na insuficiência } \\
\text { renal e hepática e na } \\
\text { pressão intracraniana alta. } \\
\text { Hipotensão grave }\end{array}$ & $\begin{array}{l}\text { Maioria das } \\
\text { emergências } \\
\text { hipertensivas }\end{array}$ \\
\hline $\begin{array}{l}\text { Nitroglicerina } \\
\text { (vasodilatador arterial e } \\
\text { venoso) }\end{array}$ & $5-100 \mathrm{mg} / \mathrm{min} \mathrm{EV}$ & $2-5 \min$ & $3-5 \mathrm{~min}$ & $\begin{array}{l}\text { Cefaleia, taquicardia } \\
\text { reflexa, taquifilaxia, flushing, } \\
\text { meta-hemoglobinemia }\end{array}$ & $\begin{array}{c}\text { Insuficiência } \\
\text { coronariana, } \\
\text { insuficiência } \\
\text { ventricular esquerda }\end{array}$ \\
\hline $\begin{array}{l}\text { Hidralazina } \\
\text { (vasodilatador de ação } \\
\text { direta) }\end{array}$ & $\begin{array}{c}10-20 \mathrm{mg} \text { EV ou } \\
10-40 \mathrm{mg} \text { IM 6/6 h }\end{array}$ & $10-30 \mathrm{~min}$ & $3-12 h$ & $\begin{array}{l}\text { Taquicardia, cefaleia, } \\
\text { vômitos. Piora da angina } \\
\text { e do infarto. Cuidado com } \\
\text { pressão intracraniana } \\
\text { elevada }\end{array}$ & Eclâmpsia \\
\hline $\begin{array}{l}\text { Metoprolol (bloqueador } \\
\beta \text {-adrenérgico seletivo) }\end{array}$ & $\begin{array}{l}5 \mathrm{mg} \text { EV (repetir 10/10 } \\
\text { min, se necessário até } \\
20 \mathrm{mg} \text { ) }\end{array}$ & $5-10 \min$ & $3-4 \mathrm{~h}$ & $\begin{array}{l}\text { Bradicardia, bloqueio } \\
\text { atrioventricular avançado, } \\
\text { insuficiência cardíaca, } \\
\text { broncoespasmo }\end{array}$ & $\begin{array}{c}\text { Insuficiência } \\
\text { coronariana. Dissecção } \\
\text { aguda de aorta (em } \\
\text { combinação com NPS). }\end{array}$ \\
\hline $\begin{array}{l}\text { Esmolol (bloqueador } \\
\beta \text {-adrenérgico seletivo } \\
\text { de ação ultrarrápida) }\end{array}$ & $\begin{array}{c}\text { Ataque: } 500 \mu \mathrm{gg} / \mathrm{kg} \\
\text { Infusão intermitente: } \\
25-50 \mu \mathrm{g} / \mathrm{kg} / \mathrm{min} \\
\uparrow 25 \mu \mathrm{g} / \mathrm{kg} / \mathrm{min} \text { cada } \\
10-20 \mathrm{~min} \\
\text { Máximo: } 300 \mu \mathrm{g} / \mathrm{kg} / \mathrm{min}\end{array}$ & $1-2 \min$ & $1-20 \mathrm{~min}$ & $\begin{array}{l}\text { Náuseas, vômitos, BAV 1o } \\
\text { grau, espasmo brônquico, } \\
\text { hipotensão }\end{array}$ & $\begin{array}{c}\text { Dissecção aguda de } \\
\text { aorta (em combinação } \\
\text { com NPS). Hipertensão } \\
\text { pós-operatória grave }\end{array}$ \\
\hline Furosemida (diurético) & $\begin{array}{c}20-60 \mathrm{mg} \\
\text { (repetir após } 30 \mathrm{~min} \text { ) }\end{array}$ & $2-5 \min$ & $30-60 \mathrm{~min}$ & Hipopotassemia & $\begin{array}{c}\text { Insuficiência ventricular } \\
\text { esquerda. Situações de } \\
\text { hipervolemia }\end{array}$ \\
\hline $\begin{array}{l}\text { Fentolamina } \\
\text { (bloqueador } \\
\text { alfa-adrenérgico) }\end{array}$ & $\begin{array}{l}\text { Infusão contínua: } 1-5 \text { mg } \\
\text { Máximo: } 15 \mathrm{mg}\end{array}$ & $1-2 \min$ & $3-5 \min$ & $\begin{array}{c}\text { Taquicardia reflexa, } \\
\text { flushing, tontura, náuseas, } \\
\text { vômitos }\end{array}$ & $\begin{array}{l}\text { Excesso de } \\
\text { catecolaminas }\end{array}$ \\
\hline
\end{tabular}

NPS - nitroprussiato de sódio. 
Na fase aguda de acidente vascular encefálico, a redução da pressão arterial deve ser gradativa e cuidadosa, evitando-se reduções bruscas e excessivas, não havendo consenso para se estabelecer a pressão arterial ideal a ser atingida.

\section{8 - Análise econômica do tratamento da hipertensão arterial sistêmica no Brasil}

A análise de custo-efetividade do tratamento antihipertensivo é útil para orientar a alocação de recursos dos financiadores do sistema de saúde, tanto públicos como privados, porém não é capaz de responder as questões específicas sobre o impacto orçamentário. Existem modelos econômicos específicos para análise de impacto no orçamento, em que o financiador estima, a partir do número de pessoas beneficiadas e da prevalência da doença em questão, qual será o comprometimento no seu orçamento. Esta análise permite complementar a tomada de decisão sobre o financiamento da terapêutica para HAS.

Dib et ${ }^{197}$ utilizaram a prevalência de 28,5\% (33,6 milhões de indivíduos hipertensos no ano de 2005). Os autores levaram em consideração que aproximadamente 50\% dos indivíduos hipertensos não estão diagnosticados ${ }^{98}$ e somente $52 \%$ encontram-se em tratamento medicamentoso [Projeto Corações do Brasil (online). Atlas Corações do Brasill ${ }^{99}$.

Os grupos de pacientes foram divididos em estágios 1, 2 e 3, com prevalência de 53,3\%,35,7\% e 11\% respectivamente.

O custo anual para tratamento da HAS no Sistema Único de Saúde foi de aproximadamente R\$ 969.231.436,00, e no Sistema Suplementar de Saúde, de R\$ 662.646.950,00 (Tabela 10). O custo total com o tratamento da HAS representou 0,08\% do produto interno bruto (PIB) Brasileiro em 2005 (Tabela 10).

Para subsidiar políticas de saúde em hipertensão, estudo brasileiro que avaliou taxas de conhecimento e controle da hipertensão arterial e a relação custo-efetividade do tratamento anti-hipertensivo em uma cidade de grande porte do Estado de São Paulo mostrou que o uso de betabloqueador em monoterapia proporcionou a melhor taxa de controle da pressão arterial, mas que o uso de diurético foi o mais custo-efetivo ${ }^{100}$

Tabela 10 - Estimativa dos recursos utilizados com o tratamento da hipertensão arterial sistêmica em 2005

\begin{tabular}{|c|c|c|c|c|c|}
\hline & SUS $(80 \%)$ & $\%$ total & Suplementar $(20 \%)$ & $\%$ total & Total (R\$) \\
\hline Consulta médica & $200.349 .916,47$ & $21 \%$ & $278.632 .334,16$ & $42 \%$ & $478.982 .250,63$ \\
\hline Avaliação nutricional & $21.116 .137,91$ & $2 \%$ & $29.366 .814,31$ & $5 \%$ & $50.482 .952,22$ \\
\hline Exames complementares & $160.328 .821,93$ & $17 \%$ & $113.551 .681,99$ & $17 \%$ & $273.880 .503,92$ \\
\hline Medicamentos anti-hipertensivos & $507.754 .332,05$ & $52 \%$ & $181.340 .832,87$ & $27 \%$ & $689.095 .164,92$ \\
\hline Atendimento de urgência & $79.682 .228,48$ & $8 \%$ & $59.755 .287,01$ & $9 \%$ & $139.437 .515,49$ \\
\hline Total & $969.231 .436,83$ & & $662.646 .950,35$ & & 1.631.878.387,19 \\
\hline
\end{tabular}

\section{Referências}

1. Kannel WB. Blood pressure as a cardiovascular risk factor: prevention and treatment. JAMA 1996; 273: 1571-1576.

2. Padwal R, Straus SE, McAlister FA. Cardiovascular risk factors and their impact on decision to treat hypertension: an evidence-based review. BMJ 2001; 322: 977-980.

3. Psaty BM, Smith NL, Siscovick DS, et al. Health outcomes associated with antihypertensive therapies used as firstline agents. A systematic review and meta-analysis. JAMA 1977; 277: 739-745

4. Wright JM, Lee C-H, Chamber GK. Systematic review of antihypertensive therapies: does the evidence assist in choosing a first-line drug. CMAJ 1999; 161: 25-32.

5. SHEP-Cooperative Research Group. Prevention of stroke by antihypertensive drug treatment in older persons with isolated systolic hypertension: final results of the Systolic Hypertension in the Elderly Program (SHEP). JAMA 1991 ; 265: 3255-3264.

6. The ALLHAT Officers and Coordinators for the ALLHAT Collaborative Research Group. Major outcome in high-risk hypertensive patients to angiotensin-converting enzyme inhibitor or calcium channel blocker vs. diuretic. The Antihypertensive and Lipid-Lowering Treatment to Prevent Heart Attack Trial (ALLHAT). JAMA 2002; 228: 2981-2997.

7. Medical Research Council Working Party. MRC trial of treatment of hypertension: principal results. BMJ 1985; 291: 97-104.
8. UK Prospective Diabetes Study Group. Efficacy of atenolol and captopril in reducing risk of macrovascular and microvascular complications in type 2 diabetes. UKPDS 39. BMJ 1998; 317: 713-720.

9. Neal B, MacMahon S, Chapman N. Blood Pressure Lowering Trialist's Collaboration. Effects of ACE inhibitors, calcium antagonists and other blood-pressure-lowering drugs: results of prospectively designed overviews of randomized trials. Lancet, 2000; 356: 1955-1964.

10. Hansson L, Lindholm, Niskanen L, et al. Effect of angiotensin converting enzyme inhibition compared with conventional therapy on cardiovascular morbidity and mortality on hypertension: the Captopril Prevention Project (CAPPP) randomized trial. Lancet 1999; 353: 611-616.

11. The Heart Outcomes Prevention Evaluation Study Investigators. Effects of an angiotensin converting enzyme inhibitor, ramipril, on cardiovascular events in high-risk patients. N Engl J Med 2000; 342: 145-153.

12. PROGRESS Collaborative Group. Randomized trial of a perindopril-basedblood pressure-lowering regimen among 6,105 individuals with previous stroke or transient ischaemic attack. Lancet 2001; 35: 1033-1041.

13. Hansson L, Lindholm LH, Ekborn T, et al. Randomized trial of old and new antihypertensive drugs in elderly patients: cardiovascular mortality and morbidity. The Swedish Trial in Old Patients with Hypertension-2 study. Lancet 1999; 34: 1129-1133.

14. Dahlof B, Devereux R; Kjeldsen S, et al. Cardiovascular morbidity and 


\section{Diretrizes}

mortality in the losartan intervention or endpoint reduction in hypertension study (LIFE): a randomized trial against atenolol. Lancet 2002; 359: 995-1003.

15. Lindholm LH, Ibsen H, Dahlof B, etal. Cardiovascular morbidity and mortality in patients with diabetes in the Losartan Intervention For Endpoint reduction in hypertension study (LIFE): a randomized trial against atenolol. Lancet 2002; 359: 1004-1010.

16. Julius S, Kejdelsen SE, Weber M, et al. Outcomes in hypertensive patients in high cardiovascular risk treated with regimens based on valsartan and amlodipine: the VALUE radomised trial. Lancet 2004; 363: 2022-2031.

17. Julius S, Weber MA, Kjeldsen SE, McInnes GT, Zanchetti A, Brunner HR Laragh J, Schork MA, Hua TA, Amerena J, Balazovjech I, Cassel G, Herczeg B, Koylan N, Magometschnigg D, Majahalme S, Martinez F, Oigman W, Seabra Gomes R, Zhu JR. The Valsartan Antihypertensive Long-Term Use Evaluation (VALUE) trial: outcomes in patients receiving monotherapy. Hypertension 2006; 48(3): 385-391.

18. Ogihara T, Nakao K, Fukui T, et al. Effects of candesartan compared with amlodipine in hypertensive patients with high cardiovascular risks. Candesartan Antihypertensive Survival Evaluation in Japan trial (CASE-J). Hypertension 2008; 51:1-6.

19. Suzuki H, Kanno Y. Effects of candesartan on cardiovascular outcomes in Japanese hypertensive patients (E-COST). Hypertens Res 2005; 28(4): 307-314

20. Telmisartan, Ramipril, or Both in Patients at High Risk for Vascular Events. The ONTARGET Investigators. N Engl J Med 2008; 358: 1547-1559.

21. Stassen JA, Fagard R, Thijs L. Randomized double-blind comparison of placebo and active treatment for older patients with isolated systolic hypertension. The Systolic hypertension in Europe (SYST-EUR). Lancet 1997; 350: 757-764.

22. Brown MJ, Palmer CR, Castaigne A, et al. Morbidity and mortality in patients randomized to double-blind treatment with long-acting calcium-channel blocker or diuretic in the International Nifedipine GITS study: Intervention as a Goal in Hypertension Treatment (INSIGHT). Lancet 2000; 356: 366-372.

23. Hansson L, Hedner T, Lund-Johansen P, et al. Randomized trial of effects of calcium antagonists compared with diuretics and alpha-blockers on cardiovascular morbidity and mortality in hypertension: the Nordic Diltiazen (NORDIL) study. Lancet 2000; 356: 359-365.

24. Pahor M, Psaty BM, Alderman MH, et al. Health outcomes associated with calcium antagonists compared with other first-line antihypertensive therapies: a meta-analyses of randomized controlled trials. Lancet 2000; 356: 1949-1954.

25. Dahlof B, Sever PS, Poulter NR, Wedel H, Beevers DG, Caulfield M, Collins R, Kjeldsen SE, Kristinsson A, Mclnnes GT, Mehlsen J, Nieminen M, O'Brien E, Ostergren J; ASCOT Investigators. Prevention of cardiovascular events with an antihypertensive regimen of amlodipine adding perindopril as required versus atenolol adding bendroflumethiazide as required, in the Anglo-Scandinavian Cardiac Outcomes Trial-Blood Pressure Lowering Arm (ASCOT-BPLA): a multicentre randomised controlled trial. Lancet 2005; 366: 895-906.

26. Law MR, Morris JK, Wald NJ. Use of blood pressure lowering drugs in the prevention of cardiovascular disease: meta-analysis of 147 randomised trials in the context of expectations from prospective epidemiological studies. BMJ 2009; 338: b1665.

27. Calberg B, Samuelsson O, Lindholm LH. Atenolol in hypertension: is it a wise choice? Lancet 2004; 364: 1684-1689.

28. Lindholm LH, Calberg B, Samuelsson O. Should b blocker remain a first choice in the treatment of primary hypertension? A meta-analysis. Lancet 2005: 366: 1545-1553.

29. Bradley H, Wiysonge CS, Volmink JA, Mayosi BM, Opie LH. How strong is the evidence for the use of beta-blockers as first-line therapy for hypertension? Systematic review and metanalyses. J Hypertens 2006; 24: 2131-2141.

30. Dulin B, Abraham WT. Pharmacology of carvedilol. Am J Cardiol 2004; 93(9A): 3B-6B.

31. Pedersen ME, Cockcroft JR. The vasodilatory beta-blockers. Curr Hypertens Rep 2007; 9(4): 269-277.

32. De Cree J, Van Nueten L, Geukens H, Verhaegen H. Comparative cardiac haemodynamics of bisoprolol, celiprolol, carvedilol and nebivolol in normal volunteers. Int J Clin Pharmacol Res 1992; 12(4): 159-163.

33. López-Sendón J, Swedberg K, McMurray J, Tamargo J, Maggioni AP, Dargie $\mathrm{H}$, Tendera M, Waagstein F, Kjekshus J, Lechat P, Torp-Pedersen C; Task Force on Beta-Blockers of the European Society of Cardiology. Expert consensus document on beta-adrenergic receptor blockers. Eur Heart J 2004 Aug; 25(15): 1341-1362.

34. Doughty RN, White HD. Carvedilol: use in chronic heart failure. Expert Rev Cardiovasc Ther 2007 Jan; 5(1): 21-31.

35. Hjalmarson A, Goldstein S, Fagerberg B, Wedel H, Waagstein F, Kjekshus J, Wikstrand J, El Allaf D, Vítovec J, Aldershvile J, Halinen M, Dietz R, Neuhaus KL, Jánosi A, Thorgeirsson G, Dunselman PH, Gullestad L, Kuch J, Herlitz J, Rickenbacher P, Ball S, Gottlieb S, Deedwania P. Effects of controlled-release metoprolol on total mortality, hospitalizations, and well-being in patients with heart failure: the Metoprolol CR/XL Randomized Intervention Trial in congestive heart failure (MERIT-HF). MERIT-HF Study Group. JAMA. 2000 Mar 8; 283(10): 1295-1302.

36. Rosenberg J, Gustafsson F. Bisoprolol for congestive heart failure. Expert Opin Pharmacother 2008; 9(2): 293-300.

37. Flather MD, Shibata MC, Coats AJ, Van Veldhuisen DJ, Parkhomenko A Borbola J, Cohen-Solal A, Dumitrascu D, Ferrari R, Lechat P, Soler-Soler J, Tavazzi L, Spinarova L, Toman J, Böhm M, Anker SD, Thompson SG, PooleWilson PA; SENIORS Investigators. Randomized trial to determine the effect of nebivolol on mortality and cardiovascular hospital admission in elderly patients with heart failure (SENIORS). Eur Heart J 2005; 26(3): 215-225.

38. Celik T, Iyisoy A, Kursaklioglu H, Kardesoglu E, Kilic S, Turhan H, Yilmaz MI, Ozcan O, Yaman H, Isik E, Fici F. Comparative effects of nebivolol and metoprolol on oxidative stress, insulin resistance, plasma adiponectin and soluble P-selectin levels in hypertensive patients. J Hypertens 2006; 24(3): 591-596.

39. Doumas M, Tsakiris A, Douma S, Grigorakis A, Papadopoulos A, Hounta A, Tsiodras S, Dimitriou D, Giamarellou H. Beneficial effects of switching from beta-blockers to nebivolol on the erectile function of hypertensive patients. Asian J Androl 2006; 8(2): 177-182.

40. The ALLHAT Officers and Coordinators for the ALLHAT Collaborative Research Group. Major cardiovascular events in hypertensive patients randomized to doxazosin vs. chlorthalidone. The Antihypertensive and Lipid-Lowering Treatment to prevent Heart Attack Trial (ALLHAT). JAMA 2000; 283: 1967-1975.

41. Lubsen J, Wagener G, Kirwan BA, de Brouwer S, Poole-Wilson PA; ACTION (A Coronary disease Trial Investigating Outcome with Nifedipine GITS) investigators. Effect of long-acting nifedipine on mortality and cardiovascular morbidity in patients with symptomatic stable angina and hypertension: the ACTION trial. J Hypertens 2005; 23(3): 641-648.

42. White WB. Angiotensin-converting enzyme inhibitors in the treatment of hypertension: an update. J Clin Hypertens (Greenwich) 2007; 9(11): 876-882.

43. Garg R, Yussuf S. Collaborative Group on ACE-inhibitor Trials. Overview of randomized trials of angiotensin converting enzyme inhibitors on mortality and morbidity in patients with heart failure. JAMA 1995; 273: 1450-1456.

44. Pfeffer MA. Angiotensin-converting enzyme inhibition in congestive heart failure: benefit and perspective. Am Heart 1993 Sep; 126(3 Pt 2): 789-793.

45. Flatcher MD, Yussuf S, Kober L, et al. for the ACE-Inhibitor Myocardial Infarction Collaborative Group. Long term ACE-inhibitor therapy in patients with heart failure or left ventricular dysfunction: a systematic overview of data from individual patients. Lancet 2000; 355: 1575-1581.

46. Palardy M, Ducharme A, O'Meara E. Inhibiting the renin-angiotensin system with ACE inhibitors or ARBs after MI. Curr Heart Fail Rep 2007; 4(4): 190-197.

47. Fox KM, Henderson JR, Bertrand ME, Ferrari R, Remme WJ, Simoons ML. The European trial on reduction of cardiac events with perindopril in stable coronary artery disease (EUROPA). Eur Heart J 1998 Sep; 19 Suppl J: J52-55.

48. Lewis EJ, Hunsicker LG, Bain RP, Rohde RD. The effect of angiotensinconverting-enzyme inhibition on diabetic nephropathy. The Collaborative Study Group. N Engl J Med 1993; 329: 1456-1462.

49. Maschio G, Alberti D, Janin G, Locatelli F, Mann JF, Motolese M, Ponticelli 
C, Ritz E, Zucchelli P. Effect of the angiotensin-converting-enzyme inhibitor benazepril on the progression of chronic renal insufficiency. The AngiotensinConverting-Enzyme Inhibition in Progressive Renal Insufficiency Study Group. N Engl J Med 1996; 334(15): 939-945.

50. Giatra I, Lau J, Levey AS. Effect of angiotensin-converting enzyme inhibitors on the progression of non-diabetic renal disease: a meta-analysis of randomized trials. Ann Intern Med 1997; 127: 337-345

51. Bakris GL, Weir MR. Angiotensin-converting enzyme inhibitor-associated elevations in serum creatinine: is this a cause for concern? Arch Intern Med 2000 Mar 13; 160(5): 685-693.

52. Cohn JN, Tognoni G on behalf of Valsartan Heart Failure Trial Investigators. A randomized trial of the angiotensin receptor blocker valsartan in chronic heart failure. N Engl J Med 2001; 345: 167-175.

53. Pfeffer MA, Swedberg K, Granger CB, Held P, McMurray IJ, Michelson EL, Olofsson B, Ostergren J, Yusuf S, Pocock S; CHARM Investigators and Committees. Effects of candesartan on mortality and morbidity in patients with chronic heart failure: The CHARM-Overall Program. Lancet 2003; 362 (9386): 759-766.

54. Konstam MA, Neaton JD, Dickstein K, Drexler H, Komajda M, Martinez FA, Riegger GA, Malbecq W, Smith RD, Guptha S, Poole-Wilson PA; HEAAL Investigators. Effects of high-dose versus low-dose losartan on clinical outcomes in patients with heart failure (HEAAL study): a randomised, doubleblind trial. Lancet 2009; 374(9704): 1840-1848.

55. Papademetriou V, Farsang C, Elmfeldt D, Hofman A, Lithell H, Olofsson B, Skoog I, Trenkwalder P, Zanchetti A, for the SCOPE study group. Stroke prevention with the angiotensin II type-1 receptor blocker candesartan in elderly patients with isolated systolic hypertension. The Study on Cognition and Prognosis in Elderly (SCOPE). J Am Coll Cardiol 2004; 44: 1175-1180.

56. Schrader I, Luders S, Kulschewsky A, et al., The ACCESS Study, Evaluation of acute candesartan cilexetil therapy in stroke survivors. Stroke 2003; 34: 1699-1703.

57. Brenner BM, Cooper ME, Zeeuw D, et al. Effects of losartan on renal and cardiovascular outcomes in patients with type 2 diabetes and nephropathy. N Engl J Med 2001; 345: 861-869.

58. Lewis EJ, Hunsicker LG, Clarke WR. Renoprotective effect of the angiotensin receptor antagonist irbersartan in patients with nephropathy due to type 2 diabetes. N Eng J Med 2001; 345: 851-860.

59. Mann JF, Schmieder RE, McQueen M, Dyal L, Schumacher H, Pogue J, Wang X, Maggioni A, Budaj A, Chaithiraphan S, Dickstein K, Keltai M, Metsärinne K, Oto A, Parkhomenko A, Piegas LS, Svendsen TL, Teo KK, Yusuf S; ONTARGET investigators. Renal outcomes with telmisartan, ramipril, or both, in people at high vascular risk (the ONTARGET study): a multicentre, randomised, double-blind, controlled trial. Lancet 2008; 372(9638): 547-553.

60. Parving H-H, Lehnert H, Brochner-Mortensen I, Gomis R, Andersen S, Arner P. The effect of irbersartan on the development of diabetic nephropathy in patients with type 2 diabetes. N Engl J Med 2001; 345: 870-878.

61. Reboldi G, Angeli F, Cavallini C, Gentile G, Mancia G, Verdecchia P. Comparison between angiotensin-converting enzyme inhibitors and angiotensin receptor blockers on the risk of myocardial infarction, stroke and death: a meta-analysis. J Hypertens 2008; 26(7): 1282-1289.

62. Strauss MH, Lonn EM, Verma S. Is the jury out? Class specific differences on coronary outcomes with ACE-Inhibitors and ARBs: Insight from meta-analysis and the Blood Pressure Lowering Treatment Trialist Collaboration. Eur Heart J 2005; 26: 2351-2353.

63. Cheung BM, Cheung GT, Lauder IJ, Lau CP, Kumana CR. Meta-analysis of large outcome trials of angiotensin receptor blockers in hypertension. J Hum Hypertens 2006; 20: 37-43.

64. Abuissa H, Jones PG, Marso SP, O'Keefe JH Jr. Angiotensin-converting enzyme inhibitors or angiotensin receptor blockers for prevention of type 2 diabetes: a meta-analysis of randomized clinical trials. J Am Coll Cardiol 2005; 46: 821-826.

65. Lindholm LH, Persson M, Alaupovic P, Carlberg B, Svensson A, Samuelsson O. Metabolic outcome during 1 year in newly detected hypertensives: results of the Antihypertensive Treatment and Lipid Profile in a North of Sweden Efficacy Evaluation (ALPINE study). J Hypertens 2003; 21: 1563-1574.
66. Wuerzner G, Azizi M. Renin inhibition with aliskiren. Clin Exp Pharmaco Physiol 2008; 35(4): 426-430.

67. Müller DN, Derer W, Dechend R. Aliskiren--mode of action and preclinical data. J Mol Med 2008; 86(6): 659-662.

68. Krop M, Garrelds IM, de Bruin RJ, van Gool JM, Fisher ND, Hollenberg NK, Jan Danser AH. Aliskiren accumulates in renin secretory granules and binds plasma prorenin. Hypertension 2008; 52(6): 1076-1083.

69. Danser AH. (Pro)renin receptors: are they biologically relevant? Curr Opin Nephrol Hypertens 2009; 18(1): 74-78.

70. Singh VP, Le B, Khode R, Baker KM, Kumar R. Intracellular angiotensin II production in diabetic rats is correlated with cardiomyocyte apoptosis, oxidative stress, and cardiac fibrosis. Diabetes 2008 Dec; 57(12): 3297-3306.

71. Sakoda M, Ichihara A, Kurauchi-Mito A, Narita T, Kinouchi K, MurohashiBokuda K, Saleem MA, Nishiyama A, Suzuki F, Itoh H. Aliskiren inhibits intracellular angiotensin II levels without affecting (pro)renin receptor signals in human podocytes. Am J Hypertens 2010; 23(5): 575-580.

72. Musini VM, Fortin PM, Bassett K, Wright JM. Blood pressure lowering efficacy of renin inhibitors for primary hypertension. Cochrane Database Syst Rev. 2008; 8;(4):CD007066.

73. Musini VM, Fortin PM, Bassett K, Wright JM. Blood pressure lowering efficacy of renin inhibitors for primary hypertension: a Cochrane systematic review. J Hum Hypertens 2009; 23(8): 495-502.

74. Luft FC, Weinberger MH. Antihypertensive therapy with aliskiren. Kidney Int 2008; 73(6): 679-683.

75. Pimenta E, Oparil S. Role of aliskiren in cardio-renal protection and use in hypertensives with multiple risk factors. Vasc Health Risk Manag 2009; 5(1): 453-463.

76. Solomon SD, Appelbaum E, Manning WJ, Verma A, Berglund T, Lukashevich V Cherif Papst C, Smith BA, Dahlöf B; Aliskiren in Left Ventricular Hypertrophy (ALLAY) Trial Investigators. Effect of the direct renin inhibitor aliskiren, the angiotensin receptor blocker losartan, or both on left ventricular mass in patients with hypertension and left ventricular hypertrophy. Circulation 2009 Feb 3; 119(4): 530-537.

77. Parving HH, Persson F, Lewis JB, Lewis EJ, Hollenberg NK; AVOID Study Investigators. Aliskiren combined with losartan in type 2 diabetes and nephropathy. N Engl J Med 2008 5; 358(23): 2433-2446.

78. Reappraisal of European Guidelines on hypertension management: a European Society of hypertension task force document. J Hypertens 2009 27: 2121-2158.

79. Hansson L, Zanchetti A, Carruthers SG, et al. Effects of intensive bloodpressure lowering and low-dose aspirin in patients with hypertension: principal results of the Hypertension Optimal Treatment (HOT) randomized trial. Lancet 1998; 351: 1755-1762.

80. UK Prospective Diabetes Study Group. Tight blood pressure control and the risk of macrovascular and microvascular complications in type diabetes. UKPDS 38. BMJ 1998; 317: 703-713.

81. American Diabetes Association. Standards of Medical Care in Diabetes 2010 Diabetes Care 2010, 33 (suppl 1): S1-S61.

82. Petterson JC, Adler S, BukartJM, et al. Blood pressure control, proteinuria, and the progression of renal disease. The Modification of Diet in Renal Disease Study (MDRD). Ann Intern Med 1995; 123: 754-762.

83. Du X, Cruickshank K, McNamee R, et al. Case-Control of stroke and quality of hypertension control in north west England. BMJ 1997; 341: 272-276.

84. Jamerson K, Weber MA, Bakris GL, Dahlöf B, Pitt B, Shi V, Hester A, Gupte J, Gatlin M, Velazquez EJ. Benazepril plus amlodipine or hydrochlorothiazide for hypertension in high-risk patients. N Engl J Med 2008; 359(23): 2417-2428.

85. Bakris GL, Sarafi PA, Weir MR, Dahlöf B, Pitt B, Jamerson K, Velazquez EJ, Staikos-Byrne L, Kelly RY, Shi V, Chiang YT, Weber MA, for the ACCOMPLISH Trial investigators. Renal outcomes with different fixed-dose combination therapies in patients with hypertension at high risk for cardiovascular events (ACCOMPLISH): a pre-specified secondary analysis of a randomised controlled trial. Lancet 2010:375(9721):1173-1181. 


\section{Diretrizes}

86. MacKinnon M, Shurraw S, Akbari A, Knoll GA, Jaffey J, Clark HD. Combination therapy with an angiotensin receptor blocker and an ACE inhibitor in proteinuric renal disease: a systematic review of the efficacy and safety data. Am J Kidney Dis 2006; 48(1): 8-20.

87. Kunz R, Friedrich C, Wolbers M, Mann JF. Meta-analysis: effect of monotherapy and combination therapy with inhibitors of the renin angiotensin system on proteinuria in renal disease. Ann Intern Med 2008; 148(1): 30-48.

88. Pimenta E, Gaddam KK, Oparil S. Mechanisms and treatment of resistant hypertension. J Clin Hypertens (Greenwich). 2008; 10(3): 239-244.

89. Antithrombotic Trialists' (ATT) Collaboration, Baigent C, Blackwell L, Collins R, Emberson J, Godwin J, Peto R, Buring J, Hennekens C, Kearney P, Meade T, Patrono C, Roncaglioni MC, Zanchetti A. Aspirin in the primary and secondary prevention of vascular disease: collaborative meta-analysis of individual participant data from randomised trials. Lancet 2009; 373(9678): 1849-1860.

90. Busnello RG, Melchior R, Faccin C, et al. Características associadas ao abandono do acompanhamento de pacientes hipertensos atendidos em um ambulatório de referência. Arq Bras Cardiol 2001; 76: 349-351.

91. Pierin AMG, Mion Jr D, Fukushima J, Pinto AR, Kaminaga M. O perfil de um grupo de pessoas hipertensas de acordo com conhecimento e gravidade da doença. In: Rev Esc Enf USP 2001; 35: 11-18.

92. Lessa I, Fonseca J. Raça, aderência ao tratamento e/ou consultas e controle da hipertensão arterial. Arq Bras Cardiol, 1997; 68: 443-449.
93. Strelec MAM, Pierin AMG, Mion Jr D. A influência do conhecimento sobre a doenças e atitude frente a tomada dos remédios no controle da hipertensão arterial. Arq Bras Cardiol 2003; 81: 349-354.

94. Gus I, Harzheim E, Zaslavsky C, Medina C, Gus M. Prevalência, reconhecimento e controle da hipertensão arterial sistêmica no Estado do Rio Grande do Sul. Arq Bras Cardiol 2004; 83(5): 424-428.

95. Pierin AMG, Strelec MAAM, Mion Jr. D. O desafio do controle da hipertensão arterial e a adesão ao tratamento. In: Pierin AMG. Hipertensão arterial: uma proposta para o cuidar. São Paulo: Ed. Manole, 2004; p. 275-289.

96. Vicek M, Bur A, Woisetschläger C, Herkner H, Laggner AN, Hirschl MM. Association between hypertensive urgencies and subsequent cardiovascular events in patients with hypertension. J Hypertens 2008; 26: 657-662.

97. Dib MW, Riera R, Ferraz MB. Estimate of the annual cost of arterial hypertension treatment in Brazil. Pan American Journal of Public Health 2010 (in press).

98. WHO Technical Report Series, no. 628, 1978 (Arterial hypertension: report of a WHO Expert Committee, p. 9)

99. Disponível em: http://educacao.cardiol.br/coracoesdobrasil. Acessado em 25 de Maio de 2009.

100. Moreira GC, Cipullo JP, Martin JF, Ciorlia LA, Godoy MR, Cesarino CB, Cordeiro JA, Lupino PL, Ciorlia G, Burdmann EA. Evaluation of the awareness, control and cost-effectiveness of hypertension treatment in a Brazilian city: populational study. J Hypertens 2009; 27(9): 1900-1907.

\section{Capítulo 7 - Hipertensão arterial sistêmica secundária}

A hipertensão arterial sistêmica secundária (HAS-S) tem prevalência de $3 \%$ a $5 \%$. Antes de se investigarem causas secundárias de HAS deve-se excluir:

- medida inadequada da PA;

- hipertensão do avental branco;

- tratamento inadequado;

- não-adesão ao tratamento;

- progressão das lesões nos órgãos-alvos da hipertensão;

- presença de comorbidades;

- interação com medicamentos.

As situações em que se deve investigar a possibilidade de HAS-S estão na tabela 1.

A seguir, serão discutidas as principais causas de HAS-S.

\section{1 - Hiperaldosteronismo primário (HAP)}

É um grupo de doenças nas quais a produção de aldosterona está aumentada de uma forma relativamente autônoma em relação ao sistema renina-angiotensina, não sendo supressível por sobrecarga salina ou bloqueio do SRAA. Essas doenças são representadas, principalmente, pela hiperplasia bilateral das adrenais (HBA) e pelo adenoma unilateral produtor de aldosterona (APA), mas podem ser causadas por hiperplasia adrenal unilateral, carcinoma adrenal, tumores extra-adrenais produtores de aldosterona, ou ter origem genética. A prevalência do HAP na população de hipertensos, de modo geral, está em torno de $6,1 \%$, mas pode variar de $3 \%$ a $22 \%$, sendo mais alta nos hipertensos em estágio 3 e/ou de difícil controle. Sabe-se que a prevalência de hipopotassemia no hiperaldosteronismo primário varia de $9 \%$ a $37 \%^{1-3}$.

As etapas para rastreamento, confirmação de diagnóstico e tratamento estão descritas na figura 1.

\section{2 - Feocromocitoma e paragangliomas}

São tumores de células argentafins que se localizam na medula adrenal (feocromocitomas) ou em regiões extra-adrenais (paragangliomas), que, em geral, produzem catecolaminas e se associam a quadro clínico de HAS paroxística (30\% dos casos) ou sustentada com ou sem paroxismos (50\% a $60 \%$ ). O diagnóstico laboratorial do tumor é baseado nas dosagens de catecolaminas e seus metabólitos no sangue e na urina (tabela 2).

Para o diagnóstico topográfico dos tumores e de metástases, os métodos de imagens recomendados são: tomografia computadorizada (TC) e ressonância nuclear magnética (RNM), ambas com sensibilidade próxima a $100 \%$ para tumores adrenais. Entretanto, a RNM mostrase superior na identificação dos paragangliomas. O mapeamento de corpo inteiro com metaiodobenzilguanidina (MIBG) tem sensibilidade de 56\% para os tumores malignos a $85 \%$ para os tumores benignos, com especificidade aproximada de 100\%. Octreoscan, mapeamento ósseo e tomografia por emissão de pósitrons (PET) com diferentes marcadores podem ser decisivos quando os exames de 
Tabela 1 - Achados que sugerem hipertensão arterial secundária

\begin{tabular}{|c|c|c|}
\hline Achados & Suspeita diagnóstica & Estudos diagnósticos adicionais \\
\hline $\begin{array}{l}\text { Ronco, sonolência diurna, síndrome metabólica (ver } \\
\text { item } 7.10 \text { do texto) }\end{array}$ & Apneia obstrutiva do sono & Polissonografia \\
\hline $\begin{array}{l}\text { Hipertensão resistente ao tratamento e/ou com } \\
\text { hipocalemia e/ou com nódulo adrenal }\end{array}$ & Hiperaldosteronismo primário & Relação aldosterona/atividade de renina plasmática \\
\hline $\begin{array}{l}\text { Insuficiência renal, doença cardiovascular } \\
\text { aterosclerótica, edema, ureia elevada, creatinina } \\
\text { elevada, proteinúria/hematúria }\end{array}$ & Doença renal parenquimatosa & $\begin{array}{l}\text { Taxa de filtração glomerular, ultrassonografia renal, } \\
\text { pesquisa de microalbuminúria ou proteinúria }\end{array}$ \\
\hline $\begin{array}{l}\text { Sopro sistólico/diastólico abdominal, edema pulmonar } \\
\text { súbito, alteração de função renal por medicamentos que } \\
\text { bloqueiam o sistema renina-angiotensina }\end{array}$ & Doença renovascular & $\begin{array}{c}\text { Angiografia por ressonância magnética ou tomografia } \\
\text { computadorizada, ultrassonografia com Doppler, } \\
\text { renograma, arteriografia renal }\end{array}$ \\
\hline $\begin{array}{l}\text { Uso de simpaticomiméticos, perioperatório, estresse } \\
\text { agudo, taquicardia }\end{array}$ & Catecolaminas em excesso & Confirmar normotensão em ausência de catecolaminas \\
\hline $\begin{array}{l}\text { Pulsos em femorais reduzidos ou retardados, raios- } x \text { de } \\
\text { tórax anormal }\end{array}$ & Coarctação da aorta & Doppler ou tomografia computadorizada de aorta \\
\hline $\begin{array}{l}\text { Ganho de peso, fadiga, fraqueza, hirsutismo, } \\
\text { amenorreia, face em "lua cheia", "corcova" dorsal, } \\
\text { estrias purpúricas, obesidade central, hipopotassemia }\end{array}$ & Síndrome de Cushing & $\begin{array}{l}\text { Determinações: cortisol urinário de } 24 \text { horas e cortisol } \\
\text { matinal (8h) basal e } 8 \text { horas após administração de } 1 \\
\text { mg de dexametasona às } 24 \mathrm{~h} \text {. }\end{array}$ \\
\hline $\begin{array}{l}\text { Hipertensão paroxística com cefaleia, sudorese e } \\
\text { palpitações }\end{array}$ & Feocromocitoma & $\begin{array}{l}\text { Determinações de catecolaminas e seus metabólitos } \\
\text { em sangue e urina }\end{array}$ \\
\hline $\begin{array}{l}\text { Fadiga, ganho de peso, perda de cabelo, hipertensão } \\
\text { diastólica, fraqueza muscular }\end{array}$ & Hipotireoidismo & Determinações de T4 livre e TSH \\
\hline $\begin{array}{l}\text { Intolerância ao calor, perda de peso, palpitações, } \\
\text { hipertensão sistólica, exoftalmia, tremores, taquicardia }\end{array}$ & Hipertireoidismo & Determinações de T4 livre e TSH \\
\hline $\begin{array}{l}\text { Litíase urinária, osteoporose, depressão, letargia, } \\
\text { fraqueza muscular }\end{array}$ & Hiperparatireoidismo & Determinações de cálcio sérico e PTH \\
\hline $\begin{array}{l}\text { Cefaleias, fadiga, problemas visuais, aumento de mãos, } \\
\text { pés e língua }\end{array}$ & Acromegalia & $\begin{array}{l}\text { Determinação IGF-1 e de hormônio do crescimento } \\
\text { basal e durante teste de tolerância oral à glicose }\end{array}$ \\
\hline
\end{tabular}

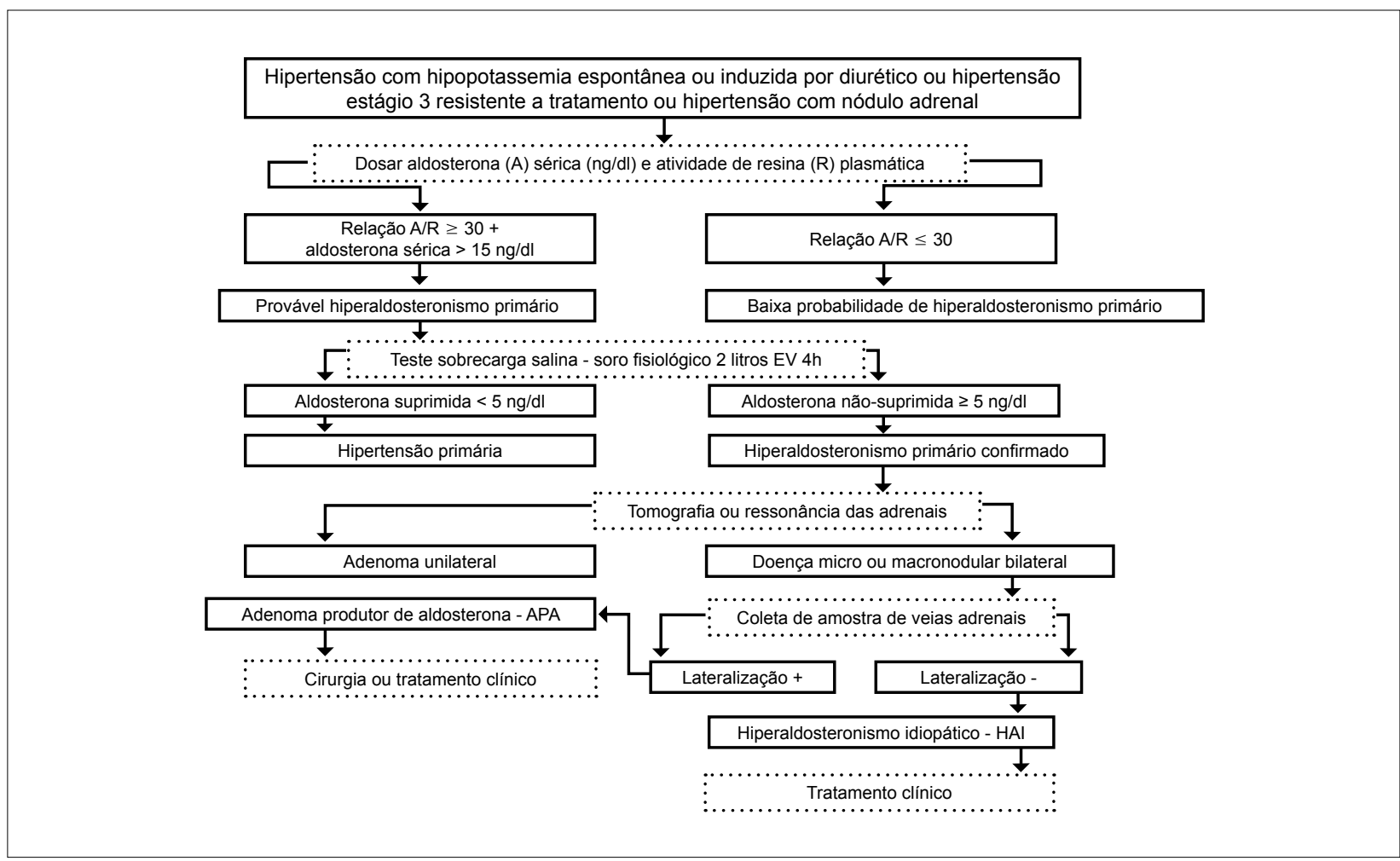

Fig. 1 - Fluxograma para investigação e tratamento do hiperaldosteronismo primário (HAP). 


\section{Diretrizes}

Tabela 2 - Percentuais de sensibilidade e especificidade com os respectivos intervalos de confiança dos testes bioquímicos para diagnóstico do feocromocitoma

\begin{tabular}{lcc}
\hline Teste Bioquímico & Sensibilidade & Especificidade \\
\hline Plasma & & \\
\hline Metanefrinas livres & $99(96-100)$ & $89(87-92)$ \\
\hline Catecolaminas & $84(78-89)$ & $81(78-84)$ \\
\hline Urina & \\
\hline Metanefrinas fracionadas & $97(92-99)$ & $69(64-72)$ \\
\hline Catecolaminas & $86(80-91)$ & $88(85-91)$ \\
\hline Metanefrinas - Total & $77(68-85)$ & $93(89-97)$ \\
\hline Ácido vanilmandélico & $64(55-71)$ & $95(93-97)$ \\
\hline
\end{tabular}

localização anteriormente citados são negativos ou então na investigação de doença maligna ${ }^{4}$.

O tratamento preferencial é o cirúrgico.

No tratamento clínico, medicamentoso, pré-operatório ou crônico são usados alfabloqueadores como prazosina ou doxazocina, combinados ou não com outros agentes, como inibidores da ECA, bloqueadores dos canais de cálcio e betabloqueadores (utilizados, apenas, após alfabloqueio efetivo). Em tumores inoperáveis ou no preparo pré-operatório pode ser utilizada, quando disponível, droga inibidora da síntese de catecolaminas: a alfametiltirosina $\left(\right.$ Demser $\left.^{\circledR}\right)$. Para a intervenção cirúrgica, recomenda-se controle da PA com o uso endovenoso de nitroprussiato de sódio e reposição volêmica, se necessária. Em crises agudas e durante a cirurgia, nitroprussiato de sódio e antiarrítmicos endovenosos (xylocaína) são agentes frequentemente utilizados ${ }^{5,6}$.

O seguimento clínico, bioquímico e radiológico, contínuo dos pacientes é essencial para a detecção de recorrências ou metástases na doença maligna e de um segundo tumor nas síndromes familiares.

\section{3 - Hipotireoidismo}

A prevalência de hipotireoidismo no Brasil não é conhecida com precisão, mas, estima-se que esteja entre $5 \%$ e $10 \%$, sendo mais frequente no sexo feminino ${ }^{7}$. A hipertensão arterial sistêmica ocorre em $20 \%$ dos pacientes com hipotireoidismo ${ }^{8-10}$. O diagnóstico precoce é feito pela dosagem de TSH aumentado e confirmado com a diminuição gradativa de T4 livre. Achados clínicos mais comuns são ganhos de peso, queda de cabelo e fraqueza muscular.

O tratamento deve ser iniciado com a reposição de hormônio tireoidiano e caso persista a HAS está indicado o uso de medicamentos anti-hipertensivos (C).

\section{4 - Hipertireoidismo}

A prevalência de hipertireoidismo no Brasil está em torno de $6,5 \%^{7}$, mas pelo excesso de iodo na dieta provavelmente esta doença deve estar se tornando mais prevalente.

A apresentação clínica mimetiza um quadro hiperadrenérgico. Os principais sintomas incluem palpitação, tremor, fadiga, intolerância ao calor, hiperatividade, perda de peso e labilidade emocional. Os sinais mais importantes são: exoftalmia, hipertermia, reflexos exaltados, primeira bulha com acentuação do componente pulmonar e pele úmida ${ }^{11}$.

O diagnóstico é confirmado por nível baixo de TSH e elevado de T4 livre. O tratamento é geralmente acompanhado por normalização da PA. Betabloqueadores são a primeira escolha para controlar os sintomas adrenérgicos (C).

\section{5 - Hiperparatireoidismo}

O hiperparatireoidismo primário pode ser devido a um adenoma ou a hiperplasia da glândula paratireóide. O hiperparatireoidismo secundário geralmente surge em estágios avançados de insuficiência renal crônica. Existe ainda o pseudo-hiperparatireoidismo que é devido a uma resistência à ação do paratormônio. Em todas essas situações é frequente HAS com prevalências de 10\% a 70\% em hiperparatireoidismo primário e 40\%-50\% em pseudo-hiperparatireoidismo. As causas que levam ao aumento da PA são multifatoriais. $\mathrm{O}$ quadro clínico manifesta-se, geralmente, por história de litíase renal, osteoporose, depressão, letargia e fraqueza muscular. $\mathrm{O}$ diagnóstico é feito pela dosagem de cálcio e PTH. A correção cirúrgica do hiperparatireoidismo reduz a PA dos hipertensos e não modifica a PA nos normotensos ${ }^{12}$.

\section{6 - Síndrome de Cushing}

Hipertensão arterial sistêmica com obesidade central, fascies em lua cheia, pletora, fraqueza muscular, cansaço fácil, hirsutismo, estrias abdominais e distúrbios emocionais levantam a suspeita clínica de HAS secundária à síndrome de Cushing. Esta síndrome é devida ao excesso de cortisol, que aumenta a retenção de sódio e água promovendo expansão de volume, sendo esse fato um dos fatores da síndrome relacionados com o aparecimento de HAS em cerca de $80 \%$ dos casos. A causa do excesso de cortisol pode ser exógena devido à administração de glicocorticoides ou do hormônio adrenocorticotrópico (ACTH), ou endógena, por excesso de produção de cortisol ou de ACTH. Teste de supressão com dexametasona e medida do cortisol livre na urina de $24 \mathrm{~h}$ são os exames recomendados para a investigação para fins diagnósticos.

A escolha e o sucesso do tratamento dependem do diagnóstico correto e da instituição do tratamento adequado. O tratamento de escolha da síndrome de Cushing é a ressecção cirúrgica da pituitária, da fonte ectópica de ACTH ou, em alguns casos, a remoção do tumor adrenocortical produtor de cortisol. Para o controle da PA é fundamental o controle hidrossalino com dieta e diuréticos, bem como associação com outras classes de medicamentos, como os inibidores da angiotensina II, os antagonistas dos canais de cálcio e os simpatolíticos centrais ${ }^{13}$.

\section{7 - Acromegalia}

A grande maioria dos casos de acromegalia decorre do excesso de hormônio de crescimento $(\mathrm{GH})$ produzido por um adenoma da glândula pituitária. Outras formas de acromegalia são liberações do $\mathrm{GH}$ em excesso devido a um tumor hipotalâmico ou carcinoide localizado em outras áreas.

As alterações estruturais e funcionais da acromegalia 
respondem bem ao controle dos níveis sanguíneos de $\mathrm{GH}$. Em muitos casos há cura com controle da PA, particularmente quando o diagnóstico e o tratamento da acromegalia são realizados precocemente ${ }^{14}$.

\section{8 - Coarctação da aorta ${ }^{15}$}

A coarctação da aorta (CoAo) é causa de HAS-S encontrada especialmente em crianças e adultos jovens, sendo a quarta causa mais frequente de cardiopatia congênita, correspondendo a $7 \%$ das doenças cardíacas inatas. É mais prevalente no sexo masculino requerendo tratamento cirúrgico no primeiro ano de vida.

Pode ocorrer em qualquer local da aorta, embora seja mais comum logo após a origem da subclávia esquerda. É muito importante o diagnóstico precoce, pois há uma relação inversa entre o tempo de exposição à HAS e a sua reversão após a correção. O exame físico revela HAS em membros superiores com uma pressão arterial sistólica pelo menos $10 \mathrm{mmHg}$ maior na artéria braquial em relação à artéria poplítea. A ausência ou diminuição dos pulsos pediosos pode também representar indício da CoAo. A ausculta pode revelar sopro sistólico interescapular proveniente do local da coarctação e também sopro sistólico amplo em crescendo-decrescendo em toda a parede torácica por causa da dilatação das artérias intercostais colaterais.

O tratamento da CoAo é sempre intervencionista, podendo ser realizado por procedimento endovascular em indivíduos mais jovens ou em crianças, ou cirurgia, nos casos de hipoplasia do arco aórtico e/ou necessidade de ressecção da coarctação. A resposta sobre a PA ao tratamento intervencionista da CoAo depende, em grande parte, da duração da hipertensão no período pré-operatório e da idade do paciente. Há cura da HAS em até $50 \%$ dos pacientes, mas pode recorrer tardiamente, especialmente se a intervenção foi feita em idades mais avançadas.

\section{9 - Hipertensão renovascular}

A hipertensão renovascular (HR) é definida como HAS decorrente de uma isquemia renal, geralmente causada por uma lesão obstrutiva parcial ou completa de uma ou ambas as artérias renais. Sua prevalência atinge $5 \%$ dos pacientes com HAS ${ }^{16,17-19}$.

A HR pode ser causada por aterosclerose, a causa mais comum, com prevalência em torno de $90 \%$, ou displasia fibromuscular ${ }^{20,21}$. A estenose aterosclerótica de artéria renal é geralmente progressiva. Cerca de $40 \%$ das obstruções arteriais acima de $75 \%$ evoluem para obstrução total entre um a cinco anos ${ }^{22-25}$.

A displasia fibromuscular, por sua vez, é mais frequentemente encontrada em mulheres jovens de cor branca. Entre os vários tipos de lesões fibrodisplásicas a mais comum é aquela que envolve a camada média da parede do vaso. Geralmente seu acometimento é bilateral envolvendo as porções distais da artéria renal.

\subsection{1 - Diagnóstico}

Devido à baixa incidência de HR em pacientes com hipertensão não-complicada, o rastreamento aplicado a todos os indivíduos não é custo-efetivo, nessas condições ${ }^{25}$. Algumas características clínicas (tabela 3) chamam a atenção para a possibilidade de hipertensão renovascular.

Os métodos disponíveis e mais comumente utilizados para o diagnóstico de HR apresentam sensibilidade e especificidade diferentes (tabela 4) (nível de evidência B).

\subsection{2 - Tratamento}

Três são as possibilidades terapêuticas na HR: medicamentosa, dilatação da estenose da artéria renal com ou sem implante de stents no vaso acometido e abordagem cirúrgica por revascularização ou autotransplante.

\subsubsection{1 - Medicamentoso}

O tratamento medicamentoso é uma opção terapêutica bastante aceitável na ausência de evidências sugestivas de que a estenose da artéria renal é causadora de HAS ou isquemia renal. A maior parte dos pacientes com estenose de artéria renal é formada por indivíduos com HAS primária preexistente e doença aterosclerótica concomitante. Não existe teste que determine se existe uma relação causal entre estenose da artéria renal e hipertensão arterial. O estudo CORAL (Cardiovascular Outcomes in Renal Atherosclerotic Lesions), ainda em andamento, tem por objetivo responder qual a abordagem mais apropriada para os casos de HR de causa aterosclerótica ${ }^{26}$.

Como a HAS secundária à estenose da artéria renal pode ser dependente da ativação do SRAA, o uso de medicamentos que o bloqueiem, como os inibidores da enzima conversora

\section{Tabela 3 - Características sugestivas de hipertensão renovascular}

\begin{tabular}{l}
\hline Início abrupto da hipertensão arterial, antes dos 30 ou após os 50 anos \\
\hline Hipertensão estágio II ou III, acelerada ou maligna \\
\hline Hipertensão refratária à múltipla terapia \\
\hline Hipertensão estágio II ou III na presença de aterosclerose difusa \\
\hline Presença de sopro epigástrico sistólico/diastólico \\
\hline Hipertensão estágio II ou III com insuficiência renal sem explicação \\
\hline Azotemia significativa induzida por inibidor da enzima conversora da \\
angiotensina ou por bloqueador do receptor da angiotensina \\
\hline Assimetria no tamanho renal \\
\hline Edema pulmonar sem causa aparente em paciente com hipertensão \\
\hline
\end{tabular}

Tabela 4 - Testes para detecção de hipertensão renovascular

\begin{tabular}{lcc}
\hline Tipo de teste & Sensibilidade (\%) & Especificidade (\%) \\
\hline Cintilografia com captopril & $92-94$ & $95-75$ \\
\hline Ultrassom com Doppler & $84-91$ & $95-97$ \\
\hline Angiografia digital & 88 & 90 \\
\hline Angiorressonância* & $90-95$ & 95 \\
\hline
\end{tabular}

*Na identificação de estenoses da artéria renal acima de 50\%. 


\section{Diretrizes}

da angiotensina (nível de evidência A) e os bloqueadores dos receptores $\mathrm{AT}_{1}$ da angiotensina II (nível de evidência $\mathrm{B}$ ) podem ser especialmente eficazes ${ }^{27}$. Contudo, esses medicamentos são contraindicados em pacientes com estenose de artéria renal bilateral ou unilateral em rim único. No mesmo nível de evidência em que estão os inibidores da enzima conversora da angiotensina estão os antagonistas dos canais de cálcio (nível de evidência A) ${ }^{28,29}$.

\subsubsection{2 - Cirurgia x procedimento percutâneo}

Considera-se estenose significativa de artéria renal a que oclui pelo menos $60 \%$ da luz do vaso estimada visualmente com gradiente de lesão maior que $20 \mathrm{mmHg}$ ou gradiente médio maior que $10 \mathrm{mmHg}^{30}$.

Pacientes com lesões fibrodisplásicas e aparecimento recente de HAS tendem a se beneficiar mais com a correção da estenose, podendo até mesmo evoluir para a normalização da $\mathrm{PA}^{31,32}$. Pacientes com lesões ateroscleróticas e longa história de HAS podem apresentar pouca ou nenhuma melhora após o procedimento ${ }^{33-36}$. Podem ocorrer complicações em decorrência da intervenção percutânea para correção da estenose de artéria renal. A tabela 5 mostra as possíveis complicações em decorrência da angioplastia.

\subsection{0 - Síndrome da apneia e hipopneia obstrutiva do sono (SAHOS)}

A SAHOS é definida como a obstrução recorrente das vias aéreas superiores durante o sono, resultando em períodos de apneia, hipopneia, dessaturação de oxiemoglobina e despertares frequentes com alteração da arquitetura do sono $^{36}$. Diversas evidências clínicas e experimentais sugerem que a SAHOS está relacionada ao desenvolvimento de HAS independentemente da obesidade ${ }^{37-41}$. O conjunto dessas e de outras evidências fez com que fosse incluída, em 2003, como uma causa de HAS-S ${ }^{42}$. Estima-se que a prevalência da SAHOS em pacientes com HAS e hipertensão arterial refratária gire em torno de $30 \%$ a $56 \%$ e $71 \%$ a $82 \%$ respectivamente ${ }^{43-46}$. Evidências sugerem também que a SAHOS pode contribuir para o surgimento de lesões de órgãos-alvo ${ }^{47}$ e de aceleração do processo de aterosclerose nos pacientes hipertensos ${ }^{68}$. No entanto, a falta de diagnóstico de SAHOS é ainda muito frequente f4,49,50. $^{\text {. }}$

\section{Tabela 5 - Complicações possíveis da revascularização percutânea}

\begin{tabular}{l}
\hline Formação de hematomas \\
\hline Hemorragias \\
\hline Infecção \\
\hline Formação de pseudoaneurisma \\
\hline Formação de fístula arteriovenosa \\
\hline Nefropatia induzida por contraste \\
\hline Insuficiência renal por microembolização de cristais de colesterol \\
\hline Embolia para membros inferiores ou mesentério \\
\hline Perfuração da artéria renal \\
\hline Óbito (raramente) \\
\hline
\end{tabular}

Embora os mecanismos precisos pelos quais promova o aumento persistente da PA, não somente durante o período de sono, não sejam totalmente conhecidos, alguns importantes componentes que contribuem diretamente para o remodelamento vascular já foram descritos. Entre eles incluem-se a ativação simpática, diminuição da sensibilidade dos barorreceptores, aumento de marcadores inflamatórios, espécies reativas de oxigênio, endotelina-1, além de disfunção endotelial, dentre outros ${ }^{51}$.

A suspeita clínica deve ser realizada especialmente se o paciente tiver diagnóstico concomitante de síndrome metabólica, pois esta condição mostrou ser uma excelente preditora de AOS em pacientes com $\mathrm{HAS}^{44}$. Deve-se, também, considerar essa possibilidade em pacientes hipertensos entre 40 e 70 anos, sobretudo se houver alta probabilidade estimada pela aplicação do questionário de Berlin ${ }^{51}$ ou quando o paciente apresentar alterações no padrão de descenso fisiológico do sono ${ }^{53}$.

O diagnóstico é confirmado pelo achado de cinco ou mais episódios de apneia e/ou hipopneia por hora - índice de apneia-hipopneia - na polissonografia ${ }^{37}$.

Para o tratamento da SAHOS, considerar sempre a perda de peso, particularmente nos indivíduos com HAS associada a sobrepeso ou obesidade ${ }^{54}$. O tratamento de escolha para os casos moderados e graves (índice de apneia-hipopneia $\geq$ 15 eventos por hora) é o uso da pressão positiva contínua em vias aéreas superiores (CPAP) durante o sono ${ }^{52}$. Este tratamento parece resultar em reduções da PA em hipertensos nãocontrolados e especialmente em hipertensos refratários ${ }^{5-58}$. No que diz respeito ao tratamento anti-hipertensivo medicamentoso, não há, até o momento, evidências de que uma classe anti-hipertensiva seja superior a outra ${ }^{58}$.

\subsection{1 - Doença renal crônica (DRC)}

A associação entre HAS e DRC é bem conhecida, tendo em vista que a doença renal é de longe a maior causa de HAS secundária ${ }^{59-62}$. Sua prevalência é bastante elevada em pacientes com doença renal, situando-se entre $60 \%-100 \%$, de acordo com o tipo de população estudada ${ }^{59-62}$. Entretanto, existem diferentes tipos de acometimento renal, sendo o diagnóstico causal importante para a escolha adequada do tratamento anti-hipertensivo a ser instituído ${ }^{63,64}$.

Os principais mecanismos patogênicos da HAS na DRC são a sobrecarga de volume e a maior ativação do SRAA ${ }^{60-62,64}$.

A meta a ser atingida com o tratamento da HAS em pacientes com DRC deve ser de PA $\leq 130 / 80 \mathrm{mmHg}$ $(B)^{63,65}$. Todas as classes de anti-hipertensivos são eficazes na redução da PA nesses pacientes ${ }^{63,65,66}$. Assim, o tratamento deve ser individualizado, tendo-se em mente a causa da DRC e a presença de doença cardiovascular preexistente. $\mathrm{O}$ tratamento anti-hipertensivo em pacientes com DRC deve visar não apenas a redução da PA, mas também a redução da proteinúria ${ }^{63,65,66}$. Os IECAs e os BRAs II reduzem a proteinúria e a progressão da DRC independentemente da doença de base $(A)^{63}$.

Os inibidores diretos de renina mostraram-se efetivos na redução da PA e da albuminúria em pacientes diabéticos; contudo, pelo pequeno número de estudos, e pela não 
Tabela 6 - Medicamentos e drogas, lícitas e ilícitas, relacionadas com o desenvolvimento ou agravamento da hipertensão arterial sistêmica

\begin{tabular}{|c|c|c|}
\hline Classe de medicamentos & Efeito sobre a PA e frequência & Ação sugerida \\
\hline \multicolumn{3}{|l|}{ Imunossupressores } \\
\hline Ciclosporina, tacrolimus & Intenso e frequente & $\begin{array}{l}\text { Inibidor de ECA e antagonista de canal de cálcio (nifedipino/ } \\
\text { anlodipino). Ajustar nível sérico. Reavaliar opções }\end{array}$ \\
\hline \multicolumn{3}{|l|}{ Glicocorticoide } \\
\hline \multicolumn{3}{|l|}{ Anti-inflamatórios não-esteroides } \\
\hline Inibidores da ciclooxigenase 1 e ciclooxigenase 2 & Eventual, muito relevante com uso contínuo & Observar função renal e informar efeitos adversos \\
\hline \multicolumn{3}{|l|}{ Anorexígenos/Sacietógenos } \\
\hline Anfepramona e outros & Intenso e frequente & Suspensão ou redução de dose \\
\hline Sibutramina & Moderado, mas pouco relevante & $\begin{array}{l}\text { Avaliar a redução da pressão arterial obtida com a redução } \\
\text { de peso }\end{array}$ \\
\hline Vasoconstritores, incluindo derivados do ergot & Variável, mas transitório & Usar por período determinado \\
\hline \multicolumn{3}{|l|}{ Hormônios } \\
\hline Eritropoietina humana & Variável e frequente & $\begin{array}{l}\text { Avaliar hematócrito e dose } \\
\text { semanal }\end{array}$ \\
\hline Anticoncepcionais orais & Variável, prevalência de hipertensão até $5 \%$ & Avaliar a substituição do método com especialista \\
\hline $\begin{array}{l}\text { Terapia de reposição estrogênica (estrogênios } \\
\text { conjugados e estradiol) }\end{array}$ & Variável & Avaliar risco e custo-benefício \\
\hline Hormônio de crescimento (adultos) & Variável, uso cosmético & Suspensão \\
\hline \multicolumn{3}{|l|}{ Antidepressivos } \\
\hline Inibidores da monoaminoxidase & Intenso, infrequente & Abordar como crise adrenérgica \\
\hline Tricíclicos & Variável e frequente & $\begin{array}{l}\text { Abordar como crise adrenérgica Vigiar interações } \\
\text { medicamentosas }\end{array}$ \\
\hline \multicolumn{3}{|l|}{ Drogas ilícitas e álcool } \\
\hline Anfetamina, cocaína e derivados & Efeito agudo, intenso. Dose-dependente & Abordar como crise adrenérgica \\
\hline Álcool & $\begin{array}{l}\text { Variável e dose-dependente } \\
\text { Muito prevalente }\end{array}$ & $\begin{array}{l}\text { Vide tratamento } \\
\text { não-medicamentoso }\end{array}$ \\
\hline
\end{tabular}

inclusão de pacientes com DRC estágios 4-5 nos estudos realizados, a importância desta classe de medicamentos nessas condições ainda não está completamente estabelecida ${ }^{67,71}$.

Tendo-se em mente que a hipervolemia é um importante determinante da elevação da PA nesses pacientes, os diuréticos devem ser incluídos na maioria dos esquemas anti-hipertensivos $(A)^{63,65,73,74}$. Antagonistas dos canais de cálcio não-dihidropirimidínicos são efetivos na redução da proteinúria em pacientes com DRC secundária a nefropatia diabética ${ }^{63,74-76}$. Em contrapartida, os dihidropirimidínicos, além de terem mostrado ser menos efetivos que outras classes de drogas em reduzir a progressão da doença renal, podem também agravar a proteinúria em pacientes com DRC, diabéticos e não-diabéticos. Por esta razão, em pacientes com DRC e proteinúria, recomenda-se o uso dos ACC dihidropirimidínicos apenas se associados a um IECA ou $\mathrm{BRA}^{63,77-80}$. Como é grande a prevalência de doença coronariana em pacientes com DRC, os betabloqueadores com frequência fazem parte do esquema anti-hipertensivo desta população. Nesse sentido é interessante notar que o carvedilol, especificamente, mostrou-se eficaz na redução da albuminúria em pacientes diabéticos tipo $2^{63,81}$. Sabendo-se, também, que pacientes com DRC apresentam atividade aumentada do sistema nervoso simpático, os alfabloqueadores e os inibidores adrenérgicos de ação central são medicamentos que podem ser utilizados, alternativamente, em associação com outras classes de anti-hipertensivos ${ }^{85,82}$. Por fim, antagonistas da aldosterona também se mostraram efetivos na redução da proteinúria, mesmo em pacientes que já se encontravam utilizando IECA e BRA em associação, contudo com aumento do risco de hipercalemia ${ }^{63,83}$.

Em pacientes com DRC estágio 5 em terapia dialítica, a hipervolemia tem papel preponderante na etiologia da HAS. Dessa forma, o ajuste adequado do "peso-seco" é a medida primordial para controle da PA nessa população $(\mathrm{A})^{84-95}$.

\subsection{2 - Medicamentos e drogas}

A tabela 6 apresenta os medicamentos e drogas, lícitas e ilícitas, relacionadas com o desenvolvimento ou agravamento da HAS. 


\section{Diretrizes}

\section{Referências}

1. Funder JW, Carey RM, Fardella C, Gomez-Sanchez CE, Mantero F, Stowasser $M$, et al. Case detection, diagnosis and treatment of patients with primary aldosteronism: an Endocrine Society Clinical Practice Guideline. J Clin Endocrinol Metab 2008; 93: 3266-3281.

2. Stowasser M. Update in primary aldosteronism. J Clin Endocrinol Metab 2009; 94: 3623-3630.

3. Wiebke A. A detour guide to The Endocrine Society Clinical Practice Guideline on case detection, diagnosis and treatment of patients with primary aldosteronism. Eur J Endocrinol 2009 Oct 1. [Epub ahead of print].

4. Eisenhofer G, Siegert G, Kotzerke J, Bornstein SR, Pacak K. Current Progress and Future Challenges in the Biochemical Diagnosis and Treatment of Pheochromocytomas and Paragangliomas. Horm Metab Res 2008; 40: 329-447.

5. Pacak K, Eisenhofer G, Ahlman H, Bornstein SR, Gimenez-Roquelo AP, Grossman AB, et al. Pheochromocytoma: recommendations for clinical practice from the First International Symposium. Nat Clin Prac Endocrinol Metab 2007; 3(2): 92-102.

6. Pacak K. Approach to the patient. Preoperative Management of the Pheochromocytoma Patient. J Clin Endocrinol Metab 2007; 92: 4069-4079.

7. Duarte GC, Tomimori EK, Camargo RYA, Rubio IGS, Wajngarten M, Rodrigues AG, et al. The prevalence of thyroid dysfunction in elderly cardiology patients with mild excessive iodine intake in the urban area of São Paulo. Clinics 2009; 64: 135-142.

8. Chiong JR, Aronow WS, Khan IA, Nair CK, Vijayaraghavan K, Dart RA, et al. Secondary hypertension: current diagnosis and treatment. Int J Cardiol 2008; 124: 6-21.

9. Liu D, Jiang F, Shan Z, Wang B, Wang J, Lai Y, et al. A cross-sectional survey of relationship between serum TSH level and blood pressure. J Hum Hypertens 2009; advance on line publication 25 june.

10. Dernellis J, Panaretou M. Effects of thyroid replacement therapy on arterial blood pressure in patients with hypertension and hypothyroidism. Am Heart J 2002; 143: 718-724.

11. Volzke H, Ittermann T, Schmidt CO, Dorr M, John U, Wallaschofski H, et al. Subclinical hyperthyroidism and blood pressure in a population-based prospective cohort study. Eur J End 2009; 161: 615-621.

12. Heyliger A, Tangpricha V, Weber C, Sharma J. Parathyroidectomy decreases systolic and diastolic blood pressure in hypertensive patients with primary hyperparathyroidism. Surgery 2009 Dec; 146(6): 1042-1047.

13. Magiakou MA, Smymaki P, Chrousos GP. Hypertension in Cushing's syndrome. Clin Endocrinol Metab 2006; 20: 467-482.

14. Ezzat S, Foster MJ, Berchtold P, Redelmeier DA, Boerlin V, Harris AG. Acromegaly: clinical and biochemical features in 500 patients. Medicine 1994; 73: 233-240.

15. Webb GD, Smallhorn JF, Therrien J, et al. Congenital heart disease. In: Braunwald E, Zipes D, Libby P (eds). Heart Disease. Philadelphia: Elsevier; 2005: 1532-1535.

16. Elliott WJ. Secondary hypertension: renovascular hypertension. In: Black \& Elliott WG (eds). Hypertension: a companion to Braunwald's heart disease. Saunders Elsevier 2007, pp 93-105. RV.

17. Uzu T, Inoue T, Fujii T, et al. Prevalence and predictors of renal artery stenosis in patients with myocardial infarction. Am J Kidney Dis 1997; 29: 733-738.

18. Wilms G, Marchal G, Peene P, et al. The angiographic incidence of renal artery stenosis in the arteriosclerotic population. Eur J Radiol 1990; 10: 195-197.

19. Swartbol P, Thorvinger BO, Parsson $\mathrm{H}$, et al. Renal artery stenosis in patients with peripheral vascular disease and its correlation to hypertension: a retrospective study. Int Angiol 1992; 11: 195-199.

20. Safian RD, Textor SC. Renal-artery stenosis. N Engl J Med 2001; 344 : 431-442.

21. White, CJ. Catheter-based therapy for atherosclerotic renal artery stenosis. Circulation 2006; 113: 1464-1473.
22. Schreiber MJ, PohI MA, Novick AC. The natural history of atherosclerotic and fibrous renal artery disease. Urol Clin North Am 1984; 11: 383-392.

23. Zierler RE, Bergelin RO, Davidson RC, et al. A prospective study of disease progression in patients with atherosclerotic renal artery stenosis. Am J Hypertens 1996; 9: 1055-1056.

24. Zierler RE. Screening for renal artery stenosis: is it justified? Mayo Clin Proc 2002; 77: 307-308.

25. Cooper CJ, Murphy TP, Matsumoto A, Steffes M, Cohen DJ, Jaff M, et al. Stent revascularization for the prevention of cardiovascular and renal events among patients with renal artery stenosis and systolic hypertension: rationale and design of the CORAL trial. Am Heart J 2006; 152: 59-66.

26. Plouin PF, Chatellier G, Darne B, et al. Blood pressure outcome of angioplasty in atherosclerotic renal artery stenosis: a randomized trial. Essai Multicentrique Medicaments vs. Angioplastie (EMMA) Study Group. Hypertension 1998; 31: 823-829.

27. Hollenberg NK. Medical therapy of renovascular hypertension: efficacy and safety of captopril in 269 patients. Cardiovasc Rev Repl 1983; 4: 852-876.

28. Olin JW. Role of duplex ultrasonography in screening for significant renal artery disease. Urol Clin North Am 1994; 21: 215-226.

29. Luscher TF, Keller HM, Imhof HG, et al. Fibromuscular hyperplasia:extension of the disease and therapeutic outcome: results of the University Hospital Zurich Cooperative Study on Fibromuscular Hyperplasia. Nephron 1986; 44 (suppl 1): 109-114.

30. Schreiber MJ, Pohl MA, Novick AC. The natural history of atherosclerotic and fibrous renal artery disease. Urol Clin North Am 1984; 11: 383-392.

31. Watson PS, Hadjipetrou P, Cox SV, Piemonte TC, Eisenhauer AC. Efect of renal artery stenting on renal function and size in patients with atherosclerotic renovascular disease. Circulation 2000; 102: 1671-1677.

32. Nordmann AJ, Woo K, Parkes R, Logan AG. Ballon angioplasty or medical therapy for hypertensive patients with atherosclerotic renal artery stenosis? A meta-analysis of randomized controlled trials. Am J Med 2003; 114: 44-50.

33. Leertouwer TC, Gussenhoven EJ, Bosch JL, et al. Stent placement for renal artery stenosis: where do we stand? A meta-analysis. Radiology 2000; 216 : 78-85.

34. Boisclair C, Therasse E, Oliva VL, Soulez G, Bui BT, Quérin S, et al. Treatment of renal angioplasty failure by percutaneous renal artery stenting with Palmaz stents. AJR Am J Roentgenol 1997; 168(1): 245-251.

35. Stanley JC. Surgical treatment of renovascular hypertension. Am J Surg. 1997; 174(2): 102-110.

36. Sleep-related breathing disorders in adults: recommendations for syndrome definition and measurement techniques in clinical research. The Report of an American Academy of Sleep Medicine Task Force. Sleep. 1999; 22(5): 667-689.

37. Peppard PE, Young T, Palta M, Skatrud J. Prospective study of the association between sleep-disordered breathing and hypertension. N Engl J Med 2000; 342: 1378-1384.

38. Nieto FJ, Young TB, Lind BK, Shahar E, Samet JM, Redline S, et al. Association of sleep-disordered breathing, sleep apnea, and hypertension in a large community-based study. Sleep Heart Health Study. JAMA. 2000; 283(14): 1829-1836. Erratum in: JAMA 2002; 288(16): 1985.

39. Lavie P, Herer P, Hoffstein V. Obstructive sleep apnoea syndrome as a risk factor for hypertension: population study. BMJ 2000; 320(7233): 479-482.

40. Brooks D, Horner RL, Kozar LF, Render-Teixeira CL, Phillipson EA. Obstructive sleep apnea as a cause of systemic hypertension. Evidence from a canine model. J Clin Invest 1997; 99(1): 106-109.

41. Chobanian AV, Bakris GL, Black HR, Cushman WC, Green LA, Izzo JL Jr et al. Joint National Committee on Prevention, Detection, Evaluation, and Treatment of High Blood Pressure. National Heart, Lung, and Blood Institute; National High Blood Pressure Education Program Coordinating Committee. Seventh report of the Joint National Committee on Prevention, Detection, Evaluation, and Treatment of High Blood Pressure. Hypertension. 2003; 42(6): 1206-1252. 
42. Sjöström C, Lindberg E, Elmasry A, Hägg A, Svärdsudd K, Janson C. Prevalence of sleep apnoea and snoring in hypertensive men: a population based study. Thorax 2002; 57(7): 602-607.

43. Drager LF, Genta PR, Pedrosa RP, Nerbass FB, Gonzaga CC, Krieger EM, et al. Characteristics and predictors of obstructive sleep apnea in patients with systemic hypertension. Am J Cardiol. 2010 (in press).

44. Gonçalves SC, Martinez D, Gus M, de Abreu-Silva EO, Bertoluci C, Dutra I, et al. Obstructive sleep apnea and resistant hypertension: a case-control study. Chest. 2007; 132(6): 1858-1862.

45. Logan AG, Perlikowski SM, Mente A, Tisler A, Tkacova R, Niroumand M, et al. High prevalence of unrecognized sleep apnoea in drug-resistant hypertension. J Hypertens 2001; 19(12): 2271-2277.

46. Drager LF, Bortolotto LA, Figueiredo AC, Silva BC, Krieger EM, Lorenzi-Filho G. Obstructive sleep apnea, hypertension and their interaction on arterial stiffness and heart remodeling. Chest 2007; 131: 1379-1386.

47. Drager LF, Bortolotto LA, Krieger EM, Lorenzi-Filho G. Additive effects of obstructive sleep apnea and hypertension on early markers of carotid atherosclerosis. Hypertension 2009; 53(1): 64-69.

48. Silverberg DS, Oksenberg A, laina A. Sleep related breathing disorders are common contributing factors to the production of essential hypertension but are neglected, underdiagnosed, and undertreated. Am J Hypertens 1997; 10: 1319-1325.

49. Gus M, Gonçalves SC, Martinez D, de Abreu Silva EO, Moreira LB, Fuchs SC, et al. Risk for obstructive sleep apnea by Berlin Questionnaire, but not daytime sleepiness, is associated with resistant hypertension: a case-control study. Am J Hypertens 2008; 21(7): 832-835.

50. Bradley TD, Floras JS. Obstructive sleep apnoea and its cardiovascular consequences. Lancet 2009; 373(9657): 82-93.

51. Netzer NC, Stoohs RA, Netzer CM, Clark K, Strohl KP. Using the Berlin Questionnaire to identify patients at risk for the sleep apnea syndrome. Ann Intern Med 1999; 131(7): 485-491.

52. Suzuki M, Guilleminault C, Otsuka K, Shiomi T. Blood pressure "dipping" and "non-dipping" in obstructive sleep apnea syndrome patients. Sleep. 1996; 19(5): 382-387.

53. Peppard PE, Young T, Palta M, Dempsey J, Skatrud J. Longitudinal study of moderate weight change and sleep-disordered breathing. JAMA. 2000; 284(23): 3015-3021.

54. Andrén A, Sjöquist M, Tegelberg A. Effects on blood pressure after treatment of obstructive sleep apnoea with a mandibular advancement appliance - a three-year follow-up. J Oral Rehabil. 2009; 36(10): 719-725.

55. Gotsopoulos H, Kelly JJ, Cistulli PA. Oral appliance therapy reduces blood pressure in obstructive sleep apnea: a randomized, controlled trial. Sleep 2004; 27(5): 934-941.

56. Sullivan CE, Issa FG, Berthon-Jones M, Eves L. Reversal of obstructive sleep apnoea by continuous positive airway pressure applied through the nares. Lancet 1981; 1(8225): 862-865

57. Bazzano LA, Khan Z, Reynolds K, He J. Effect of nocturnal nasal continuous positive airway pressure on blood pressure in obstructive sleep apnea. Hypertension 2007; 50: 417-423.

58. Haentjens P, Van Meerhaeghe A, Moscariello A, De Weerdt S, Poppe K, Dupont $A$, et al. The impact of continuous positive airway pressure on blood pressure in patients with obstructive sleep apnea syndrome: evidence from a meta-analysis of placebo-controlled randomized trials. Arch Intern Med 2007; 167(8): 757-764.

59. Campese VM, Mitra D, Sandee D. Hypertension in renal parenchymal disease: why is it so resistant to treatment? Kidney Int 2006; 69(6): 967-973.

60. Ritz E. Hypertension: the kidney is the culprit even in the absence of kidney disease. Kidney Int 2007; 71(5): 371-372.

61. Siamopoulos K. Treatment of hypertension in patients with chronic renal failure. Nephrol Dial Transplant 2001; 16 (Suppl 6): 46-47.

62. K/DOQI clinical practice guidelines on hypertension and antihypertensive agents in chronic kidney disease. Am J Kidney Dis 2004; 43(5 Suppl 1): S1-290.
63. Sica DD, Carl D. Pathologic basis and treatment considerations in chronic kidney disease-related hypertension. Semin Nephrol 2005; 25(4): 246-251.

64. Mancia G, De Backer G, Dominiczak A, Cifkova R, Fagard R, et al. 2007 Guidelines for the Management of Arterial Hypertension: The Task Force for the Management of Arterial Hypertension of the European Society of Hypertension (ESH) and of the European Society of Cardiology (ESC). J Hypertens 2007; 25(6): 1105-1187.

65. Khosla N, Bakris G. Lessons learned from recent hypertension trials about kidney disease. Clin J Am Soc Nephrol 2006; 1(2): 229-235.

66. Bakris GL, Copley JB, Vicknair N, Sadler R, Leurgans S. Calcium channel blockers versus other antihypertensive therapies on progression of NIDDM associated nephropathy. Kidney Int 1996; 50(5): 1641-1650.

67. Brenner BM, Cooper ME, de Zeeuw D, Keane WF, Mitch WE, Parving HH, et al. Effects of losartan on renal and cardiovascular outcomes in patients with type 2 diabetes and nephropathy. N Engl J Med 2001; 345(12): 861-869.

68. Chan JC, Ko GT, Leung DH, Cheung RC, Cheung MY, So WY, et al. Long-term effects of angiotensin-converting enzyme inhibition and metabolic control in hypertensive type 2 diabetic patients. Kidney Int 2000; 57(2): 590-600.

69. Hebert LA, Bain RP, Verme D, Cattran D, Whittier FC, Tolchin N, et al. Remission of nephrotic range proteinuria in type I diabetes. Collaborative Study Group. Kidney Int 1994; 46(6): 1688-1693.

70. Hovind P, Rossing P, Tarnow L, Smidt UM, Parving HH. Remission and regression in the nephropathy of type 1 diabetes when blood pressure is controlled aggressively. Kidney Int 2001; 60(1): 277-283.

71. Lebovitz HE, Wiegmann TB, Cnaan A, Shahinfar S, Sica DA, Broadstone V, et al. Renal protective effects of enalapril in hypertensive NIDDM: role of baseline albuminuria. Kidney Int Suppl 1994; 45: S150-155.

72. Lewis EJ, Hunsicker LG, Bain RP, Rohde RD. The effect of angiotensinconverting-enzyme inhibition on diabetic nephropathy. The Collaborative Study Group. N Engl J Med 1993; 329(20): 1456-1462.

73. Lewis EJ, Hunsicker LG, Clarke WR, Berl T, Pohl MA, Lewis JB, et al. Renoprotective effect of the angiotensin-receptor antagonist irbesartan in patients with nephropathy due to type 2 diabetes. N Engl J Med 2001; 345(12): 851-860.

74. Nielsen FS, Rossing P, Gall MA, Skott P, Smidt UM, Parving HH. Impact of lisinopril and atenolol on kidney function in hypertensive NIDDM subjects with diabetic nephropathy. Diabetes 1994; 43(9): 1108-1113.

75. Parving HH, Lehnert H, Brochner-Mortensen J, Gomis R, Andersen S, Arne P. The effect of irbesartan on the development of diabetic nephropathy in patients with type 2 diabetes. N Engl J Med 2001; 345(12): 870-878.

76. Ravid M, Savin H, Jutrin I, Bental T, Katz B, Lishner M. Long-term stabilizing effect of angiotensin-converting enzyme inhibition on plasma creatinine and on proteinuria in normotensive type II diabetic patients. Ann Intern Med 1993; 118(8): 577-581.

77. Schoolwerth AC, Sica DA, Ballermann BJ, Wilcox CS. Renal considerations in angiotensin converting enzyme inhibitor therapy: a statement for healthcare professionals from the Council on the Kidney in Cardiovascular Disease and the Council for High Blood Pressure Research of the American Heart Association. Circulation 2001; 104(16): 1985-1991.

78. Viberti G, Mogensen CE, Groop LC, Pauls JF. Effect of captopril on progression to clinical proteinuria in patients with insulin-dependent diabetes mellitus and microalbuminuria. European Microalbuminuria Captopril Study Group. JAMA 1994; 271(4): 275-279.

79. Wilmer WA, Hebert LA, Lewis El, Rohde RD, Whittier F, Cattran D, et al. Remission of nephrotic syndrome in type 1 diabetes: long-term follow-up of patients in the Captopril Study. Am J Kidney Dis 1999; 34(2): 308-314

80. Brown MJ. Aliskiren. Circulation 2008; 118(7): 773-784.

81. Musini VM, Fortin PM, Bassett K, Wright JM. Blood pressure lowering efficacy of renin inhibitors for primary hypertension: a Cochrane systematic review. J Hum Hypertens 2009; 23(8): 495-502.

82. Parving HH, Persson F, Lewis JB, Lewis EJ, Hollenberg NK. Aliskiren combined with losartan in type 2 diabetes and nephropathy. N Engl J Med 2008; 358(23): 2433-2446. 


\section{Diretrizes}

83. Peixoto AJ, Orias M. Is there a role for direct renin inhibitors in chronic kidney disease? Curr Opin Nephrol Hypertens 2009; 18(5): 397-403.

84. Persson F, Rossing P, Schjoedt KJ, Juhl T, Tarnow L, Stehouwer CD, et al. Time course of the antiproteinuric and antihypertensive effects of direct renin inhibition in type 2 diabetes. Kidney Int 2008; 73(12): 1419-1425.

85. Segura J, Ruilope LM. Should diuretics always be included as initial antihypertensive management in early-stage CKD? Curr Opin Nephrol Hypertens 2009; 18(5): 392-396.

86. Wilcox CS. New insights into diuretic use in patients with chronic renal disease. J Am Soc Nephrol 2002; 13(3): 798-805.

87. Bakris GL. Effects of diltiazem or lisinopril on massive proteinuria associated with diabetes mellitus. Ann Intern Med 1990; 112(9): 707-708.

88. Bakris GL, Barnhill BW, Sadler R. Treatment of arterial hypertension in diabetic humans: importance of therapeutic selection. Kidney Int 1992; 41(4): 912-919.

89. Bakris GL, Weir MR, Shanifar S, Zhang Z, Douglas J, van Dijk DJ, Brenner BM. Effects of blood pressure level on progression of diabetic nephropathy: results from the RENAAL study. Arch Intern Med, 2003. 163(13): 1555-1565.
90. Koshy S, Bakris GL. Therapeutic approaches to achieve desired blood pressure goals: focus on calcium channel blockers. Cardiovasc Drugs Ther 2000; 14(3): 295-301.

91. Bakris GL, Fonseca V, Katholi RE, McGill JB, Messerli F, Phillips RA, et al. Differential effects of beta-blockers on albuminuria in patients with type 2 diabetes. Hypertension 2005; 46(6): 1309-1315.

92. Marin R, Gorostidi M, Fernandez-Vega F, Alvarez-Navascues R. Systemic and glomerular hypertension and progression of chronic renal disease: the dilemma of nephrosclerosis. Kidney Int Suppl 2005; (99): S52-56.

93. Navaneethan SD, Nigwekar SU, Sehgal AR, Strippoli GF. Aldosterone antagonists for preventing the progression of chronic kidney disease. Cochrane Database Syst Rev 2009; (3): CD007004.

94. Agarwal R, Alborzi P, Satyan S, Light RP. Dry-weight reduction in hypertensive hemodialysis patients (DRIP): a randomized, controlled trial. Hypertension 2009; 53(3): 500-507.

95. Horl MP, Horl WH. Dialysis: Normovolemia is a therapeutic target for hypertension. Nat Rev Nephrol 2009; 5(8): 438-439.

\section{Capítulo 8 - Hipertensão em situações especiais}

\section{1 - Afrodescendentes e miscigenados}

Os afrodescendentes em geral respondem menos à monoterapia com betabloqueadores, IECA e BRA do que aos diuréticos e ACC dihidropiridínicos (grau de recomendação [GR] II, nível de evidência [NE] B $)^{1,2}$. A escolha do anti-hipertensivo para tratar este grupo étnico é norteada pela presença de comorbidades e pela eficácia em atingir as metas pretendidas ${ }^{3}$. O uso de terapia nãomedicamentosa tem apresentado melhores resultados em afrodescendentes do que em brancos (GRI, NE A) ${ }^{4-6}$. Em indivíduos com proteinúria o uso de IECA está indicado, da mesma forma que ocorre em indivíduos de cor branca $(\mathrm{GRI}, \mathrm{NEA})^{7}$.

\section{2 - Idosos}

O objetivo do tratamento é a redução gradual da PA para valores abaixo de 140/90 mmHg. Em pacientes com valores muito elevados de PA sistólica, podem ser mantidos inicialmente níveis de até 160 mmHg (GR I, NE A). Não está bem estabelecido o nível mínimo tolerável da PA diastólica $(\mathrm{GR} I, \mathrm{NE} \mathrm{A})^{8,9}$.

O tratamento não-medicamentoso é recomendado para os idosos $(G R I, N E A)^{10}$, e a redução de sal moderada na dieta é benéfica $(\mathrm{GR} I, N E B)^{11}$. Quando o tratamento medicamentoso for necessário, a dose inicial deve ser mais baixa, e o incremento de doses ou a associação de novos medicamentos devem ser feitos com mais cuidado (GR I, NE C). A presença de outros fatores de risco e lesões de órgão-alvo e doença cardiovascular associada devem nortear a escolha do anti-hipertensivo inicial (GR I, NE
C) ${ }^{12}$. A maioria, porém, necessita de terapia combinada, principalmente para o controle adequado da PA sistólica (GR I, NE C).

Ocorre redução de morbidade e mortalidade com diferentes agentes: diuréticos tiazídicos, betabloqueadores em combinação, antagonistas de canais de cálcio de ação longa, IECA e BRA (GR I, NE A) ${ }^{13-17}$. O tratamento da hipertensão no idoso reduz a incidência de déficit cognitivo e demência $(\mathrm{GR} \text { I, NE C) })^{12,18-20}$.

O tratamento de hipertensos com idade acima de 79 anos por meio da associação de IECA e diurético reduziu o desenvolvimento de AVE e das taxas de insuficiência cardíaca (GR Ila, NE B) ${ }^{21}$. As evidências disponíveis sugerem redução de eventos sem impacto sobre a mortalidade (GR Ila, NE B $)^{22}$. Os idosos portadores de comorbidades múltiplas não-cardiovasculares devem ter seu tratamento cuidadosamente individualizado.

\section{3 - Crianças e adolescentes}

Quanto mais altos forem os valores da PA e mais jovem o paciente, maior é a possibilidade de a HAS ser secundária, com maior prevalência das causas renais (GR 1, NE C). A ingestão de álcool, o tabagismo, uso de drogas ilícitas, utilização de hormônios esteroides, hormônio do crescimento, anabolizantes e anticoncepcionais orais devem ser considerados possíveis causas de hipertensão nesta população (GR 1, NE C). O objetivo do tratamento é atingir valores de PA sistólica e diastólica abaixo do percentil 95 para sexo, altura e faixa etária na HAS nãocomplicada, e abaixo do percentil 90 quando complicada por comorbidades. O tratamento não-medicamentoso deve ser recomendado a partir do percentil 90 de PA sistólica ou diastólica, correspondente à hipertensão limítrofe (GR 1, NE C). O emprego de medicamentos anti-hipertensivos 
deve ser considerado para os que não respondem ao tratamento não-medicamentoso, naqueles com evidência de lesão em órgãos-alvo ou fatores de risco conhecidos, como diabetes, e na hipertensão arterial secundária (GR 1, NE C). Não há estudos de longo prazo sobre o uso de anti-hipertensivos na infância ou na adolescência. A escolha dos medicamentos obedece aos mesmos critérios utilizados para adultos. Medicamentos das classes IECA e BRA II não devem ser utilizados em adolescentes do sexo feminino, exceto quando houver indicação absoluta, em razão da possibilidade de graves efeitos associados à utilização desses medicamentos durante o período gestacional (GR $1, \mathrm{NE} \mathrm{C)^{23 }}$.

\section{4 - Hipertensão arterial na mulher}

A mulher se expõe a situações especiais que por si só contribuem para o surgimento de HAS - o uso de contraceptivo oral (CO), a gestação e a própria menopausa, como exemplos.

\subsection{1 - Contraceptivos orais (CO)}

Embora não seja frequente a HAS induzida por $\mathrm{CO}$, os riscos de complicações cardiovasculares associadas ao seu uso são consistentemente maiores em mulheres fumantes, com idade superior a 35 anos. A prescrição de CO deverá levar em conta as seguintes recomendações:

- a menor dose efetiva de estrogênio e progestágeno;

- monitorizar a pressão arterial de seis em seis meses ou a qualquer momento em que a mulher não se sentir bem;

- suspender o uso se a PA se elevar significativamente, provendo outro método anticoncepcional alternativo;

- tratar apropriadamente e proceder à investigação diagnóstica adequada caso a PA não retorne aos valores normais dentro de três meses;

- manter o CO caso não haja outra forma de contracepção aplicável e considerar o uso de anti-hipertensivos para controlar a PA;

- $\quad$ os CO não devem ser utilizados em mulheres fumantes com mais de 35 anos, principalmente se portadoras de HA não-controlada, lúpus eritematoso sistêmico, história prévia de doença tromboembólica;

- devem ser usados com cautela em mulheres portadoras de enxaqueca, sendo contraindicados em casos de enxaqueca com aura e sintomas neurológicos focais ${ }^{24-26}$.

\subsection{2 - Hipertensão após a menopausa}

O tratamento da HAS na mulher após a menopausa deve sempre começar por modificações no estilo de vida. Quando necessário são introduzidas drogas anti-hipertensivas ${ }^{27}$. As decisões de se iniciar o tratamento medicamentoso a partir de valores de PA mais baixos, podem ser tomadas levando-se em conta as mesmas indicações que norteiam o tratamento anti-hipertensivo nas mulheres em geral.

\subsection{3 - Terapêutica de reposição hormonal (TRH)}

A TRH não é recomendada para prevenção primária ou secundária de doença cardiovascular, podendo mesmo aumentar o risco cardiovascular ou outras doenças, como câncer de mama, demência, tromboembolismo e colecistopatia. Recomenda-se a TRH apenas para o tratamento de sintomas pós-menopáusicos, enfatizando que ela deverá ser prescrita na menor dose efetiva e durante curto período de tempo ${ }^{28,29}$. A simples presença de HAS não deve ser limitação para a TRH se ela tiver que ser aplicada.

\subsection{4 - Hipertensão na gravidez}

A definição de hipertensão na gravidez considera os valores absolutos de PA sistólica $>140 \mathrm{mmHg}$ e/ou diastólica $>90$ $\mathrm{mmHg}$. A PA diastólica deve ser identificada pela fase $\mathrm{V}$ de Korotkoff $^{30}$. A HAS na gestação é classificada nas seguintes categorias principais: pré-eclâmpsia, eclâmpsia; pré-eclâmpsia superposta à hipertensão crônica; hipertensão crônica; hipertensão gestacional.

\subsubsection{1 - Pré-eclâmpsia, eclâmpsia e pré-eclâmpsia} sobreposta

A pré-eclâmpsia é caracterizada pelo aparecimento de HAS e proteinúria ( $>300 \mathrm{mg} / 24 \mathrm{~h}$ ) após a $20^{\underline{a}}$ semana de gestação em mulheres previamente normotensas. A eclâmpsia corresponde à pré-eclâmpsia complicada por convulsões que não podem ser atribuídas a outras causas. Pré-eclâmpsia superposta à HAS crônica é definida pela elevação aguda da PA à qual se agregam proteinúria, trombocitopenia ou anormalidades da função hepática, em gestantes portadoras de HAS crônica, com idade gestacional superior a 20 semanas.

Para prevenção da pré-eclâmpsia não se recomenda prescrever ácido acetilsalicílico para gestantes normais (GR III, NE A $)^{31-33}$, porém em mulheres com risco moderado e elevado de pré-eclâmpsia o uso de baixas doses pode ser útil, sendo iniciado na 12a à 14a semana de gestação (GR Ila, NE B $)^{33-35}$. A suplementação de cálcio não é recomendável para as gestantes que ingerem quantidades normais desse íon (GR III, NE A) ${ }^{33}$, mas admite-se que a sua suplementação oral possa ter efeitos favoráveis na prevenção entre gestantes de moderado a alto risco e com baixa ingestão (GR Ila, NE A $)^{36-38}$.

O tratamento definitivo da pré-eclâmpsia é a interrupção da gestação, sempre benéfica para a mãe. Entretanto, a interrupção da gestação pode não ser benéfica para o feto devido às complicações inerentes à prematuridade. Embora o feto esteja também em risco, muitas vezes é instituído tratamento conservador para assegurar maior grau de maturidade fetal ${ }^{30}$.

O tempo para a interrupção da gravidez é baseado, sobretudo na idade gestacional, nas condições maternas e fetais e na gravidade da pré-eclâmpsia. Na gestação a termo não existem dúvidas e a indicação é feita no momento do diagnóstico. Recomenda-se, ainda, que a intervenção seja considerada em todos os casos a partir da 37ạ semana de gravidez (GR Ila, NE C) ${ }^{39-41}$. No período pré-termo, inferior a 37 semanas, algumas considerações deverão ser feitas:

- mulheres com idade gestacional de 32 a 34 semanas 


\section{Diretrizes}

e mais poderão ser consideradas para tratamento conservador em unidades especializadas (GR Ila, NE C);

- a administração de corticoide está indicada para grávidas pré-eclâmpticas com idade gestacional entre 24 e 34 semanas (GR Ila, NE B) ${ }^{42}$;

- a interrupção da gestação deverá sempre ser considerada nos casos de pré-eclâmpsia grave independentemente da idade gestacional ${ }^{41}$.

Recomenda-se o uso de sulfato de magnésio para prevenir eclâmpsia em mulheres com pré-eclâmpsia grave (GR I, NE A) e para a prevenção de eclâmpsia, se a pré-eclâmpsia é leve, porém com impacto diferente (GR Ila, NE B $)^{43}$.

As indicações para o tratamento anti-hipertensivo não se baseiam em ensaios clínicos com desfechos claramente definidos, mas sim em padrões da prática clínica estabelecidos ao longo de muitos anos.

Sugere-se que o tratamento seja instituído mais precocemente quando a PA for $\geq 150 / 100 \mathrm{mmHg}^{44}$. Em situações especiais, como é o caso de gestantes adolescentes com PA anterior à gravidez inferior a 90/75 mmHg e em grávidas com sintomas que podem ser atribuídos à HAS, admite-se iniciar o tratamento mais precocemente ${ }^{30}$. O objetivo do tratamento anti-hipertensivo na pré-eclâmpsia é alcançar PA sistólica entre 130 a 150 mmHg e PA diastólica de 80 a $100 \mathrm{mmHg}^{44}$.

Quanto ao tratamento, dois cenários devem ser considerados:

- Tratamento agudo - Em urgência ou emergência hipertensiva requerendo hospitalização, monitoração intensiva, antecipação do parto e administração parenteral de anti-hipertensivos; recomendase a administração endovenosa de sulfato de magnésio considerado a droga de escolha para prevenção da eclâmpsia $(\mathrm{GR} \mathrm{I}, \mathrm{NE} \mathrm{A})^{41}$. Para o tratamento da HAS grave recomenda-se hidralazina endovenosa $^{30}$. A escolha para o tratamento da emergência hipertensiva dependerá da experiência e familiaridade com a medicação. Em situações excepcionais, principalmente quando existe risco de edema pulmonar concomitante, admite-se o uso de nitroprussiato de sódio por período inferior a quatro horas, como última opção para controle urgente da HAS grave e refratária ${ }^{30,45}$.

A administração de nifedipino de ação rápida, por via oral ou sublingual, deve ser evitada (GR III) ${ }^{46}$.

- Tratamento de longo prazo - Em pacientes com pré-eclâmpsia com quadro clínico estabilizado sem necessidade de parto imediato, está indicado tratamento anti-hipertensivo por via oral (GRI, NE B $)^{44}$. Recomenda-se não prescrever anti-hipertensivo para
HAS com valores de PA $<150 / 100 \mathrm{mmHg}$ associada a pré-eclâmpsia $(G R \text { II, NE B })^{45}$ ou a hipertensão crônica (GR II, NE B) ${ }^{44}$. Não há comprovação de benefícios para a mãe ou para o feto, exceto redução do risco de HAS grave, que é considerado insuficiente diante da exposição do feto ao risco potencial de comprometimento do seu crescimento ${ }^{47}$.

As opções de uso de anti-hipertensivos orais são as mesmas apresentadas para as gestantes portadoras de HA crônica ou preexistente. A alfametildopa é a droga preferida por ser a mais bem estudada e não haver evidência de efeitos deletérios para o feto (GR I, NE C) ${ }^{30}$. Outros ACC, como nifedipino, anlodipino e verapamil, podem ser considerados drogas alternativas ${ }^{44,48,49}$. Os betabloqueadores são considerados seguros na gravidez, embora se atribua a eles redução no crescimento fetal ${ }^{50}$.

Na pré-eclâmpsia, a prescrição de diuréticos é geralmente evitada, porém os tiazídicos podem ser continuados em gestantes com HA crônica, desde que não promovam depleção de volume ${ }^{51,52}$. Os IECAs e os BRAs são contraindicados ${ }^{53,54}$.

\subsubsection{2 - Hipertensão arterial sistêmica crônica}

A HAS crônica é definida por hipertensão registrada antes da gestação, no período que precede a $20^{\underline{a} \text { semana de }}$ gravidez, ou além de doze semanas após o parto.

Em relação à HAS crônica, recomenda-se o início ou a reinstituição do tratamento medicamentoso com PA sistólica $\geq 150$ mmHg e PA diastólica de 95 a 99 mmHg ou sinais de lesão em órgão-alvo ${ }^{44}$. Para gestantes portadoras de HAS crônica que estão em uso de anti-hipertensivos e $\mathrm{PA}<120 / 80 \mathrm{mmHg}$, recomenda-se reduzir ou mesmo descontinuar o tratamento e iniciar monitorização cuidadosa da PA (GR II, NE C) ${ }^{44}$.

\subsubsection{3 - Hipertensão gestacional}

É caracterizada por HA detectada após a 20a semana, sem proteinúria, podendo ser definida como "transitória" quando ocorre normalização após o parto, ou "crônica", quando persistir a hipertensão.

\section{5 - Tratamento anti-hipertensivo na lactante}

A utilização de anti-hipertensivos na mulher que está amamentando merece alguns cuidados. É necessário considerar que todos os medicamentos, de alguma forma e com diferentes concentrações, passam para o leite materno. A tabela 1 mostra as medicações antihipertensivas disponíveis no Brasil consideradas seguras, moderadamente seguras e as não-recomendadas para essa situação em particular ${ }^{55}$. 
Tabela 1 - Segurança para o lactente com o uso de medicações anti-hipertensivas pela lactante ${ }^{55}$

\begin{tabular}{lc}
\hline Medicamentos & Recomendação \\
\hline Diuréticos: hidroclorotiazida, espironolactona & Seguros \\
Inibidores adrenérgicos: alfametildopa, propranolol & \\
Vasodilatadores: hidralazina, minoxidil & \\
Antagonistas dos canais de cálcio: verapamil, nifedipino, nitrendipino & \\
Inibidores da ECA: benazapril, captopril, enalapril, quinadril & \\
\hline
\end{tabular}

Diuréticos: indapamida, furosemida, triantereno

Inibidores adrenérgicos: atenolol, bisoprolol, carvedilol, metoprolol

Antagonistas dos canais de cálcio: anlodipino, isradipino, nisoldipino Moderadamente seguros

Inibidores da ECA: fosinopril, lisinopril, ramipril

Bloqueadores do receptor $\mathrm{AT}_{1}$ : candesartana, olmesartana, telmisartana

Inibidores adrenérgicos: reserpina, nadolol, prazosina, terazosina

Inibidores da ECA: fosinopril*, quinapril ${ }^{*}$

Bloqueadores do receptor $\mathrm{AT}_{1}$ : telmisartana*, valsartana

Potencialmente perigosos

\section{Referências}

1. Park IU, Taylor AL. Race and ethnicity in trials of antihypertensive therapy to prevent cardiovascular outcomes: a systematic review. Ann Fam Med 2007; 5: 444-452.

2. Freis ED, Reda DJ, Materson BJ. Volume (weight) loss and blood pressure response following thiazide duiretics. Hypertension 1988; 12: 244-250.

3. Brewster LM, van Montfrans GA, Kleijnen J. Systematic review: antihypertensive drug therapy in black patients. Ann Intern Med 2004; 141: 614-627.

4. MacGregor GA, Markandu ND, Best FI, Elder DM Cam JM, Sagnella GA, et al. Double-blind randomized crossover trial of moderate sodium restriction in essential hypertension. Lancet 1982; 351-355.

5. Shaper AG, Leonard PJ, Jones KW, Jones M. Environmental effects on the body built, blood pressure and blood chemistry of nomadic warriors serving in the army of Kenya. East Afric Med J 1969; 46: 282-289.

6. Luft FC, Rankin LI, Bloch R, Weyman AE, Willis LR, Murray RH, et al. Cardiovascular and humoral responses to extremes of sodium intake in normal black and white men. Circulation 1979; 60: 697-706.

7. Wright JT, Bakris G, Greene T, Agodoa LY, Appel LJ, Charleston J, et al., for the African American Study of Kidney Disease and Hypertension Study Group. Effect of blood pressure lowering and antihypertensive drug class on progression of hypertensive kidney disease. Results from the AASK Trial. JAMA 2002; 288: 2421-2431.

8. Somes GW, Pahor M, Shorr RI, Cushman WC, Applegate WB. The role of diastolic blood pressure when treating isolated systolic hypertension. Arch Int Med 1999; 159: 2004-2009.

9. Messerli FH, Panjrath GS. The J-Curve between blood pressure and coronary artery disease or essential hypertension. Exactly how essential? J Am Coll Cardiol 2009; 54: 1827-1834.

10. Whelton PK, Appel LJ, Espeland MA, Applegate WB, Ettinger WH Jr, Kostis $\mathrm{JB}$, et al. Sodium reduction and weight loss in the treatment of hypertension in older people: a randomized controlled trial of nonpharmacologic interventions in the elderly (TONE). TONE Collaborative Research Group. JAMA 1998; 279: 839-846.

11. Appel LJ, Espeland MA, Easter L, Wilson AC, Folmar S, Clifton R. Effects of reduced sodium intake on hypertension control in older individuals: results from the Trial of Nonpharmacologic Interventions in the Elderly (TONE). Arch Intern Med 2001; 161: 685-693.

12. Mancia G, De Backer G, Dominiczak A, Cifkova R, Fagard R, Germano G, et al. The task force for the management of arterial hypertension of the European Society of Hypertension, The task force for the management of arterial hypertension of the European Society of Cardiology. 2007 Guidelines for the management of arterial hypertension: The task force for the management of arterial hypertension of the European Society of Hypertension (ESH) and of the European Society of Cardiology. Eur Heart J 2007; 28: 1462-1536.

13. SHEP Cooperative Research Group. Prevention of stroke by antihypertensive drug treatment in older persons with isolated systolic hypertension. Final results of the Systolic Hypertension in the Elderly Program (SHEP). JAMA 1991; 265: 3255-3264.

14. Staessen JA, Fagard R, Thijs L, Celis H, Arabidze GG, Birkenhäger WH, et al Randomized double-blind comparison of placebo and active treatment for older patients with isolated systolic hypertension. The Systolic Hypertension in Europe (SYST-EUR) Trial Investigators. Lancet 1997; 350: 757-764.

15. Hansson L, Lindholm LH, Ekbom T, Dahlöf B, Lanke J, Scherstén B, et al., for the STOP-Hypertension-2 study group. Randomised trial of old and new antihypertensive drugs in elderly patients: cardiovascular mortality and morbidity the Swedish Trial in Old Patients with Hypertension-2 study. Lancet, 1999; 354: 1751-1756.

16. The ALLHAT Officers and Coordinators for the ALLHAT Collaborative Research Group. Major outcomes in high-risk hypertensive patients randomized to angiotensin-converting enzyme inhibitor or calcium channel blocker vs. diuretic: The Antihypertensive and Lipid-Lowering treatment to prevent Heart Attack Trial (ALLHAT). JAMA 2002; 288: 2981-2997.

17. Lithell H, Hansson L, Skogg I, Elmfeldt D, Hofman A, Olofsson B, et al, for the SCOPE Study Group. The Study on Cognition and Prognosis in the Elderly (SCOPE): principal results of a randomized double-blind intervention trial. . Hypertens 2003;21:875-886.

18. Forette F, Seux ML, Staessen JA, Thijs L, Babarskiene MR, Babeanu S, et al ., for the Systolic Hypertension in Europe Investigators. The prevention of dementia with antihypertensive treatment. New evidence from the Systolic Hypertension in Europe (Syst-Eur) study. Arch Intern Med 2002; 162(18) 2046-2052.

19. The PROGRESS Collaborative Group. Effects of blood pressure lowering with perindopril and indapamide therapy on dementia and cognitive decline in patients with cerebrovascular disease. Arch Intern Med 2003; 163: 1069-1075.

20. Papademitriou V, Farsang C, Elmfeldt D, Hofman A, Lithell H, Olofsson B, et al., for the SCOPE Study Group. Stroke prevention with the angiotensin II type 1 receptor blocker candesartan in elderly patients with isolated systolic hypertension. The study on cognition and prognosis in the elderly (SCOPE). J Am Coll Cardiol 2004; 44: 1175-1180.

21. Becket NS, Peters R, Fletcher AE, Staessen JA, Liu L, Dumitrascu D, et al. The HYVET Study Group. The HYVET Study Group Treatment of Hypertension in patients 80 years of age and older. N Engl J 2008; 358: 1887-1898.

22. Gueyffier F, Bulpitt C, Boissel JP, Schron E, Ekbom T, Fagard R, et al., for the 


\section{Diretrizes}

INDIANA Group. Antihypertensive drugs in very old people: a subgroup analysis of randomised controlled trials. Lancet 1999; 353: 793-796.

23. National High Blood Pressure Education Program Working Group on High Blood Pressure in Children and Adolescents. The fourth report on the diagnosis, evaluation, and treatment of high blood pressure in children and adolescents. Pediatrics 2004; 114: 555-576.

24. Croft P, Hannaford PC. Risk factors for acute myocardial infarction in women: evidence from the Royal College of General Practitioners Oral Contraception Study. BMJ 1989; 298: 165-168.

25. Woods JW. Oral contraceptives and hypertension. Hypertension 1988; 11 (suppl II): II-11-II-15.

26. Chasan-Taber L, Willett WC, Manson JE, et al. Prospective study of oral contraceptives and hypertension among women in the United States. Circulation 1996; 94: 483-489.

27. Stampfer MJ, Hu FB, Manson JE, Rimm EB, Willet WC. Primary prevention of coronary heart disease in women through diet and lifestyle. N Engl J Med 2000; 343: 16-22.

28. Hulley S, Grady D, Bush T, Furberg C, Herrington D, Riggs B, et al., for the Heart and Estrogen/progestin Replacement Study (HERS) Research Group. Randomized trial of estrogen plus progestin for secondary prevention of coronary heart disease in postmenopausal women. JAMA 1998; 280: 605.

29. Writing Group for the Women's Health Initiative Investigators. Risk and benefits of estrogen plus progestin in health postmenopausal women. Principal results from the Women's Health Initiative randomized controlled trial. JAMA 2002; 288: 321-333.

30. National High Blood Pressure Education Program Working Group on High Blood Pressure in Pregnancy. Report of the National High Blood Pressure Education Program Working Group on High Blood Pressure in Pregnancy. Am J Obstet Gynecol 2000; 183: S1-S22.

31. CLASP: a randomised trial of low-dose aspirin for the prevention and treatment of pre-eclampsia among 9364 pregnant women. CLASP (Collaborative Low-dose Aspirin Study in Pregnancy) Collaborative Group. Lancet 1994; 343: 619-629.

32. Caritis S, Sibai B, Hauth J, Lindheimer MD, Klebanoff M, Thom E, et al. Lowdose aspirin to prevent preeclampsia in women at high risk. N Engl J Med 1998: 338: 701-705.

33. August P. Prevention of preeclampsia. UpToDate Version 17.3: sep 2009 [acesso em 12 Jan 2010]. Disponível em http://www.uptodate.com.

34. Coomarasamy A, Honest H, Papaioannou S, Gee H, Khan KS. Aspirin for prevention of preeclampsia in women with historical risk factors: a systematic review. Obstet Gynecol 2003; 101: 1319-1332.

35. Askie LM, Duley L, Henderson-Smart D, Stewart LA, on behalf of the PARIS Collaborative Group. Antiplatelet agents for prevention of pre-eclampsia: a meta-analysis of individual patient data. Lancet 2007; 369: 1791-1798.

36. Hofmeyr GJ, Atallah NA, Duley L. Calcium supplementation during pregnancy for preventing hypertensive disorders and related problems, Cochrane Database of Systematic Reviews. In: The Cochrane Library, Issue 3, Art. No. CD001059. DOI: 10.1002/14651858.CD001059.pub3.

37. Bucher HC, Guyatt GH, Cook RJ, Hatala R, Cook DJ, Lang JD, et al. Effect of calcium supplementation on pregnancy-induced hypertension and preeclampsia. A meta-analysis of randomized controlled trials. JAMA 1996; 275: 1113-1117.

38. DerSimonian R, Levine RJ. Resolving discrepancies between a meta-analysis and a subsequent large controlled trial. JAMA 1999; 282: 664-670.

39. Churchill D, Duley L. Interventionist versus expectant care for severe preeclampsia before term. Cochrane Database of Systematic Reviews. In: The Cochrane Library, Issue 3, Art. No. CD003106. DOI: 10.1002/14651858. CD003106.pub3

40. Duley L, Henderson-Smart DJ, Meher S. Drugs for treatment of very high blood pressure during pregnancy. Cochrane Database of Systematic Reviews. In: The Cochrane Library, 2009, Issue 3, Art. No. CD001449. DOI: 10.1002/14651858.CD001449.pub2.

41. Norwitz ER, Repke JT. Management of preeclampsia. UpToDate Version 17.3: Sep 2009 [acesso em 12 Jan 2010]. Disponível em http://www.uptodate.com.

42. Devender R, Dalziel SR. Antenatal corticosteroids for accelerating fetal lung maturation for women at risk of preterm birth. Cochrane Database of Systematic Reviews. In: The Cochrane Library, Issue 3, Art. No. CD004454. DOI: 10.1002/14651858.CD004454.pub3.

43. Duley L, Gülmezoglu AM, Henderson-Smart DJ. Magnesium sulphate and other anticonvulsants for women with pre-eclampsia. Cochrane Database of Systematic Reviews. In: The Cochrane Library, Issue 3, Art. No. CD000025. DOI: 10.1002/14651858.CD000025.pub3.

44. August P. Management of hypertension in pregnancy. UpToDate Version 17.3: Sep 2009 [acesso em 12 Jan 2010]. Disponível em http://www.uptodate.com.

45. Sass N, Itamoto $\mathrm{CH}$, Silva MP, Torloni MR, Atallah AN. Does sodium nitroprusside kill babies? A systematic review. Sao Paulo Med J 2007; 125: 108-111.

46. Impey, L. Severe hypotension and fetal distress following sublingual administration of nifedipine to a patient with severe pregnancy induced hypertension at 33 weeks. Br J Obstet Gynaecol 1993; 100: 959.

47. Abalos E, Duley L, Steyn DW, Henderson-Smart DJ. Antihypertensive drug therapy for mild to moderate hypertension during pregnancy. Cochrane Database of Systematic Reviews. In: The Cochrane Library, Issue 3, Art. No. CD002252. DOI: 10.1002/14651858.CD002252.pub2.

48. Magee LA, Schick B, Donnenfeld AE, Sage SR, Conover B, Cook L, et al. The safety of calcium channel blockers in human pregnancy: a prospective multicenter cohort study. Am J Obstet Gynecol 1996; 174: 823-828.

49. Podymow T, August P, Umans JG. Antihypertensive therapy in pregnancy. Semin Nephrol 2004; 24: 616-625.

50. Butters L, Kennedy S, Rubin PC. Atenolol in essential hypertension during pregnancy. BMJ 1990; 301: 587-589.

51. Cunningham FG, Lindheimer MD. Hypertension in pregnancy. N Engl J Med 1992; 326: 927-932.

52. Sibai BM, Grossman RA, Grossman HG. Effects of diuretics on plasma volume in pregnancies with long-term hypertension. Am J Obstet Gynecol 1984; 150: 831-835.

53. Shotan A, Widerhorn J, Hurst A, Elkayam U. Risks of angiotensin-converting enzyme inhibition during pregnancy: experimental and clinical evidence, potential mechanisms, and recommendations for use. Am J Med 1994; 96: $451-456$.

54. Saji H, Yamanaka M, Hagiwara A, Ijiri R. Losartan and fetal toxic effects. Lancet $2001 ; 357: 363$.

55. Chaves RG, Lamounier JA, César CC. Medicamentos e amamentação: atualização e revisão aplicadas à clínica materno-infantil. Rev Paul Pediatr 2007; 25: 276-288. 


\section{Capítulo 9 - Hipertensão e condições clínicas associadas}

\section{1 - Diabetes melito}

A medida da PA no consultório em pacientes com diabetes melito (DM) deve ser feita nas posições supina e ortostática em função da maior ocorrência de hipotensão ortostática $^{1}$ (C4). Por se tratar de pacientes de alto risco para eventos cardiovasculares, as metas a serem atingidas devem ser 130/80 mmHg ${ }^{2,3}$ (A1). Estudos demonstraram não haver benefícios adicionais com redução da PA, em diabéticos, inferior a esses valores ${ }^{4}(\mathrm{~A} 1)$. A avaliação inicial pode ser estabelecida por meio da medição em duplicata da razão albumina/creatinina em amostra de urina isolada (micrograma/mg de creatinina) considerando-se normais valores menores que 30 e microalbuminúria aqueles entre 30 e $299 \mathrm{mg}$. Valores maiores que $300 \mathrm{mg}$ estabelecem o diagnóstico de macroproteinúria e determinam propensão adicional ao desenvolvimento de doença renal crônica ${ }^{5}$ (A1). Todos os agentes anti-hipertensivos podem ser utilizados, sendo que na maioria das vezes dois ou mais deles precisam ser associados para que os objetivos do tratamento sejam atingidos. Existem vantagens no uso de bloqueadores do SRAA e na associação destes com um antagonista dos canais de cálcio ${ }^{6-11}$ (A1,B2). A associação de IECA com BRA II já se mostrou eficiente para promover maior redução da proteinúria ${ }^{10}$ (A1). Mais recentemente, a associação do inibidor direto da renina, alisquireno, com o BRA II losartan, também resultou em redução adicional da albuminúria em pacientes com nefropatia diabética ${ }^{12}$ (A1). Nos casos de hipotensão postural, a escolha da medicação antihipertensiva e o ajuste das doses a serem utilizadas devem levar em conta a hora do dia e a posição do paciente no momento da medida da PA. Elevação da cabeceira da cama e uso de agentes que aumentem o volume plasmático, como a fludrocortisona e o domperidone, constituem alternativas para evitar a hipotensão matutina e a consequente hipertensão vespertina e noturna ${ }^{13}(\mathrm{C} 4)$.

\section{2 - Síndrome metabólica (SM)}

O diagnóstico de SM identifica indivíduos com quadro cardiometabólico extremamente adverso, que apresentam aumento significativo do risco cardiovascular e que necessitarão de intervenção agressiva para cada fator de risco específico ${ }^{14}$ (A1). Devido a sua associação frequente com a obesidade, a abordagem da HAS nesses indivíduos deve ser considerada em conjunto com o tratamento da hipertensão no indivíduo obeso.

\section{3 - Obesidade e síndrome metabólica}

\subsection{1 - Redução do peso}

A redução do peso corporal contribui para o controle da PA de forma consistente e significativa. Em metanálise publicada em 2008, que avaliou 38 estudos controlados e randomizados, registrou-se diminuição da média da $\mathrm{PA}$ de $6,3 / 3,4 \mathrm{mmHg}$ associada à perda de peso ${ }^{15}$ (A1)

\subsection{2 - Anti-hipertensivos}

O uso de diuréticos tiazídicos em baixas doses deve ser o tratamento medicamentoso inicial preferido. IECA, BRA II e ACC podem ser usados com segurança, isoladamente ou em associações. Deve-se enfatizar que mudanças no estilo de vida constituem as medidas mais eficazes para a prevenção e para o tratamento da HAS, contribuindo para a redução do risco cardiovascular.

\section{4 - Doença renal crônica (DRC)}

\subsection{1 - Doença renal crônica estágios 1 e 2}

Em estágios iniciais da DRC, o controle da PA parece constituir a medida mais eficaz para a prevenção de progressão do dano renal, independentemente da classe da medicação anti-hipertensiva utilizada. No entanto, nos pacientes com perda proteica preconiza-se o bloqueio do SRAA, visando à redução da hipertensão intraglomerular e à diminuição da excreção urinária de proteínas.

\subsection{2 - Doença renal crônica estágios 3, 4 e 5 (não-} dialítica)

Tanto os IECAs quantos os BRAs têm comprovada eficácia, muitas vezes ultrapassando os benefícios gerados pela redução da pressão arterial per se ${ }^{16}$ (A1). Sua eficácia na nefroproteção é maior em pacientes com perda proteica ${ }^{11}$ (A1). Publicações recentes, em hipertensos primários, mostram que o duplo bloqueio do SRAA em diferentes versões resultou em maior redução da pressão arterial quando comparado com monoterapia equivalente ${ }^{17,18}$ (B2). Uma publicação ${ }^{19}$ (B2) colocou o bloqueio vigoroso do SRAA, por meio da combinação IECA e BRA, "sob suspeita", já que, apesar do bloqueio duplo comparado com a monoterapia ter resultado em maior redução da PA, a esperada diminuição de eventos cardiovasculares não ocorreu. Em adição, a associação provocou maior queda da função renal, apesar de maior redução da microalbuminúria e, ainda, número superior de eventos adversos em comparação com monoterapia. Deste modo, o duplo boqueio do SRAA não está indicado para pacientes portadores de DRC sem perda proteica ou com microalbuminúria. No que tange ao uso de inibidores diretos da renina observou-se redução significativa da proteinúria em diabéticos quando se associou alisquireno a losartana ${ }^{20}$ (A1). Do mesmo modo, estudos iniciais em humanos têm demonstrado redução da proteinúria com o uso de bloqueadores da aldosterona ${ }^{21}$ (B2). Normalmente, os diuréticos tiazídicos são mais eficazes em pacientes nos estágios 1,2 e 3 da DRC, enquanto os diuréticos de alça são preconizados para os estágios 4 e 5 . Comprovadamente, os diuréticos reduzem a morbidade e mortalidade cardiovascular ${ }^{22,23}$ (A1) e são a segunda opção para o tratamento da hipertensão na DRC, especialmente quando combinados com IECA ou BRA (B2). Para atingir as metas de PA em pacientes com DRC, em geral é necessária a combinação de três ou mais anti-hipertensivos, em doses plenas $^{24}$ (A1). Assim, os ACC ${ }^{25,26}$ (A1), são indicados como terceira opção e seu uso combinado com IECA se associou a maior redução de eventos $\mathrm{CV}^{9}$ (B2). Outras opções incluem 


\section{Diretrizes}

os betabloqueadores, os inibidores adrenérgicos de ação central e, eventualmente, os vasodilatadores de ação direta como o minoxidil e a hidralazina.

\subsection{3 - Doença renal crônica estágio 5 em programa de diálise}

O controle da hipervolemia, a investigação de coronariopatia e da disfunção ventricular e a identificação de arritmias constituem estratégias para a abordagem terapêutica nestes pacientes.

\subsection{4 - Transplantados renais}

Os ACC constituem a primeira escolha para o tratamento da HAS em pacientes transplantados ${ }^{27}$ (A1). Pacientes em uso de ciclosporina apresentam vasoconstrição arteriolar, que pode ser revertida pelo uso de $\mathrm{ACC}^{28}$ (C4). Nos transplantados, há evidências de que os medicamentos que bloqueiam o SRAA podem melhorar os resultados do transplante ${ }^{29}$ (B2). Os diuréticos são medicamentos que podem ser prescritos no controle da HAS de pacientes submetidos a transplante renal, mas o seu uso requer monitorização cuidadosa dos eletrólitos séricos e da função renal ${ }^{30}$.

\section{5 - Doença arterial coronariana}

Está claramente demonstrada a associação entre HAS e doença arterial coronariana (DAC), independentemente da idade. A redução adequada da PA é fundamental para a prevenção de eventos relacionados à DAC, independentemente do grupo de medicamentos antihipertensivos utilizados ${ }^{31,32}$ (A1) objetivando-se metas de PA de $130 \times 80 \mathrm{mmHg}^{31,32}$ (A1). Especula-se sobre a possibilidade da redução excessiva da PA diastólica (PAD) aumentar este risco, configurando a chamada curva $\mathrm{J}^{33}$. Em pacientes idosos ou diabéticos com DAC obstrutiva e evidência de isquemia, parece mais adequado reduzir a PAD lentamente e evitar valores muito baixos. Há controversias sobre até que nível reduzir a PAD sem problemas ${ }^{32}(\mathrm{C} 2)$. Os betabloqueadores devem ser utilizados nos pacientes com angina ou com infarto do miocárdio prévio, exceto se houver contraindicação formal ${ }^{34}$ (A1). Os IECA e os BRA II estão indicados para a prevenção primária em pacientes de alto risco cardiovascular, em hipertensos com DAC estável ou com infarto do miocárdio prévio ${ }^{35,36}$ (A1). Os diuréticos tiazídicos demonstraram proteção contra eventos coronarianos em estudos randomizados em prevenção primária ${ }^{37-39}$ (A1). Os bloqueadores dos canais lentos do cálcio também demonstraram prevenção de eventos $\operatorname{coronários}^{40,41}$ (A1) e podem ser utilizados como alternativa aos betabloqueadores para o tratamento da angina, porém não são recomendados para prevenção secundária.

\section{6 - Acidente vascular encefálico}

O tratamento anti-hipertensivo está associado a uma redução de $35 \%$ a $44 \%$ na incidência de acidente vascular encefálico (AVE) ${ }^{42}(\mathrm{~A} 1)$.

\subsection{1 - Acidente vascular encefálico isquêmico}

Uma resposta hipertensiva aguda ocorre em cerca de $80 \%$ dos pacientes nas primeiras 48 horas após o AVE isquêmico ${ }^{43}(\mathrm{~A} 1)$, reduzindo espontaneamente em algumas semanas após o evento. Estudos mostram que os BRA II previnem a recorrência de eventos vasculares em pacientes com AVE do tipo isquêmico ${ }^{44}$ (A1) enquanto outros relatam que o tratamento com labetolol ou lisinopril reduziu a mortalidade aos 90 dias, em comparação com placebo em portadores de AVE isquêmico ou hemorrágico ${ }^{45}$ (A1). Na ausência de evidências de ensaios clínicos, as diretrizes atuais sugerem que a PA não deve ser reduzida na fase aguda do AVE isquêmico, a não ser quando a PA sistólica estiver em torno dos $200 \mathrm{mmHg}$ e a PA diastólica, superior a $120 \mathrm{mmHg}$, ou, ainda, na presença de complicações em outros órgãos (C4). Nos pacientes candidatos a tratamento trombolítico, a PA sistólica deve ser reduzida para valores abaixo de $185 \mathrm{mmHg}$ e a PA diastólica para valores inferiores a $110 \mathrm{mmHg}$ antes da infusão do trombolítico e mantidos nessa faixa nas primeiras 24 horas após a realização da trombólise ${ }^{46,47}$ (B2).

\subsection{2 - Hemorragia intracerebral}

Estudos observacionais sugerem que a HAS está relacionada com a expansão do hematoma nas primeiras 24 horas $^{48}$ (B). O crescimento do hematoma foi menor no grupo de pacientes cuja PA sistólica-alvo foi de $140 \mathrm{mmHg}$ do que no grupo cujo alvo foi de $180 \mathrm{mmHg}$, embora após a correção para o tamanho inicial do hematoma a diferença não tenha sido estatisticamente significante ${ }^{48,49}$. As diretrizes atuais sugerem PA da ordem de $160 \times 90 \mathrm{mmHg}^{50,51}$ (C).

\section{Referências}

1. Freeman R. Clinical practice. Neurogenic orthostatic hypotension. N Engl J Med 2008; 358(6): 615-624.

2. Patel A, MacMahon S, Chalmers J, Neal B, Woodward M, Billot L, et al. Effects of a fixed combination of perindopril and indapamide on macrovascular and microvascular outcomes in patients with type 2 diabetes mellitus (the ADVANCE trial): a randomised controlled trial. Lancet 2007; 370(9590): 829-840.

3. The sixth report of the Joint National Committee on Prevention, Detection, Evaluation, and Treatment of High Blood Pressure. Arch Intern Med 1997; 157(21): 2413-2446.
4. ACCORD Study Group, Cushman WC, Evans GW, Byington RP et al. Effects of intensive blood-pressure control in type 2 diabetes mellitus. N Engl J Med 2010, 362(17): 1575-1585.

5. Gall MA, Hougaard P, Borch-Johnsen K, Parving HH. Risk factors for development of incipient and overt diabetic nephropathy in patients with non-insulin dependent diabetes mellitus: prospective, observational study. BMJ 1997; 314(7083): 783-788.

6. Yusuf S, Gerstein H, Hoogwerf B, Pogue J, Bosch J, Wolffenbuttel BH, et al. Ramipril and the development of diabetes. JAMA 2001; 286(15): 1882-1885. 
7. Dahlof B, Devereux RB, Kjeldsen SE, Julius S, Beevers G, de FU, et al. Cardiovascular morbidity and mortality in the Losartan Intervention For Endpoint reduction in hypertension study (LIFE): a randomised trial against atenolol. Lancet 2002; 359(9311): 995-1003.

8. Yusuf S, Teo KK, Pogue J, Dyal L, Copland I, Schumacher H, et al. Telmisartan, ramipril, or both in patients at high risk for vascular events. N Engl J Med 2008; 358(15): 1547-1559.

9. Jamerson K, Weber MA, Bakris GL, Dahlof B, Pitt B, Shi V, et al. Benazepril plus amlodipine or hydrochlorothiazide for hypertension in high-risk patients. N Engl J Med 2008; 359(23): 2417-2428.

10. Atkins RC, Briganti EM, Lewis JB, Hunsicker LG, Braden G, Champion de Crespigny PJ, et al. Proteinuria reduction and progression to renal failure in patients with type 2 diabetes mellitus and overt nephropathy. Am J Kidney Dis 2005; 45(2): 281-287.

11. de ZD, Remuzzi G, Parving HH, Keane WF, Zhang Z, Shahinfar S, et al. Proteinuria, a target for renoprotection in patients with type 2 diabetic nephropathy: lessons from RENAAL. Kidney Int 2004; 65(6):2309-2320.

12. Parving HH, Persson F, Lewis JB, Lewis EJ, Hollenberg NK. Aliskiren combined with losartan in type 2 diabetes and nephropathy. N Engl J Med 2008; 358(23): 2433-2446.

13. Lopes de Faria SR, Zanella MT, Andriolo A, Ribeiro AB, Chacra AR. Peripheral dopaminergic blockade for the treatment of diabetic orthostatic hypotension. Clin Pharmacol Ther 1988; 44(6): 670-674.

14. Lakka HM, Laaksonen DE, Lakka TA, Niskanen LK, Kumpusalo E, Tuomilehto $\mathrm{J}$, et al. The metabolic syndrome and total and cardiovascular disease mortality in middle-aged men. JAMA 2002; 288(21): 2709-2716.

15. Horvath K, Jeitler K, Siering U, Stich AK, Skipka G, Gratzer TW, et al. Longterm effects of weight-reducing interventions in hypertensive patients: systematic review and meta-analysis. Arch Intern Med 2008; 168(6): 571-580.

16. Lewis EJ, Hunsicker LG, Clarke WR, Berl T, Pohl MA, Lewis JB, et al. Renoprotective effect of the angiotensin-receptor antagonist irbesartan in patients with nephropathy due to type 2 diabetes. N Engl J Med 2001; 345(12): 851-860.

17. Geiger H, Barranco E, Gorostidi M, Taylor A, Zhang X, Xiang Z, et al. Combination therapy with various combinations of aliskiren, valsartan, and hydrochlorothiazide in hypertensive patients not adequately responsive to hydrochlorothiazide alone. J Clin Hypertens (Greenwich ) 2009; 11(6): 324-332.

18. Scaglione R, Argano C, Di CT, Parrinello G, Colomba D, Avellone G, et al. Effect of dual blockade of renin-angiotensin system on TGFbeta1 and left ventricular structure and function in hypertensive patients. J Hum Hypertens 2007; 21(4): 307-315

19. Mann JF, Schmieder RE, McQueen M, Dyal L, Schumacher H, Pogue J, et al. Renal outcomes with telmisartan, ramipril, or both, in people at high vascular risk (the ONTARGET study): a multicentre, randomised, double-blind, controlled trial. Lancet 2008; 372(9638): 547-553.

20. Parving HH, Brenner BM, McMurray JJ, de ZD, Haffner SM, Solomon SD, et al. Aliskiren Trial in Type 2 Diabetes Using Cardio-Renal Endpoints (ALTITUDE): rationale and study design. Nephrol Dial Transplant 2009; 24(5): 1663-1671.

21. Sato A, Hayashi K, Naruse M, Saruta T. Effectiveness of aldosterone blockade in patients with diabetic nephropathy. Hypertension 2003; 41(1): 64-68.

22. Psaty BM, Smith NL, Siscovick DS, Koepsell TD, Weiss NS, Heckbert SR, et al. Health outcomes associated with antihypertensive therapies used as first-line agents. A systematic review and meta-analysis. JAMA 1997; 277(9): 739-745.

23. Prevention of stroke by antihypertensive drug treatment in older persons with isolated systolic hypertension. Final results of the Systolic Hypertension in the Elderly Program (SHEP). SHEP Cooperative Research Group. JAMA 1991 265(24): 3255-3264.

24. Plantinga LC, Miller ER, III, Stevens LA, Saran R, Messer K, Flowers N, et al. Blood pressure control among persons without and with chronic kidney disease: US trends and risk factors 1999-2006. Hypertension 2009; 54(1):47-56

25. Hansson L, Hedner T, Lund-Johansen P, Kjeldsen SE, Lindholm LH, Syvertsen $\mathrm{OO}$, et al. Randomised trial of effects of calcium antagonists compared with diuretics and beta-blockers on cardiovascular morbidity and mortality in hypertension: the Nordic Diltiazem (NORDIL) study. Lancet 2000 356(9227):359-365.

26. Dahlof B, Sever PS, Poulter NR, Wedel H, Beevers DG, Caulfield M, et al. Prevention of cardiovascular events with an antihypertensive regimen of amlodipine adding perindopril as required versus atenolol adding bendroflumethiazide as required, in the Anglo-Scandinavian Cardiac Outcomes Trial-Blood Pressure Lowering Arm (ASCOT-BPLA): a multicentre randomised controlled trial. Lancet 2005; 366(9489):895-906.

27. Cross NB, Webster AC, Masson P, O'Connell PJ, Craig JC. Antihypertensives for kidney transplant recipients: systematic review and meta-analysis of randomized controlled trials. Transplantation 2009; 88(1):7-18.

28. Venkat-Raman G, Feehally J, Elliott HL, Griffin P, Moore RJ, Olubodun JO, et al. Renal and haemodynamic effects of amlodipine and nifedipine in hypertensive renal transplant recipients. Nephrol Dial Transplant 1998; 13(10):2612-2616 .

29. Hernandez D, Lacalzada J, Salido E, Linares J, Barragan A, Lorenzo V et al. Regression of left ventricular hypertrophy by lisinopril after renal transplantation: role of ACE gene polymorphism. Kidney Int 2000; 58(2):889897.

30. Weir MR. Blood pressure management in the kidney transplant recipient. Adv Chronic Kidney Dis 2004; 11(2):172-183.

31. Sipahi I, Tuzcu EM, Schoenhagen P, Wolski KE, Nicholls SJ, Balog C, et al. Effects of normal, pre-hypertensive, and hypertensive blood pressure levels on progression of coronary atherosclerosis. J Am Coll Cardiol 2006; 48(4):833-838.

32. Rosendorff C, Black HR, Cannon CP, Gersh BJ, Gore J, Izzo JL, et al. Treatment of hypertension in the prevention and management of ischemic heart disease: a scientific statement from the American Heart Association Council fo High Blood Pressure Research and the Councils on Clinical Cardiology and Epidemiology and Prevention. Circulation 2007; 115(21):2761-2788.

33. Cruickshank JM, Thorp JM, Zacharias FJ. Benefits and potential harm of lowering high blood pressure. Lancet 1987; 1(8533):581-584.

34. Bangalore S, Messerli FH, Kostis JB, Pepine Cl. Cardiovascular protection using beta-blockers: a critical review of the evidence. J Am Coll Cardiol 2007; 50(7):563-572.

35. Yusuf S, Sleight P, Pogue I, Bosch J, Davies R, Dagenais G. Effects of an angiotensin-converting-enzyme inhibitor, ramipril, on cardiovascular events in high-risk patients. The Heart Outcomes Prevention Evaluation Study Investigators. N Engl J Med 2000; 342(3):145-153.

36. Major outcomes in high-risk hypertensive patients randomized to angiotensin-converting enzyme inhibitor or calcium channel blocker vs diuretic: The Antihypertensive and Lipid-Lowering Treatment to Prevent Heart Attack Trial (ALLHAT). JAMA 2002; 288(23):2981-2997.

37. Mochizuki S, Dahlof B, Shimizu M, Ikewaki K, Yoshikawa M, Taniguch I, et al. Valsartan in a Japanese population with hypertension and other cardiovascular disease (likei Heart Study): a randomised, open-label, blinded endpoint morbidity-mortality study. Lancet 2007; 369(9571):1431-1439.

38. Pfeffer MA, McMurray JJ, Velazquez EJ, Rouleau JL, Kober L, Maggioni AP, et al. Valsartan, captopril, or both in myocardial infarction complicated by heart failure, left ventricular dysfunction, or both. N Engl J Med 2003; 349(20):1893-1906

39. Julius S, Kjeldsen SE, Weber M, Brunner HR, Ekman S, Hansson L, et al. Outcomes in hypertensive patients at high cardiovascular risk treated with regimens based on valsartan or amlodipine: the VALUE randomised trial. Lancet 2004; 363(9426):2022-2031.

40. Pepine CJ, Handberg EM, Cooper-DeHoff RM, Marks RG, Kowey P, Messerli $\mathrm{FH}$, et al. A calcium antagonist vs a non-calcium antagonist hypertension treatment strategy for patients with coronary artery disease. The International Verapamil-Trandolapril Study (INVEST): a randomized controlled trial. JAMA 2003; 290(21):2805-2816.

41. Hansson L, Hedner T, Lund-Johansen P, Kjeldsen SE, Lindholm LH, Syvertsen $\mathrm{JO}$, et al. Randomised trial of effects of calcium antagonists compared with diuretics and beta-blockers on cardiovascular morbidity and mortality in hypertension: the Nordic Diltiazem (NORDIL) study. Lancet 2000; 356(9227):359-365 


\section{Diretrizes}

42. Goldstein LB, Adams R, Alberts MJ, Appel LJ, Brass LM, Bushnell CD, et al. Primary prevention of ischemic stroke: a guideline from the American Heart Association/American Stroke Association Stroke Council: cosponsored by the Atherosclerotic Peripheral Vascular Disease Interdisciplinary Working Group; Cardiovascular Nursing Council; Clinical Cardiology Council; Nutrition, Physical Activity, and Metabolism Council; and the Quality of Care and Outcomes Research Interdisciplinary Working Group: the American Academy of Neurology affirms the value of this guideline. Stroke 2006; 37(6):1583-1633.

43. Leonardi-Bee J, Bath PM, Phillips SJ, Sandercock PA. Blood pressure and clinical outcomes in the International Stroke Trial. Stroke 2002; 33(5):13151320

44. Schrader J, Luders S, Kulschewski A, Berger J, Zidek W, Treib J, et al. The ACCESS Study: evaluation of Acute Candesartan Cilexetil Therapy in Stroke Survivors. Stroke 2003; 34(7):1699-1703.

45. Potter JF, Robinson TG, Ford GA, Mistri A, James M, Chernova J, et al. Controlling hypertension and hypotension immediately post-stroke (CHHIPS): a randomised, placebo-controlled, double-blind pilot trial. Lancet Neurol 2009; 8(1):48-56.

46. Adams HP, Jr., del ZG, Alberts MJ, Bhatt DL, Brass L, et al. Guidelines for the early management of adults with ischemic stroke: a guideline from the American Heart Association/American Stroke Association Stroke Council,
Clinical Cardiology Council, Cardiovascular Radiology and Intervention Council, and the Atherosclerotic Peripheral Vascular Disease and Quality of Care Outcomes in Research Interdisciplinary Working Groups: The American Academy of Neurology affirms the value of this guideline as an educational tool for neurologists. Circulation 2007; 115(20):e478-e534.

47. Guidelines for management of ischaemic stroke and transient ischaemic attack 2008. Cerebrovasc Dis 2008; 25(5):457-507.

48. Tikhonoff V, Zhang H, Richart T, Staessen JA. Blood pressure as a prognostic factor after acute stroke. Lancet Neurol 2009; 8(10):938-948.

49. Anderson CS, Huang Y, Wang JG, Arima H, Neal B, Peng B, et al. Intensive blood pressure reduction in acute cerebral haemorrhage trial (INTERACT): a randomised pilot trial. Lancet Neurol 2008; 7(5):391-399.

50. Broderick J, Connolly S, Feldmann E, Hanley D, Kase C, Krieger D, et al. Guidelines for the management of spontaneous intracerebral hemorrhage in adults: 2007 update: a guideline from the American Heart Association/ American Stroke Association Stroke Council, High Blood Pressure Research Council, and the Quality of Care and Outcomes in Research Interdisciplinary Working Group. Circulation 2007; 116(16):e391-e413.

51. Pontes-Neto OM, Oliveira-Filho J, Valiente R, Friedrich M, Pedreira B, Rodrigues $\mathrm{BC}$, et al. [Brazilian guidelines for the manegement of intracerebral hemorrhage]. Arq Neuropsiquiatr 2009; 67(3B):940-950. 